NBER WORKING PAPER SERIES

\title{
RECOVERY FROM THE GREAT DEPRESSION: THE FARM CHANNEL IN SPRING 1933
}

\author{
Joshua K. Hausman \\ Paul W. Rhode \\ Johannes F. Wieland \\ Working Paper 23172 \\ http://www.nber.org/papers/w23172 \\ NATIONAL BUREAU OF ECONOMIC RESEARCH
1050 Massachusetts Avenue
Cambridge, MA 02138 \\ February 2017, Revised June 2018
}

This paper previously circulated with the title "Growth After a Financial Crisis: The U.S. in Spring 1933." We are grateful for comments and encouragement from four anonymous referees, Alan Deardorff, Brad DeLong, Kathryn Dominguez, Barry Eichengreen, Price Fishback, Timothy Guinnane, James Hamilton, Walker Hanlon, Catherine Hausman, David Lagakos, John Leahy, Atif Mian (discussant), Naomi Lamoreaux, Maurice Obstfeld, Rodney Ramcharan (discussant), Valerie Ramey, Gary Richardson, Christina Romer, David Romer, Jonathan Rose, Matthew Shapiro, Jason Taylor, Peter Temin, and Noam Yuchtman as well as audiences at UC Irvine, Michigan State, Chicago Fed, Hitotsubashi University, CEBRA Workshop for Commodities and Macroeconomics, Yale, UC Berkeley, Queen's University, NBER Macro Across Time and Space, NBER ME, University of Michigan, UC San Diego, Wharton, IMF, NBER DAE, UCLA, and Social Science History Association Meetings. Jon Denton-Schneider, Tejaswi Velayudhan, and Niccolo Beltramo provided superb research assistance. Rhode's work was in part funded by NSF grant SES- 0921732 ("Dramatic Rise in Agricultural Productivity in the U.S During the Twentieth Century: Disentangling the Roles of Technological Change, Government Policy, and Climate"). The views expressed herein are those of the authors and do not necessarily reflect the views of the National Bureau of Economic Research.

NBER working papers are circulated for discussion and comment purposes. They have not been peer-reviewed or been subject to the review by the NBER Board of Directors that accompanies official NBER publications.

(C) 2017 by Joshua K. Hausman, Paul W. Rhode, and Johannes F. Wieland. All rights reserved. Short sections of text, not to exceed two paragraphs, may be quoted without explicit permission provided that full credit, including $(\odot$ notice, is given to the source. 
Recovery from the Great Depression: The Farm Channel in Spring 1933

Joshua K. Hausman, Paul W. Rhode, and Johannes F. Wieland

NBER Working Paper No. 23172

February 2017, Revised June 2018

JEL No. E32,E65,N12,N52

\section{ABSTRACT}

From March to July 1933, industrial production rose 57 percent. We show that an important source of recovery was the effect of dollar devaluation on farm prices, incomes, and consumption. Devaluation immediately raised traded crop prices, and auto sales grew more rapidly in states and counties most exposed to these price increases. The response was amplified in counties with more severe farm debt burdens. For plausible assumptions about farmers' relative MPC, the incidence of higher farm prices, and the aggregate multiplier, this redistribution to farmers accounted for a substantial portion of spring 1933 growth. This farm channel thus provides an example of how the distributional consequences of macroeconomic policies can have large aggregate effects. That recovery in 1933 benefited from redistribution to farmers suggests an important limitation to the use of 1933 as a guide to the effects of monetary regime changes in other circumstances.

Joshua K. Hausman

Gerald R. Ford School of Public Policy University of Michigan

735 South State Street, \#3309

Ann Arbor, MI 48109

and NBER

hausmanj@umich.edu

Paul W. Rhode

Economics Department

University of Michigan

205 Lorch Hall

611 Tappan St.

Ann Arbor, MI 48109-1220

and NBER

pwrhode@umich.edu
Johannes F. Wieland

Department of Economics

University of California, San Diego

9500 Gilman Drive \#0508

La Jolla, CA 92093

and NBER

jfwieland@ucsd.edu 
"T/he depression in the manufacturing industry of the country is due chiefly to the fact that agricultural products generally have been selling below the cost of production, and thereby destroyed the purchasing power in the domestic market of nearly half of all our people. We are going to restore the purchasing power of the farmer." - Franklin D. Roosevelt, campaign speech in Atlanta, Georgia, 24 October $1932 .^{1}$

\section{Introduction}

From its low point in March 1933, seasonally adjusted industrial production rose 57 percent in four months, the most rapid four months of industrial production growth on record. As shown in figure 1, in these four months the U.S. economy recovered from two years of the Depression. ${ }^{2}$ We argue that an important driver of this extraordinary recovery was the effect of devaluation on farm prices, incomes, and consumption. We call this mechanism the farm channel.

As the quote beginning the paper suggests, the importance of farmers for recovery was much emphasized in the 1930s. But with the exception of Temin and Wigmore (1990)which inspired this paper - it has not figured prominently in the modern literature. Our goal is to document the farm channel's operation and its relevance to the aggregate economy's recovery. We do so in three steps. First, we show that crop prices rose rapidly in spring 1933, and that this increase was in part caused by devaluation. Second, we show that auto sales and income grew much more in farm areas of the country, particularly in those areas most burdened by farm mortgage debt. Third, we discuss why the farm channel likely accounted for a substantial portion of aggregate spring 1933 growth. Our findings illustrate how microeconomic heterogeneity - in this case between farmers and nonfarmers - can shape the impact of macroeconomic policies.

We start our analysis of the farm channel in section 2 by examining the 1933 path of prices and production of all major farm products. The data show a large increase in crop

\footnotetext{
${ }^{1}$ See http://teachingamericanhistory.org/library/document/campaign-speech/ for the complete speech.

${ }^{2}$ Industrial production data are from FRED series INDPRO. We verify in appendix A that rapid recovery is a feature not only of the industrial production data, but also of other aggregate economic indicators. Our conclusion that the economy indeed grew extraordinarily rapidly in spring 1933 matches that of Taylor and Neumann (2016).
} 
Figure 1 - Industrial production, 1929-1937

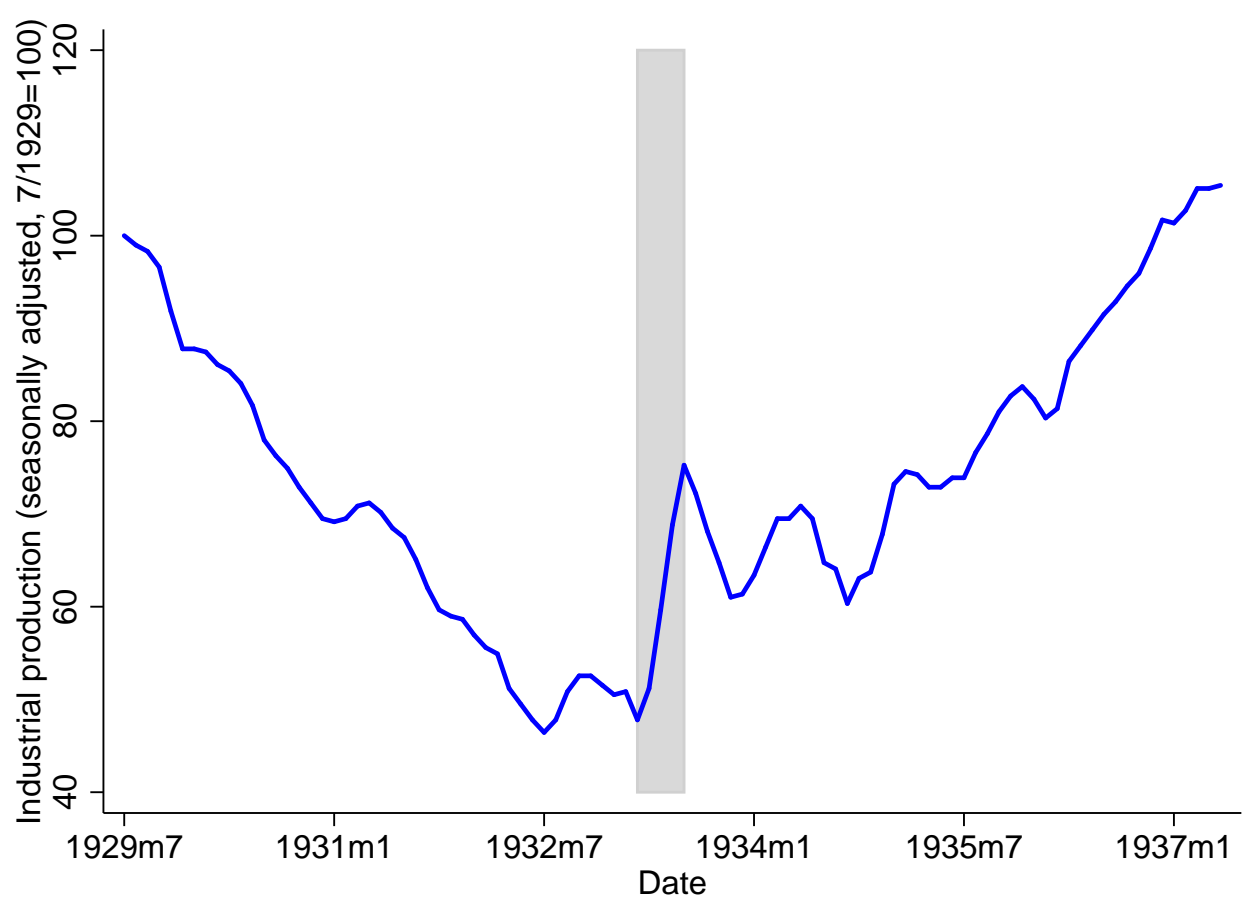

Note: Shading indicates March-July 1933. Source: FRED series INDPRO.

prices after devaluation, with much smaller price increases for (nontraded) livestock and dairy products. An analysis of daily farm spot and futures prices around the announcement of the U.S. departure from the gold standard provides evidence for a causal role of devaluation in driving crop price increases. Importantly, this was an increase in real crop prices, since the CPI rose only modestly.

In section 3, we examine consumption choices in farm relative to nonfarm areas. Using monthly state and annual county auto sales data, we find that new auto sales in spring 1933 grew much more in farm areas of the country. Our baseline estimates imply that a onestandard-deviation increase in the share of a state's population living on farms was associated with a nearly 30 percentage point increase in auto sales growth in spring 1933 . The effect is driven by areas benefitting from higher farm prices in spring 1933, not agricultural areas in general; conditional on 1932 farm product value per capita in a state, a $\$ 1$ larger change in farm product value in spring 1933 is associated with 1-2 percentage points more rapid auto sales growth. This result holds both within and across states and is robust to a battery of controls. We focus on new car sales because we observe these data at a monthly frequency for 
U.S. states and at an annual frequency for U.S. counties, allowing for a more precise analysis of the farm channel in the crucial spring 1933 window than would be possible with other economic indicators. ${ }^{3}$ But we obtain quantitatively similar results from annual state-level data on new truck sales and electric refrigerator sales.

Given small contributions of net exports to GDP growth in 1933 and 1934, higher farm product prices primarily redistributed income to farmers from nonfarm households and businesses. It is not a priori obvious that this transfer would be beneficial for the aggregate economy. A plausible way that higher farm prices could have had aggregate benefits is if they redistributed income from low marginal propensity to consume (MPC) agents to highMPC agents. A long-standing theoretical literature (e.g., Bewley, 1986; Aiyagari, 1994) and more recent empirical work (e.g., Mian, Rao, and Sufi, 2013) suggest that debtors are likely to have a higher MPC than creditors. Since farmers had large mortgage debt burdens in early 1933, a transfer of income to farmers could have raised aggregate demand. Consistent with this hypothesis, in section 4 we estimate that the farm channel's effect on consumption was largest in those counties where farmers were most encumbered by farm mortgage debt.

Higher farm product prices could also have raised aggregate output through their effect on the banking sector and inflation expectations. We find that counties more exposed to the farm channel experienced faster deposit growth. This is indicative of improved bank health in rural areas, which were among the most hard-hit by the Depression's banking crises. And we find narrative evidence that delayed pass-through from higher farm product prices to final goods prices increased inflation expectations.

In section 5, we gauge the aggregate effect of the farm channel. Guided by a simple heterogeneous agent model, in which farmers gain at the expense of nonfarmers, we extrapolate from our cross-sectional estimates to an aggregate effect. To do so, we adjust for the extent to which the cross-sectional estimates reflect reduced consumption by high-MPC consumers in nonfarm areas and for aggregate general equilibrium effects. Since the form and magnitude of these adjustments rest on assumptions about the structure of the economy, our calculations are an indicator of the rough magnitude of the effect of the farm channel, not a precise quantitative estimate. With this caveat in mind, we find that the aggregate effect of

\footnotetext{
${ }^{3}$ Here and throughout we use 'car' and 'auto' interchangeably. These data exclude trucks and tractors.
} 
the farm channel was large, in the range of 20-60 percent of spring 1933 output growth. We find a large effect because our cross-sectional estimates indicate a high MPC in farm areas, the pass-through of higher farm prices to urban workers was incomplete, and the aggregate spending multiplier was likely large.

Like us, Friedman and Schwartz (1963), Edwards (2015), Edwards (2018), and Rauchway (2015) emphasize the priority that the Roosevelt administration put on raising the price of agricultural goods. According to Edwards (2015) p. 20, Henry Morgenthau, head of the farm relief administration and later treasury secretary, "believed that uncoupling the value of the dollar from gold was a requisite to increase agricultural prices and, in that way, bring relief to farmers. His main concern was not gold itself, but relative prices; for him the goal of policy - and a required step towards recovery - was increasing the price of agricultural products relative to manufacturing goods." This is consistent with the view of George Warren and Frank Pearson (Warren and Pearson, 1935), the former of whom became an important economic advisor to Roosevelt (Edwards, 2018). Bessler (1996) summarizes Warren's views, and both he and Temin and Wigmore (1990) document a close link between the exchange rate and traded crop prices. Edwards (2017) confirms this link and shows that expectations of monetary regime change were an important determinant of agricultural prices in 1933. That crop prices responded more - and more rapidly - than the overall price level to devaluation also fits with the current understanding that commodity prices are particularly flexible (Nakamura and Steinsson, 2008), a view formalized in Bordo (1980).

Temin and Wigmore (1990) were the first (and have remained the only) authors in the modern economics literature to emphasize the importance of farmers for the aggregate economy in 1933. They argue that a weaker dollar led to higher expected inflation and was also expansionary through its effect on current and expected farm incomes. But they are only able to provide circumstantial evidence for the importance of higher farm incomes (the farm channel). ${ }^{4}$ We build on their work by providing econometric evidence for each stage of the

\footnotetext{
${ }^{4}$ Temin and Wigmore's principal evidence comes from a state-level regression of the level of auto sales in all of 1933 on farm income and other income in 1933. They interpret a larger coefficient on farm income as evidence in support of their hypothesis. While suggestive, this regression has three limitations: first, the left-hand side variable is the level of auto sales, while their hypothesis is about the growth of auto sales. Second, the farm income regression coefficient is positive and large for all years from 1932 to 1940 , suggesting that these results are not necessarily informative about events in 1933 per se. Third, the regression uses annual data, hence it conflates auto sales in the period of interest, spring 1933, with sales later in the year.
} 
farm channel's operation, and by explicitly considering the general equilibrium implications of higher farm product prices.

Recent papers on the initial recovery in spring 1933 include Eggertsson (2008), Jalil and Rua (2016), Sumner (2015), and Taylor and Neumann (2016). These papers credit Roosevelt with inducing inflation expectations and reducing ex-ante real interest rates, thus stimulating demand for investment goods and consumer durables. The farm channel we emphasize is largely distinct from this expectations channel, although higher farm product prices and resulting higher farm incomes could have contributed to economy-wide expectations of higher future prices and income.

Our attention to farmers' debt positions in spring 1933 aligns with the literature emphasizing debt deflation as a cause of the Great Depression. Fisher (1932) and Fisher (1933) first argued for this mechanism as a cause of the Great Depression, and Fisher (1933) credits Roosevelt's policies with ending the debt-deflation cycle. Hamilton $(1987,1992)$ provide evidence that a significant part of the deflation during the Great Depression was unanticipated, concluding that debt-deflation and bank failures played an important role in the contraction. And Mishkin (1978) emphasizes the general importance of debt as a determinant of consumption in the 1930s, though he does not specifically focus on farmers or the MPC.

An older literature emphasized that devaluation may affect output by redistributing income among groups with different MPCs (e.g., Diaz Alejandro, 1965; Krugman and Taylor, 1978), but this literature did not consider the recovery from the Great Depression. Prominent recent research has emphasized the importance of income redistribution and MPC heterogeneity for the propagation of monetary policy shocks (a partial list includes Auclert, 2017; Broer, Hansen, Krusell, and Öberg, 2016; Cloyne, Ferreira, and Surico, 2016; Kaplan, Moll, and Violante, 2018; McKay, Nakamura, and Steinsson, 2016; Werning, 2015). Our results are complementary in that we stress the distributional effect of dollar depreciation.

Our paper is also relevant to understanding macroeconomic policy at the zero lower bound. In the United States in spring 1933, short-term interest rates were near zero, and hence conventional monetary policy was ineffective. Economists continue to debate the extent to which unconventional monetary policy can stimulate an economy in these conditions (e.g., Woodford, 2012). In these debates, the U.S. experience in 1933 serves as an example 
of what policy may be able to achieve (Romer, 2014). For instance, the governor of the Bank of Japan, Haruhiko Kuroda, has used 1933 as a reference point for his ongoing attempts at a regime change in Japan (Kuroda, 2015). To the extent that recovery in spring 1933 was helped along by redistribution to high-MPC farmers, however, the spring 1933 analogy may be an overly optimistic guide to the effect of a monetary regime change alone (Hausman and Wieland, 2014, 2015).

\section{Spring 1933: Relative farm prices rose}

Central to our argument for the importance of agriculture in 1933 is the behavior of agricultural prices. Figure 2 graphs the overall CPI and the BLS index of farm product prices. From 1932 to 1934, there was relatively little change in the CPI, though it did rise 3 percent between June and July 1933. By contrast, farm product prices rose 40 percent in the four months from March to July. The figure points to devaluation as a possible cause of this large price change. In the three months following devaluation on 19 April, the dollar depreciated by 30 percent relative to the British pound. The exchange rate vis a vis many other currencies behaved similarly in the April to July period: against the French franc, the dollar depreciated 34 percent; against the German mark, 36 percent (Survey of Current Business, 12/33, p. 31). Since prices of traded farm products were set in world markets, when the dollar depreciated, the dollar price of many farm products rose.

This effect of devaluation on farm prices was no accident; as discussed in the introduction, raising the relative price of agricultural products was an explicit goal of the Roosevelt administration. Roosevelt himself frequently and publicly emphasized this. The quote beginning the paper comes from a campaign speech given by Roosevelt in October 1932. As president, he repeated this message. For instance, in a fireside chat in October 1933, Roosevelt said: "I do not hesitate to say in the simplest, clearest language of which I am capable, that although the prices of many products of the farm have gone up and although many farm families are better off than they were last year, I am not satisfied either with the amount or the extent of the rise, and that it is definitely a part of our policy to increase the rise and to extend it to those products which have as yet felt no benefit. If we cannot do this one way we will do 
Figure 2 - The CPI, the exchange rate, and farm prices

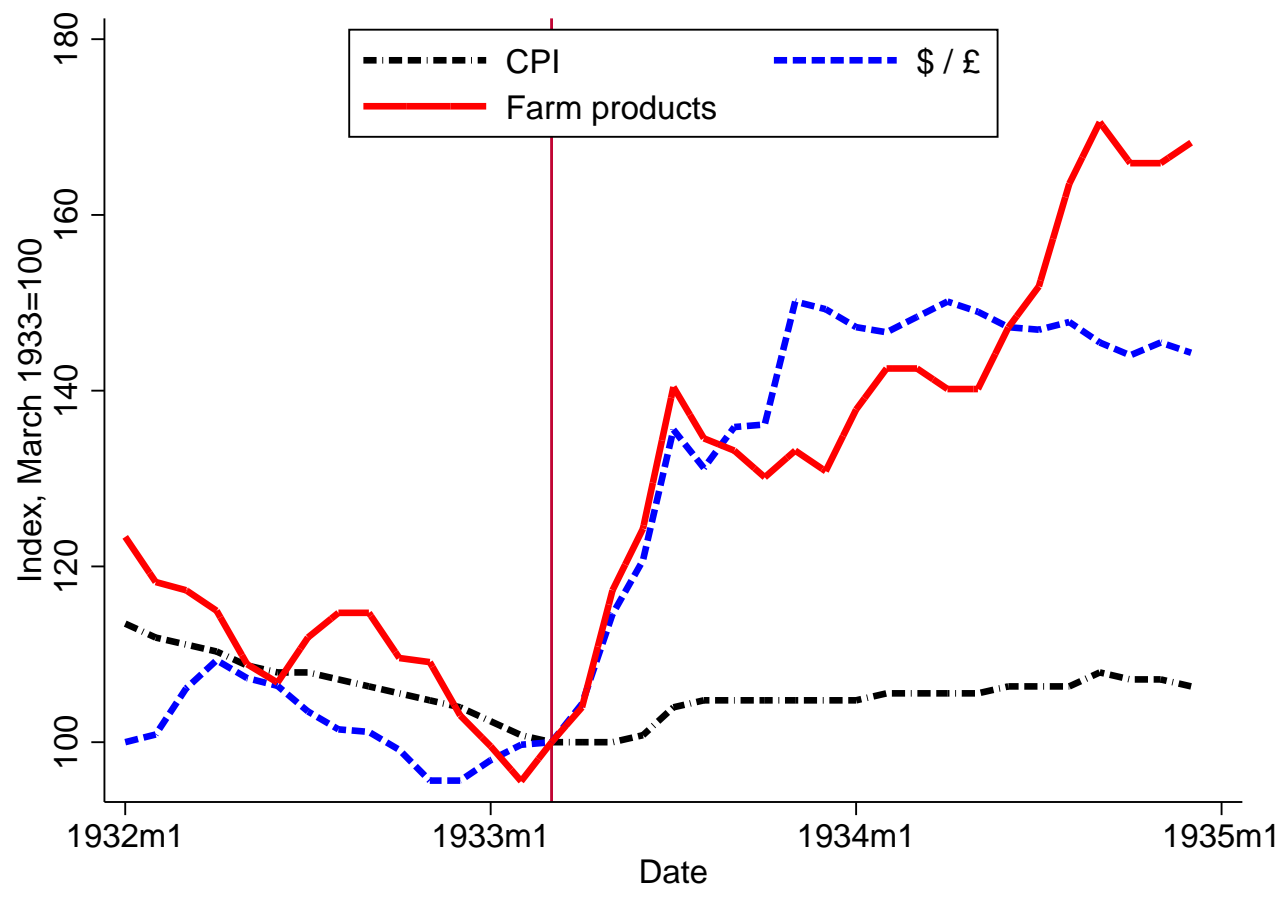

Note: The vertical line indicates March 1933, the month before the U.S. devalued. Sources: CPI data from FRED series CPIAUCNS; exchange rate from Survey of Current Business, $12 / 32$ p. 32, 12/33 p. 31, 12/34 p. $32,12 / 35$ p. 33; farm product price index from Federal Reserve Bulletin, 12/32 p. 788, 12/33 p. 783, 4/35 p. 237.

it another. Do it, we will." ${ }^{5}$ Weakening the dollar was part of this strategy. As Friedman and Schwartz (1963), p. 465 put it: "The aim of the gold policy was to raise the price level of commodities, particularly farm products and raw materials . . ."

We show that the administration succeeded in this goal; in other words we identify a causal effect of devaluation on farm prices. To do this, we examine the announcement effect of the U.S. departure from the gold standard on daily spot and future prices. This approach complements the analyses in Temin and Wigmore (1990), Bessler (1996), and Edwards (2017). Temin and Wigmore (1990) show that monthly cotton prices comove closely with the dollar-pound and the dollar-franc exchange rate from 1930-1936, and they note that a similar correlation exists for grains. Bessler (1996) conducts a VAR analysis with daily data on gold, cotton, corn, hog, and lard prices; he concludes that gold price movements explain most of the 1933 increase in cotton, corn, and lard prices. Edwards (2017) also finds that commodity prices moved with the dollar. Relative to this prior work, we use a narrower

\footnotetext{
${ }^{5}$ Complete speech available at Fireside chat, 10/22/33.
} 
date range but a broader range of farm products. For the purpose of understanding the causal effect of devaluation on farm prices, this has the advantage that there are likely fewer confounding factors in a narrow time window, and that any product-specific shocks average out over a large number of products. ${ }^{6}$

We examine daily data on the exchange rate and the price of wheat, cotton, corn, oats, lard, pork belly, hogs, steers, ${ }^{7}$ and lambs around the day of devaluation, 19 April. These data are presented in figure 3. Between noon on 18 April and noon on 20 April, the dollar depreciated slightly more than 10 percent. Over this period, most crop prices rose by a similar amount. The exception was wheat, whose price was negatively affected by news on 19 April of beneficial rains in winter wheat-growing areas (Wood, 1933).

Beyond the close co-movement of crop prices with the exchange rate over this narrow time window, three additional pieces of evidence suggest a causal role for devaluation. First, for cotton we observe Liverpool, England prices. As shown in figure 3, around the day of devaluation, Liverpool cotton prices expressed in sterling were nearly unchanged. This suggests that the change in the dollar price of cotton was a response to devaluation rather than to other shocks. Second, the prices of hogs, steers, and lambs did not respond to devaluation. This is likely because most of the dollar value of these animals was nontraded. So we would not expect their prices to have been affected by devaluation despite the price response of tradable derivative products (e.g., lard, pork belly). ${ }^{8}$ Third, narrative evidence attributes the increase in crop prices to devaluation. The Chicago Tribune (Wood, 1933) wrote "Yesterday's [19 April] commodity price advances were attributed almost entirely to the administration's announcement of its inflation program and the consequent decline of the dollar in foreign exchange." Similarly, the Commercial and Financial Chronicle (4/22/33,

\footnotetext{
${ }^{6}$ Rigobon (2003) proposes a heteroskedasticity-based identification method that may be used to filter out the influence of confounding factors around events. It requires, however, that only the variances of shocks change, while the economic structure remains fixed. This is unlikely to be true in our case, since the impact of demand and supply shocks on the exchange rate almost certainly changed after the United States left the Gold Standard.

${ }^{7}$ Steers are castrated male cattle under age four.

${ }^{8}$ On the lack of relationship between international pork product prices and U.S. hog prices, see Taylor (1932), particularly p. 203. The lack of a price response of lamb is more puzzling, since wool futures prices rose after devaluation (Commercial and Financial Chronicle, 4/22/1933, p. 2818). It is possible that the steadiness of lamb prices on 20 April and 21 April reflects idiosyncratic supply factors on those days (Wall Street Journal, 4/21/1933, p. 32 and 4/22/1933 p. 27). Large receipts and low quality may also have contributed to falling steer prices on 20 April (Wall Street Journal, 4/21/1933, p. 32).
} 
Figure 3 - The exchange rate and farm prices after devaluation

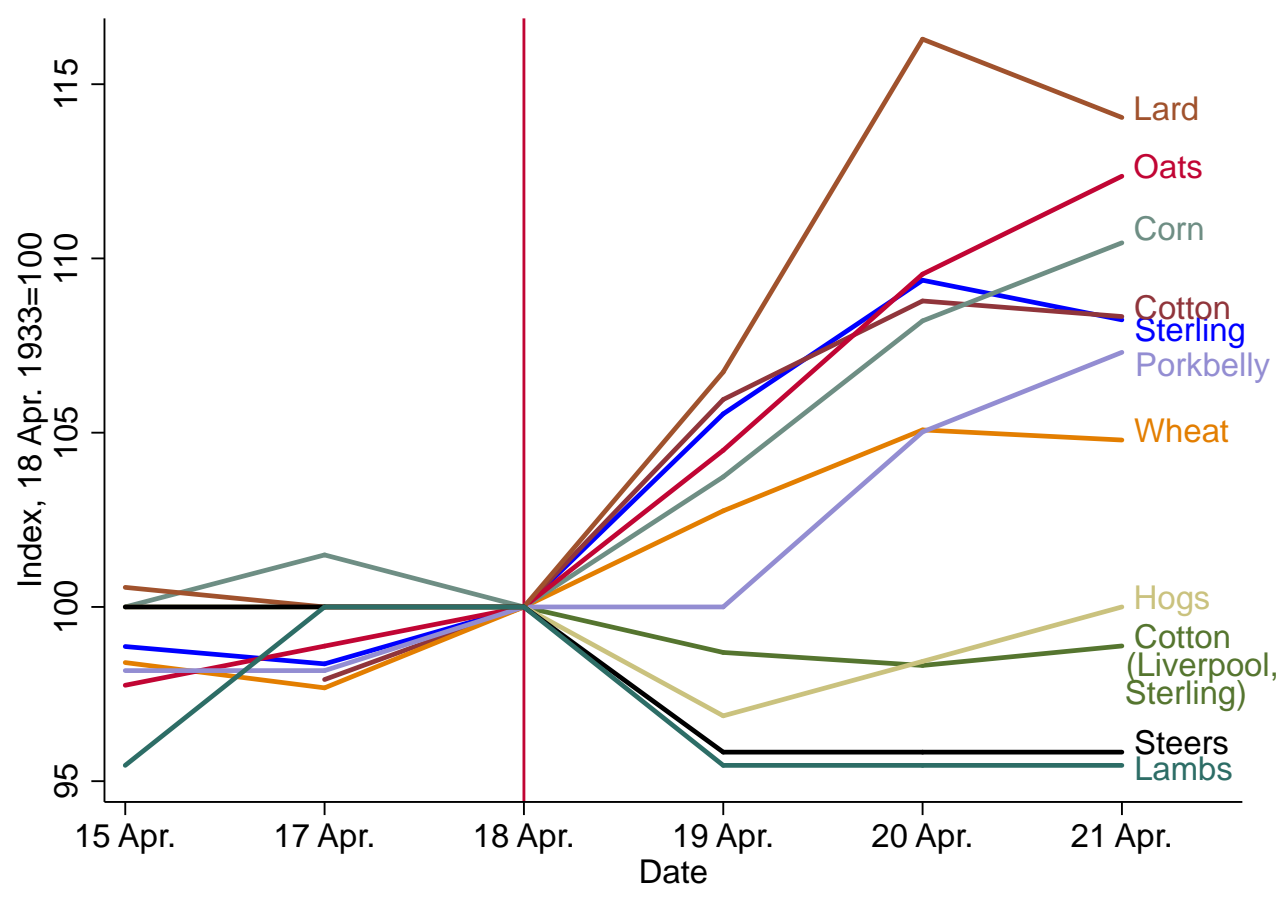

Note: The vertical line indicates 4/18/33, the day before the U.S. devalued. All prices are indexed to 100 on that day. Sources: The exchange rate is the closing rate from New York Times 4/18/33 p. 26, 4/20/33 p. 31 , and $4 / 22 / 33$ p. 21. The U.S. cotton price is the New Orleans price for Middling Upland; the Liverpool cotton price (in British pounds) is also for Middling Upland; the wheat price is the New York closing price for No. 2 red. These are from the Commercial and Financial Chronicle, 4/22/33, p. 2821 (U.S. cotton), p. 2823 (Liverpool cotton), and p. 2823 (wheat). The corn, oats, lard, pork belly ("dry salted bellies") and hog spot prices are the low prices from Annual Report of the Trade and Commerce of Chicago for the year ended December 31, 1933 (1934), pp. 98-99. Steer prices are low prices for prime steers, and lamb prices are low prices for native lambs good to choice; both are from the Chicago Tribune, 4/16/33 part 3 p. 12, 4/18/33 p. 26, 4/19/33 p. $31,4 / 20 / 33$ p. $22,4 / 21 / 33$ p. 32 , and 4/22/33 p. 27.

pp. 2820, 2823) credits the U.S. departure from the gold standard with raising cotton and wheat prices.

To see whether the price effect of devaluation was expected to persist, figure 4 shows the behavior of wheat, cotton, corn, and oats futures prices around the day of devaluation. These are the same data used by Hamilton (1992) to measure inflation expectations in the 1930s. Like their spot prices, wheat and cotton futures prices rose significantly, even for the furthest dated contracts. This suggests that people believed the price effect of devaluation would persist. ${ }^{9}$

\footnotetext{
${ }^{9}$ The fact that futures and spot prices moved by similar amounts suggests that a change in carrying costs cannot account for the movement in futures prices around the day of devaluation. Also, farm land prices rose 4 percent between 1 March 1933 and 1 March 1934, suggesting that at least some of the increase in farm prices and incomes was expected to be long-lasting (Stauber and Regan, 1935, table 1, pp. 6-7).
} 
Figure 4 - Devaluation and futures prices

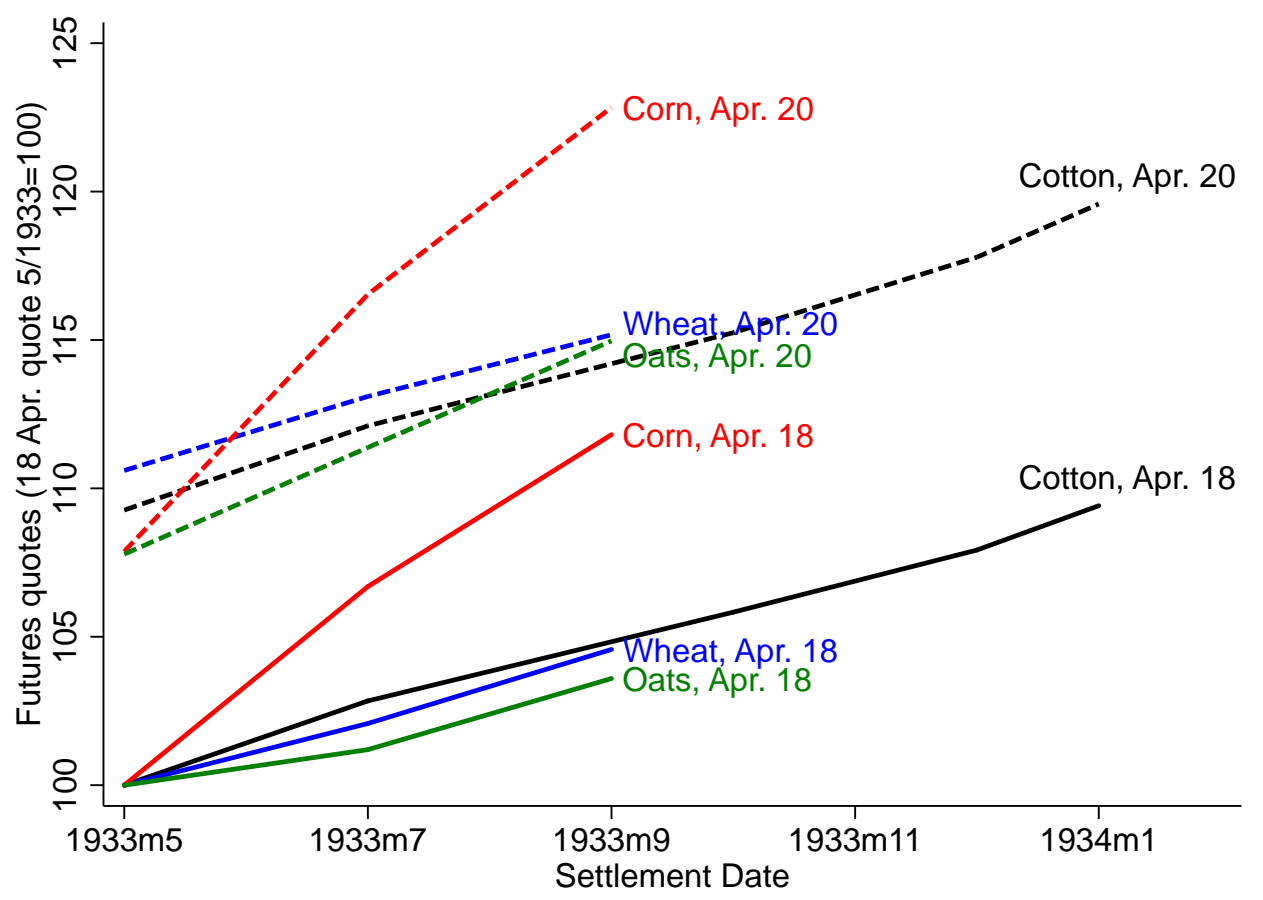

Notes: The lines show prices for future delivery for the specified crop on the specified day. Devaluation occurred on 4/19/33. Source: low prices from Annual Report of the Trade and Commerce of Chicago for the year ended December 31, 1933 (1934): p. 98 for wheat; p. 99 for corn and oats; p. 131 for cotton.

Thus far we have focused on an analysis of daily prices in a narrow window around devaluation, since this provides the best setting for identifying the causal effect of devaluation. But what mattered for farmers was the path of prices and production over the entire spring. Table 1 summarizes prices and production for the 12 farm products with greater than $\$ 100$ million of farm product value in 1932. ${ }^{10}$ The top panel provides data for crops and the bottom panel for animal products. For reference, the first column shows the dollar / pound exchange rate. This makes clear that in the second and third quarters of 1933 crop prices rose as the dollar weakened.

The mechanism through which devaluation affected farm prices is clearest for the traded crops of cotton, wheat, and tobacco. As Friedman and Schwartz (1963, p. 466) describe:

The prices of [traded] commodities in foreign currencies were determined by world demand and supply and were affected by events in the United States only insofar

\footnotetext{
${ }^{10}$ Farm product value is physical production times the producer price. In addition to the products in the table, butterfat had a farm product value of greater than $\$ 100$ million. We exclude it from the table because it is a by-product of milk production.
} 
Table 1 - Farm product prices

Panel A: Crops

\begin{tabular}{|c|c|c|c|c|c|c|c|c|}
\hline & $\$ / £$ & Wheat & Corn & Oats & Cotton & Tobacco & Hay & Potatoe \\
\hline \multicolumn{9}{|l|}{ Prices $(\mathrm{SA}$, Index, 1932=100) } \\
\hline 1932 Q3 & 100 & 98 & 96 & 94 & 104 & & 95 & 99 \\
\hline 1932 Q4 & 95 & 88 & 78 & 80 & 107 & & 88 & 92 \\
\hline 1933 Q1 & 97 & 83 & 72 & 68 & 98 & & 76 & 86 \\
\hline 1933 Q2 & 111 & 138 & 125 & 106 & 131 & & 81 & 103 \\
\hline 1933 Q3 & 131 & 205 & 164 & 208 & 156 & & 102 & 237 \\
\hline 1933 Q4 & 142 & 179 & 160 & 185 & 171 & & 106 & 185 \\
\hline 1932, average & 100 & 100 & 100 & 100 & 100 & 100 & 100 & 100 \\
\hline 1933, average & 120 & 151 & 130 & 142 & 139 & 137 & 91 & 153 \\
\hline 1934, average & 144 & 207 & 221 & 236 & 207 & 194 & 143 & 157 \\
\hline \multicolumn{9}{|l|}{ Production } \\
\hline 1932 farm product value ( $\$$, millions) & - & 284 & 925 & 195 & 424 & 108 & 516 & 141 \\
\hline 1932-1933 change in quantity (\%) & - & -29 & -19 & -41 & 0 & 34 & -10 & -11 \\
\hline 1933, trade output share, $(\mathrm{X}+\mathrm{M}) / \mathrm{Y}(\%)$ & - & 9 & 0 & 0 & 62 & 39 & 0 & 1 \\
\hline AAA intervention in 1933 & - & Yes & Yes & No & Yes & Yes & No & No \\
\hline
\end{tabular}

Panel B: Animal products

\begin{tabular}{|c|c|c|c|c|c|c|}
\hline & $\$ / £$ & Cattle & Hogs & Milk & Chickens & Eggs \\
\hline \multicolumn{7}{|l|}{ Prices $($ SA, Index, 1932=100) } \\
\hline 1932 Q3 & 100 & 108 & 108 & 97 & 100 & 102 \\
\hline $1932 \mathrm{Q} 4$ & 95 & 94 & 91 & 95 & 90 & 122 \\
\hline 1933 Q1 & 97 & 82 & 85 & 84 & 80 & 91 \\
\hline $1933 \mathrm{Q} 2$ & 111 & 92 & 109 & 89 & 83 & 91 \\
\hline 1933 Q3 & 131 & 93 & 103 & 111 & 84 & 100 \\
\hline $1933 \mathrm{Q} 4$ & 142 & 85 & 108 & 113 & 80 & 106 \\
\hline 1932, average & 100 & 100 & 100 & 100 & 100 & 100 \\
\hline 1933, average & 120 & 88 & 102 & 99 & 82 & 97 \\
\hline 1934 , average & 144 & 95 & 123 & 116 & 97 & 117 \\
\hline \multicolumn{7}{|l|}{ Production } \\
\hline 1932 farm product value $(\$$, millions $)$ & - & 525 & 540 & 1,314 & 267 & 374 \\
\hline 1932-1933 change in quantity (\%) & - & 8 & 7 & 3 & 1 & -1 \\
\hline 1933, trade output share, $(\mathrm{X}+\mathrm{M}) / \mathrm{Y}(\%)$ & - & 1 & 4 & $\mathrm{~N} / \mathrm{A}$ & $\mathrm{N} / \mathrm{A}$ & 0 \\
\hline AAA intervention in 1933 & - & Yes & Yes & Yes & No & No \\
\hline
\end{tabular}

Notes and sources: The exchange rate is not seasonally adjusted. Prices are producer prices (prices received by farmers); annual prices are unweighted calendar year averages. Farm product value equals physical production times price. Farm product value and production figures are for the crop year, not the calendar year. The presence or absence of AAA intervention is based on facts reported in Nourse, Davis, and Black (1937) and United States Department of Agriculture (1934a). For further notes and source details, see appendix C.1. 
as these, in turn, affected the amounts supplied and demanded by the United States. Even then, such prices were affected much less than in proportion to the changes in U.S. sales and purchases. Hence, the decline in the foreign exchange value of the dollar meant a roughly proportional rise in the dollar price of such commodities, which is, of course, what did happen to the dollar prices of cotton, petroleum products, leaf tobacco, wheat, and similar items.

It is less obvious how devaluation raised the price of other crops. A likely channel through which devaluation affected the prices of the principal nontraded grains, corn and oats, was through substitution. For instance, wheat, corn, and oats could all be used as animal feed (Davis, 1935, p. 23; Taylor, 1932, p. 129). Substitution between grains meant that as a weaker dollar increased the price of traded grains such as wheat, it likely also put upward pressure on the price of nontraded grains such as corn and oats. Indeed, Taylor (1932, p. 170) identifies the price of wheat as one of the determinants of the price of corn.

Accepting that substitution can explain the response of nontraded crop prices to devaluation, a puzzle remains: why did crop prices rise by more than the dollar weakened? Mechanically, this is in part explained by rising British pound prices of many crops. For instance, Liverpool prices in sterling of imported wheat rose 24 percent between March and July 1933, and the sterling price of Indian cotton rose 17 percent. ${ }^{11}$ A reason to credit international factors with the large increase in crop prices is the lack of response of nontraded animal product prices shown in panel B of table 1. Unlike crop prices, animal product prices rose only moderately in spring 1933. This fits with the lack of response of daily hog, steer, and lamb prices to devaluation shown in figure 3.

A likely contributing factor to the increase in international crop prices was global economic recovery. Between 1932 and 1933, world industrial production rose 13 percent (Woytinsky and Woytinsky, 1953, table 427, p. 1002), and farm prices are expected to react quickly to aggregate demand (Bordo, 1980). In addition to international factors, two U.S. specific supply shocks may have contributed to higher prices of certain crops. First, drought reduced production of grains (United States Department of Agriculture, 1934b,a). This may explain

\footnotetext{
${ }^{11}$ United States Department of Agriculture (1936), table 19, p. 21 and table 111, p. 85 converted to British Pounds using the exchange rate in Federal Reserve Bulletin, 12/34, p. 765.
} 
Figure 5 - Farm income

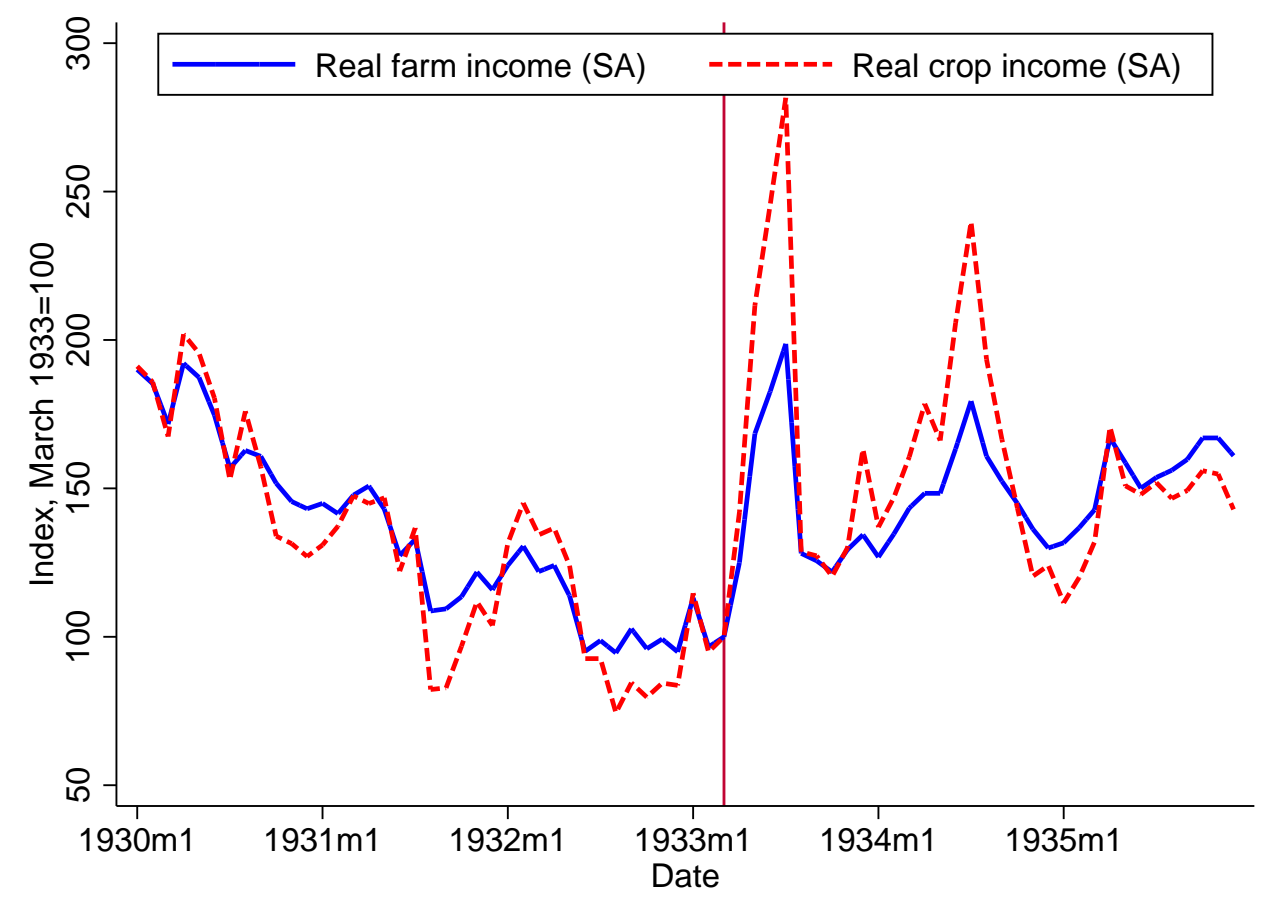

Note: The vertical line indicates March 1933, the month before the U.S. devalued. Sources: $1930-31$ income: U.S. Department of Commerce, 1934a, p. 19; 1932-35 income: U.S. Department of Commerce, 1936, p. 9. Deflated with FRED CPI series CPIAUCNS.

why in spring 1933 the price of corn in the United States rose much more than the price of Argentinian corn in Liverpool. ${ }^{12}$ (Recall that unlike wheat, little U.S. corn was traded.) Second, even for those crops (like cotton) for which production did not decline, there may have been expectations of future production declines driven by Agricultural Adjustment Administration (AAA) intervention. However, we observe little change in Liverpool cotton prices when the AAA passed the House (22 March 1933), the Senate (28 April), or was signed by Roosevelt (12 May). (Domestic cotton prices rose by 5 percent on 29 April in part reflecting a 2 percent decline in the dollar, but not on the other days.) In the following sections, we will go to substantial effort to control for the possible confounding effects of the drought and the AAA.

Figure 5 shows that higher real farm prices translated quickly into higher real farm incomes. Deflated by the CPI, the Department of Agriculture's seasonally adjusted index of

\footnotetext{
${ }^{12}$ Between March and July 1933, the wholesale price of corn in Chicago rose 115 percent, while the Liverpool price of La Plata corn in dollars rose 25 percent (United States Department of Agriculture, 1936, tables $46-47$, p. 40).
} 
income from crops rose 182 percent from March 1933 to July 1933; that of total farm income (crop and animal products) deflated by the CPI rose 99 percent. On a non-seasonally adjusted basis, total real farm income was higher in June and July 1933 than it had been in any month after October 1931 (U.S. Department of Commerce, 1936, p. 9, U.S. Department of Commerce, 1934a, p. 19). As noted by Temin and Wigmore (1990), higher farm prices led quickly to higher farm incomes in part because farmers sold crops in storage. The stock of wheat on farms, for instance, fell from 182 million bushels to 82 million bushels between 1 April 1933 and 1 July 1933 (United States Department of Agriculture, 1936, table 7, p. 14). By comparison, total wheat production in 1933 was 529 million bushels (United States Department of Agriculture, 1936, table 1, p. 6). ${ }^{13}$

To sum up, the evidence strongly suggests that devaluation accounted for a significant part of the increase in crop prices, and thus the increase in farm income, in spring 1933.

\section{Farm consumption}

We now examine the effect of higher farm prices on farm consumption. This is a crosssectional exercise in which we compare consumption in areas with more farmers or larger increases in farm income to areas with fewer farmers or smaller increases in farm income. In sections 4 and 5, we will consider national general equilibrium effects of higher farm product prices.

We estimate cross-sectional regressions of the form:

$$
\% \Delta \text { Auto sales }{ }_{i, \text { Spring } 1933}=\beta_{0}+\beta_{1} \text { Agricultural exposure }_{i}+\gamma^{\prime} X_{i}+\varepsilon_{i}
$$

where $\% \Delta$ Auto sales $i$,Spring 1933 is auto sales growth in spring 1933, "Agricultural exposure" is a state or county $i$ 's exposure to the farm channel in spring 1933, and $X$ is a set of control variables. We use new auto sales as our main indicator of local economic conditions. Unlike other economic indicators, auto sales were reported at the state and county level and at reasonably high frequency: monthly at the state level and annually at the county level.

\footnotetext{
${ }^{13}$ In addition to stocks of wheat held on farms, there were also substantial stocks held commercially, e.g. by elevators and mills (United States Department of Agriculture, 1936, table 14, p. 18). The extent to which the sale of these stocks directly raised farmers' incomes is unclear.
} 
We expect that $\beta_{1}$ is positive, since higher farm prices redistributed income towards farmers. Also important for our purposes is the size of $\beta_{1}$; it determines the aggregate importance of the farm channel in our analysis in section 5 .

Importantly, $\beta_{1}$ may not be an estimate of the effect of devaluation alone. For example, expectations of other agricultural policies may have differentially affected farm and nonfarm regions. To ensure that we are primarily picking up a devaluation effect, we check that auto sales grow disproportionally in regions growing traded crops or close substitutes, and we use a variety of control variables. Even so, we cannot separate the effect of devaluation from the effect of other shocks that disproportionally fell on traded farm goods and that our control variables do not capture.

3.1 Cross-state results We collected data on new passenger car sales by state and month from the Automotive Daily News Review and Reference Book (1935, pp. 22-23). Appendix D provides further details on these data and their accuracy. We seasonally adjust the monthly state auto sales using twelve monthly dummies, excluding the year 1933 to avoid conflating the rapid recovery in spring with a seasonal effect. ${ }^{14}$

The ideal independent variable would exactly measure the portion of the spring 1933 income change that was due to locally exogenous farm price increases. Since no such exact measure exists, we consider proxy variables. Simplest is the percent of local residents living on a farm. This measure has the disadvantage that many farmers were engaged in the production of livestock and dairy products whose prices moved relatively little in 1933. Thus, we also look at the value of crops sold per capita in 1929.

Figure 6a shows a scatter plot of the farm share of the population and the seasonallyadjusted percentage change in car sales from the 1932:Q4-1933:Q1 quarterly average to 1933:Q3. We show the change between quarterly averages since single month values have large amounts of noise that is more likely due to idiosyncratic variation than it is to macro shocks. For the base period, we choose a longer, two-quarter period since real farm income and industrial production changed little over these months (figures 5 and 1), and since

\footnotetext{
${ }^{14}$ Specifically, seasonally adjusted sales in month $t$ are $e^{\hat{\varepsilon}_{t}+\sum_{j=1}^{12} \hat{\beta}_{j} / 12}$, where $\hat{\varepsilon}_{t}$ is the residual from the regression of the natural log of sales on monthly dummies, and $\hat{\beta}_{j}$ is the regression coefficient on the jth monthly dummy. We separately seasonally adjust sales for each state.
} 
Figure 6 - Percent change in car sales and farm channel exposure

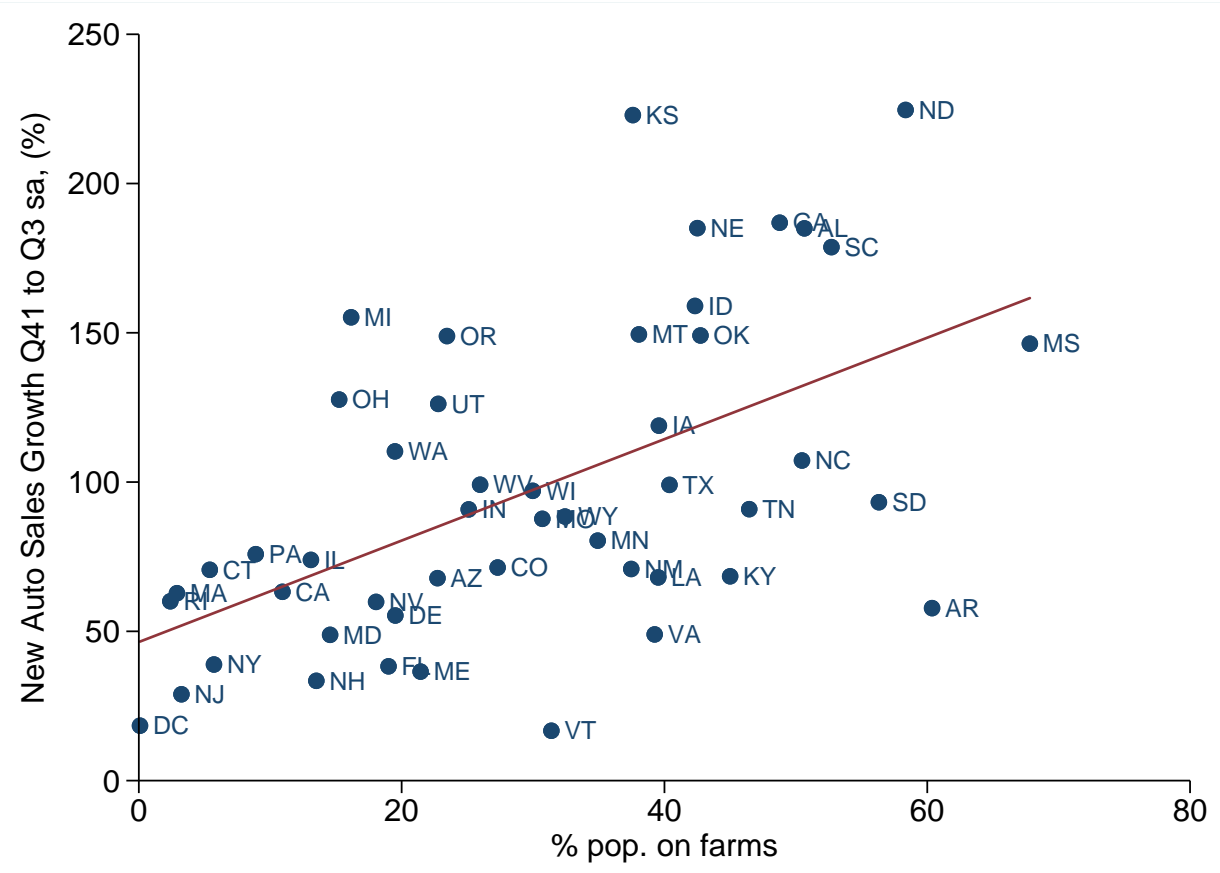

(a) Farm population share

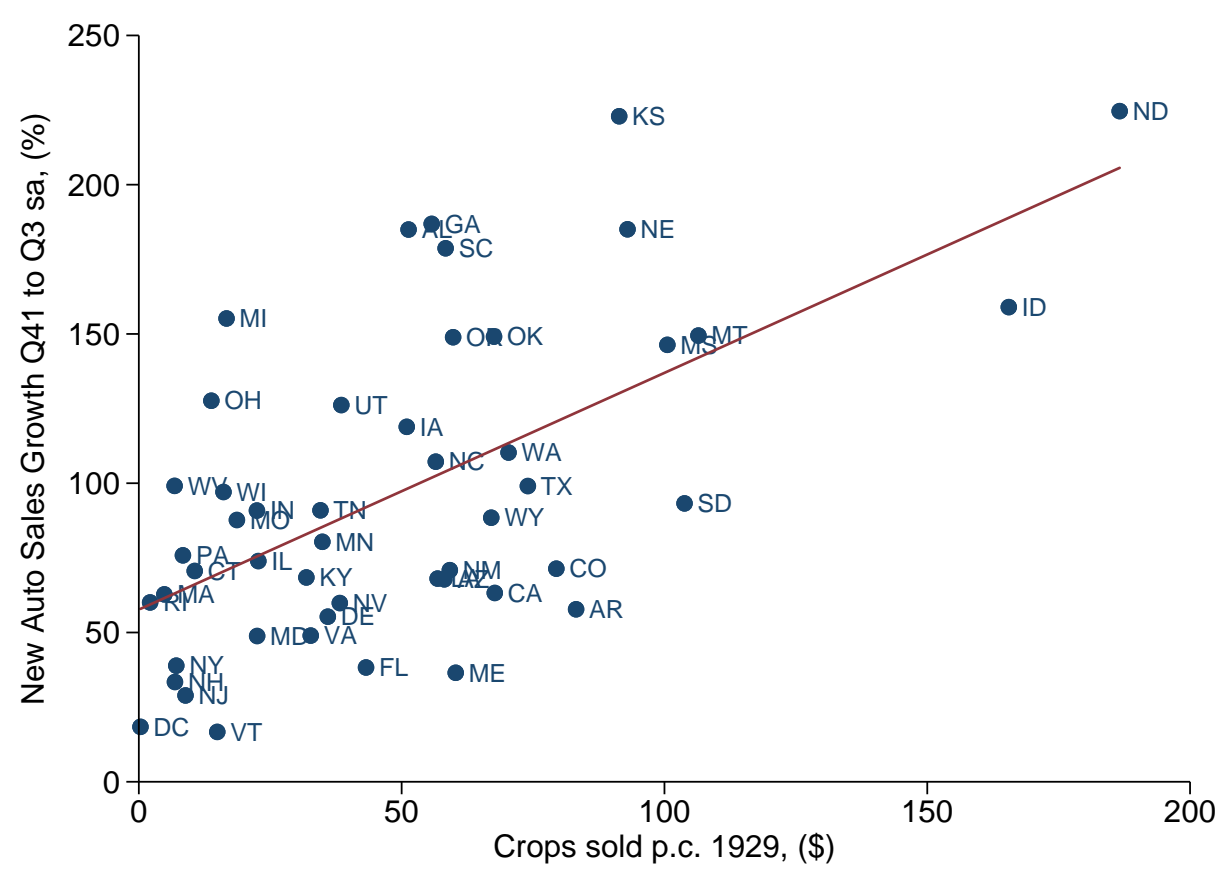

(b) Crops sold per capita

Notes: Auto sales growth is measured as the percent change in seasonally-adjusted auto sales from the 1932:Q4-1933:Q1 quarterly average to 1933:Q3. The straight line is the OLS regression line. Sources: Auto sales - see text. Farm share - the 1930 Census as reported in Haines and ICPSR (2010). Crops sold - the 1940 Census as reported in Haines et al. (2015). 
averaging over more months means filtering out more noise. We end the calculation in the third quarter of 1933, since this largely avoids contaminating the effect of higher crop prices on auto sales with the effect of AAA payments on auto sales. ${ }^{15}$

In figure $6 \mathrm{a}$, there is a clear positive relationship, with the farm population share explaining a substantial fraction of the cross-state variation in auto sales growth $\left(R^{2}=0.31\right)$. Column (1) of table 2 shows the corresponding regression. The slope of the regression line, 1.7, is economically large and significantly different from zero with a t-statistic of 4.5. It implies that a one-standard-deviation increase in the farm share (17 percent) raised auto sales growth by 29.2 percentage points $(1.70 \times 17.2=29.2)$. Furthermore, the effect is almost certainly large; the 95 percent confidence interval ranges from 16.2 percentage points to 42.2 percentage points. As another benchmark, a coefficient of 1.7 means that if a state's farm share rose from 11 percent (that in California) to 50 percent (that in North Carolina), then auto sales growth would rise 66.3 percentage points $((50-11) \times 1.70=66.3)$.

Figure 6b replaces farm share with the per capita value of crops sold in 1929. Again, the relationship is positive and explains a large fraction of the variation $\left(R^{2}=0.36\right)$. The regression coefficient of 0.79 (t-statistic 6.3), shown in column (3) of table 2, means that a $\$ 1$ increase in the value of crops sold per capita increased car sales by 0.79 percentage points. The standard deviation of the per capita value of crops sold was $\$ 39.7$, so a onestandard-deviation increase in crops sold per person raised spring 1933 auto sales growth by 31.5 percentage points. This is nearly identical to the effect of a one-standard-deviation increase in farm population share. And again, the relatively narrow 95 percent confidence interval (21.5 percentage points to 41.5 percentage points) suggests that this effect was almost certainly large.

The scatter plots also highlight several features of the farm channel. First, with the exception of Michigan, the ten states with the most rapid auto sales growth were all either in the top quintile of wheat production per capita (North Dakota, Kansas, Montana, Idaho, Nebraska, and Oklahoma) or in the top quintile of cotton production per capita (Alabama, South Carolina, and Georgia). Relatedly, the most rapid auto sales growth was not con-

\footnotetext{
${ }^{15}$ In the third quarter of 1933, AAA payments totaled $\$ 80.8$ million (Nourse et al. (1937), appendix C, table V, p. 588); this can be compared to average quarterly farm personal income in 1933 of $\$ 700$ million (BEA regional data, table SA4).
} 
Table 2 - New auto sales growth in spring $1933(\%, \mathrm{SA})$

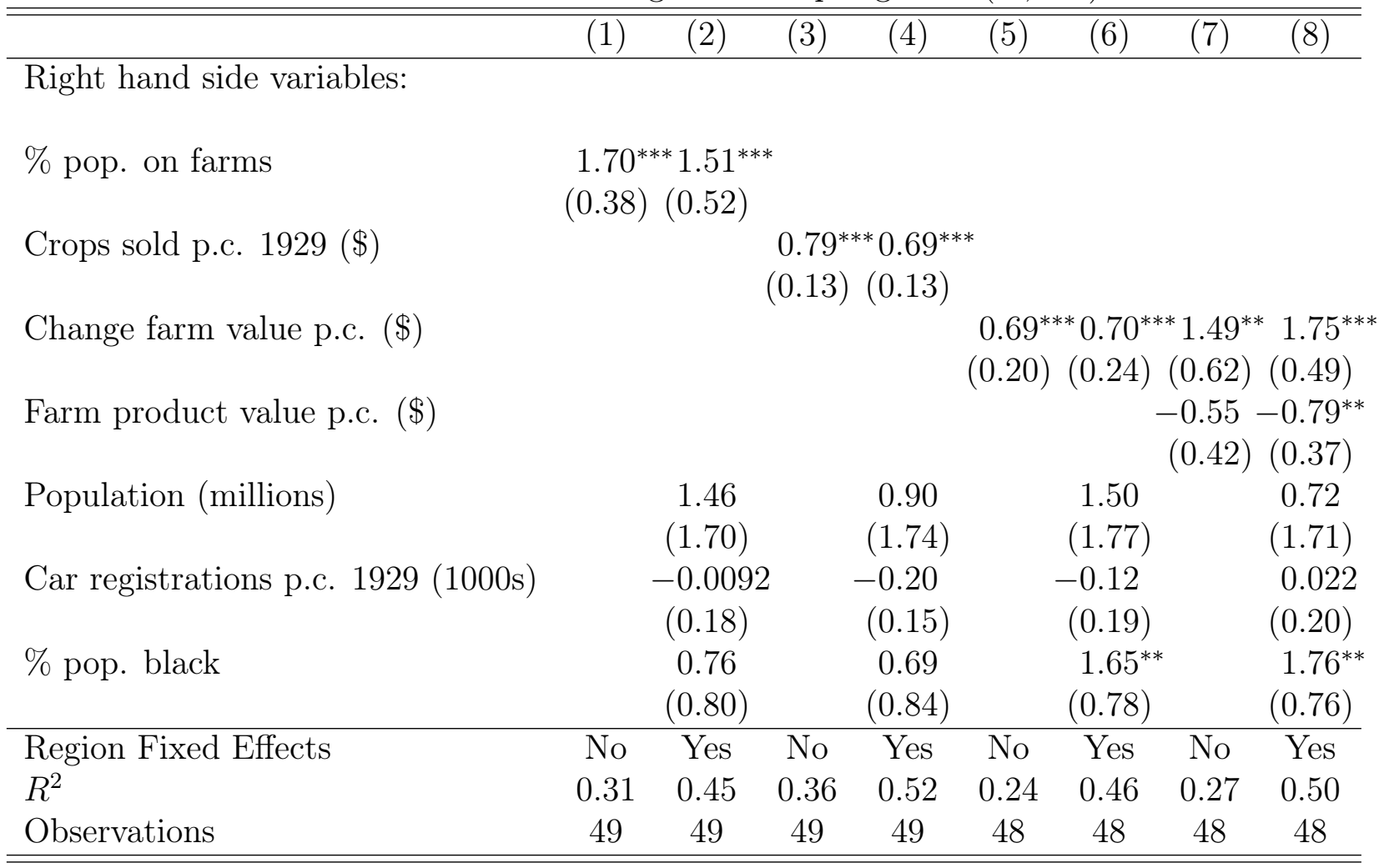

Notes: The dependent variable is the percent change in seasonally adjusted auto sales from the 1932:Q41933:Q1 average to the 1933:Q3 average. "p.c." means per capita. Robust standard errors in parenthesis. ${ }^{*} p<0.1,{ }^{* *} p<0.05,{ }^{* * *} p<0.01$

Sources: New auto sales - see text; 1929 car registrations - Automotive Daily News Review and Reference Book, 1934, p. 32; percent of population on farms and percent of population black - the 1930 Census as reported in Haines et al. (2015); value of crops sold per capita - the 1940 Census as reported in Haines et al. (2015); population - 1930 Census figures as reported in Haines and ICPSR (2010); farm value - see text and appendix C.2.

centrated in one specific region of the country, and there was substantial variation within regions. Second, farm share of the population and crops sold per capita were not strongly correlated with population; Texas was a large-population state highly exposed to the farm channel, whereas New Hampshire was a small-population state little exposed to the farm channel. The overall correlation between farm share and state population was -0.28 ; between crops sold per capita and state population, -0.34 .

Columns (2) and (4) of table 2 include controls for state population levels, car registrations per capita in 1929, the black population share, and census region fixed effects. The fact that the coefficients in columns (2) and (4) are similar to those in columns (1) and (3) shows that we are not conflating the farm channel with other variables that could correlate with agricultural exposure. 
Figure 7 - Auto sales by farm share quartile

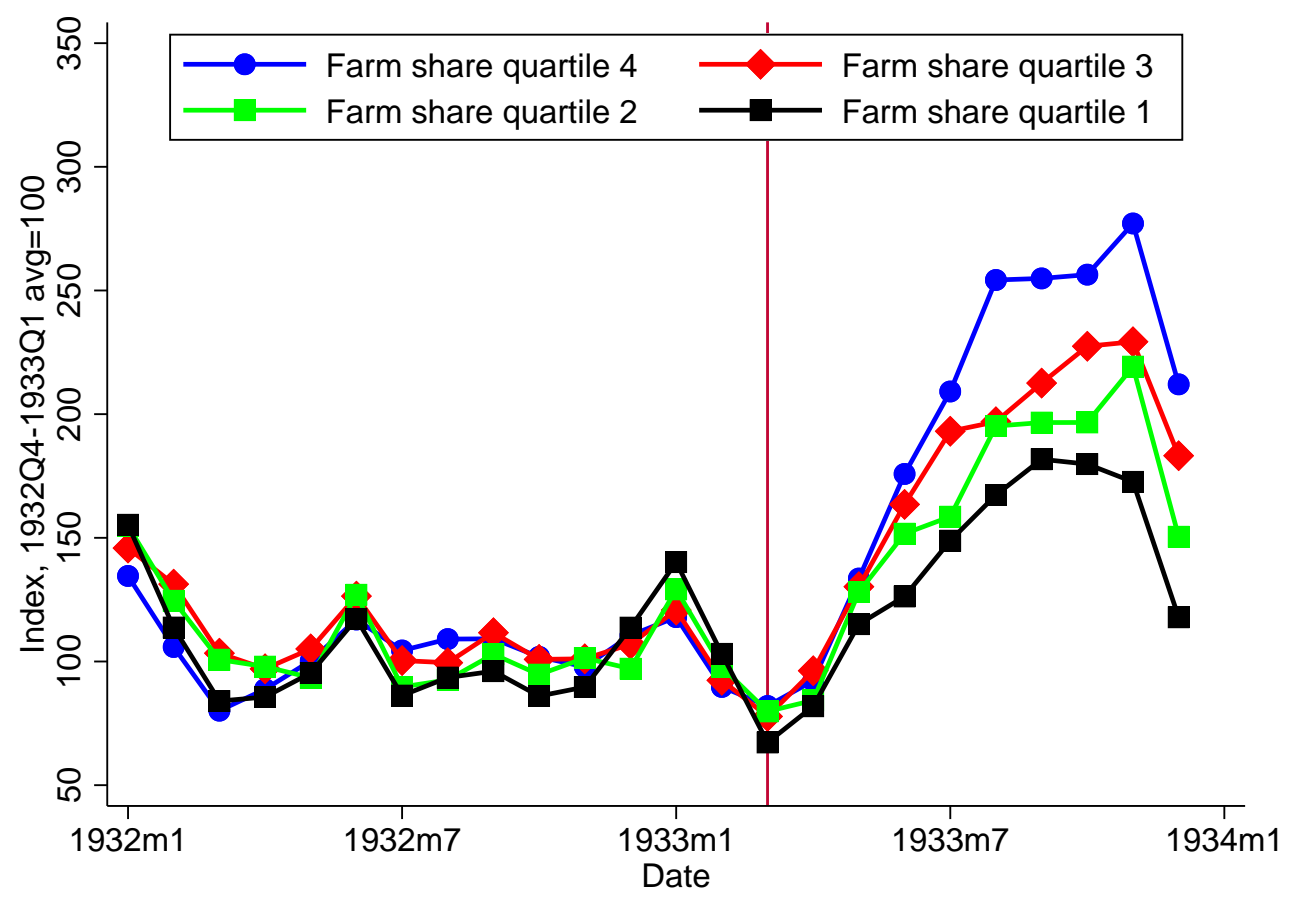

Note: Quartiles are based on 1930 farm population share. They are constructed by first indexing each state to 100 for 1932:Q4-1933:Q1 and then averaging across states in a quartile. Sources: Auto sales - see text. Farm share - the 1930 Census as reported in Haines and ICPSR (2010).

Next we check that we are not wrongly extrapolating from pre-existing trends in agricultural states. We group states into quartiles based on their 1930 farm population share. We then base each states' auto sales at 100 for 1932:Q4-1933:Q1 and average across all states in the quartile. Figure 7 plots the evolution of auto sales in each quartile in 1932 and 1933. While low farm-share states and high farm-share states followed roughly similar trends up to March 1933, thereafter there is a clear divergence, as auto sales in more agricultural states grew faster.

Farm share of the population and crops sold per capita are a proxy for the positive effect of higher farm prices on local income. To better measure the income effect of the price shock in locality $i$ we calculate:

Change farm product value per capita $i=\frac{1}{\text { population }_{i}} \sum_{j=1}^{16}$ farm product value $e_{i, j, 1932} \times \% \Delta$ price $_{j}$.

Here 1932 farm product value in location $i$ for farm product $j$ equals the quantity of the product produced in that locality times the national price $\left(Q_{i, j, 1932} \times P_{j, 1932}\right)$. We define 
$\% \Delta$ price $_{j}=\frac{P_{j, 1933: Q 3}-\left(P_{j, 1932: Q 4}+P_{j, 1933: Q 1}\right) / 2}{\left(P_{j, 1932: Q 4}+P_{j, 1933: Q 1}\right) / 2}$, consistent with our timing of auto sales growth. ${ }^{16}$ In equation (2), we deliberately omit data on 1933 farm production, since local supply conditions are not locally exogenous. For the same reason, we use national prices throughout. ${ }^{17}$

Columns (5) and (6) examine the effect of this measure on the spring 1933 change in auto sales. The coefficients mean that a $\$ 1$ increase in per capita farm product value is associated with a 0.7 percentage point increase in auto sales. We can obtain stronger evidence on the farm channel by controlling for the value of 1932 farm production. Doing so means the regression compares states similar in agricultural intensity but differentially treated by the spring 1933 farm price changes. Columns (7) and (8) show that the change in farm product value alone accounts for the faster recovery. By contrast, holding the change in farm product value fixed, higher agricultural exposure is associated with weaker car sales growth. As in columns (1) to (4), in columns (5) to (8) we easily reject a zero effect of a $\$ 1$ change in farm product value; t-statistics range from 2.4 to 3.6.

Using the estimates in columns (7) and (8) of table 2, one can perform a back-of-theenvelope calculation of the local dollar amount of spending on cars in response to a $\$ 1$ change in farm value. Spending in locality $i$ on cars in response to a $\$ 1$ change in farm product value is:

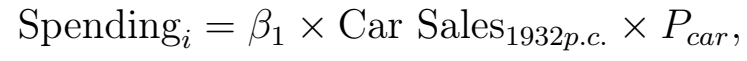

where $P_{\text {car }}$ is the average price of a car in $1933 .{ }^{18}$ Per capita U.S. car sales in 1932 were 0.0088 , and the average retail value of a car sold was $\$ 725 .{ }^{19}$ Thus with the coefficient of 1.75 percentage points in column (8), Spending $_{i}=.0175 \times 0.0088 \times \$ 725=\$ 0.11$; that is, we find spending of 11 cents on new cars for every $\$ 1$ increase in farm product value. The uncertainty in our estimate of $\beta_{1}$ implies a 95 percent confidence interval of 4.9 cents to 17.4

\footnotetext{
${ }^{16}$ The data we use in calculating equation 2 are detailed in appendix C.2. Crop quantities are for the crop year.

${ }^{17}$ We also estimated the regression using state-level farm prices to construct our measure of farm product value in 1932. Results are quantitatively similar.

${ }^{18} \beta_{1}$ measures the percent change in car purchases per annual dollar flow of farm income per person, $\% \Delta$ cars per annual $\$ /$ p.c.. Multiplying by annual car sales per person converts the units to the annual change in car purchases per annual dollar flow of farm income, annual $\Delta$ cars per annual $\$$. Further multiplying by the price yields the annual dollar change in the value of car purchases per annual dollar flow of farm income, annual $\Delta$ car value per annual $\$$.

${ }^{19} \mathrm{Car}$ sales are from Automotive Industries, 2/25/33, p. $224 . \quad 1932$ population is from https://www.census.gov/population/estimates/nation/popclockest.txt. The retail value of a car is from Suits (1958), table A-2, column 4, p. 279.
} 
cents. $^{20}$

Unfortunately, a clean quantitative interpretation of the dollar spending response is limited by three factors. First, this spending response is not a marginal propensity to consume (MPC). It measures spending in a treated state relative to a non-treated state. Because of spillovers across households it will generally not be equal to a household MPC. Second, since our measurement of the change in farm product value includes only major crops and livestock products, it likely underestimates the actual dollar change in farm product value. We use 16 farm products in equation 2, accounting for roughly 80 percent of total U.S. farm product value, so we suspect that the resulting bias is small. ${ }^{21}$ Third, and likely more important, the right hand side variable is the change in farm product value, not the change in farm income. As stated above, the farm product value of product $j$ is price $_{j} \times$ quantity $_{j}$. Across all farm products $j$, farm product values need not sum to farm income. Consider, for example, the case of a farmer growing corn to feed pigs and then obtaining income from selling the pigs. If the price of corn rises, the income of the farmer will go up only insofar as the price of pigs also rises. But farm value will increase along with the price of corn. Since farm value exceeds farm income, the response of car sales to a given change in farm product value will be below the response of car sales to a given change in farm income.

Acknowledging these difficulties in interpretation, two comparisons may help to illustrate the magnitude of the spending response we find. First, in 1932, total spending on new motor vehicles was 1.2 percent of all consumption spending, so spending of 11 cents on new cars per dollar change in farm value is consistent with a substantial overall consumption response (NIPA table 2.4.5). Second, this response is also consistent with Hausman's (2016a) estimates of the 1936 veterans' bonus' impact on new car spending. In a cross-state regression, Hausman (2016a) estimates a local increase in new car spending of 25-35 cents per $\$ 1$ of veterans' bonus received. That this number is larger than the 11 cent result for farm product

\footnotetext{
${ }^{20}$ When we normalize the change in farm product value by lagged car sales as opposed to population, these estimates are smaller although still large relative to the share of cars in consumption. The mean estimate in the state data is 2.4 cents with a 95 percent confidence interval of -1.6 cents to 6.4 cents. And the mean estimate in the county data is 4.0 cents with a 95 percent confidence interval of 1.1 cents to 6.9 cents. Note that there are other sources of uncertainty in this spending estimate. For instance, we are using an average price for cars sold in 1933 which may not be equal to the price of the marginal car sold.

${ }^{21}$ The 80 percent figure is based on the data for 1934 in United States Department of Agriculture (1936), tables 437 and 440, pp. 330-331, 334 .
} 
Figure 8 - The farm channel in other years

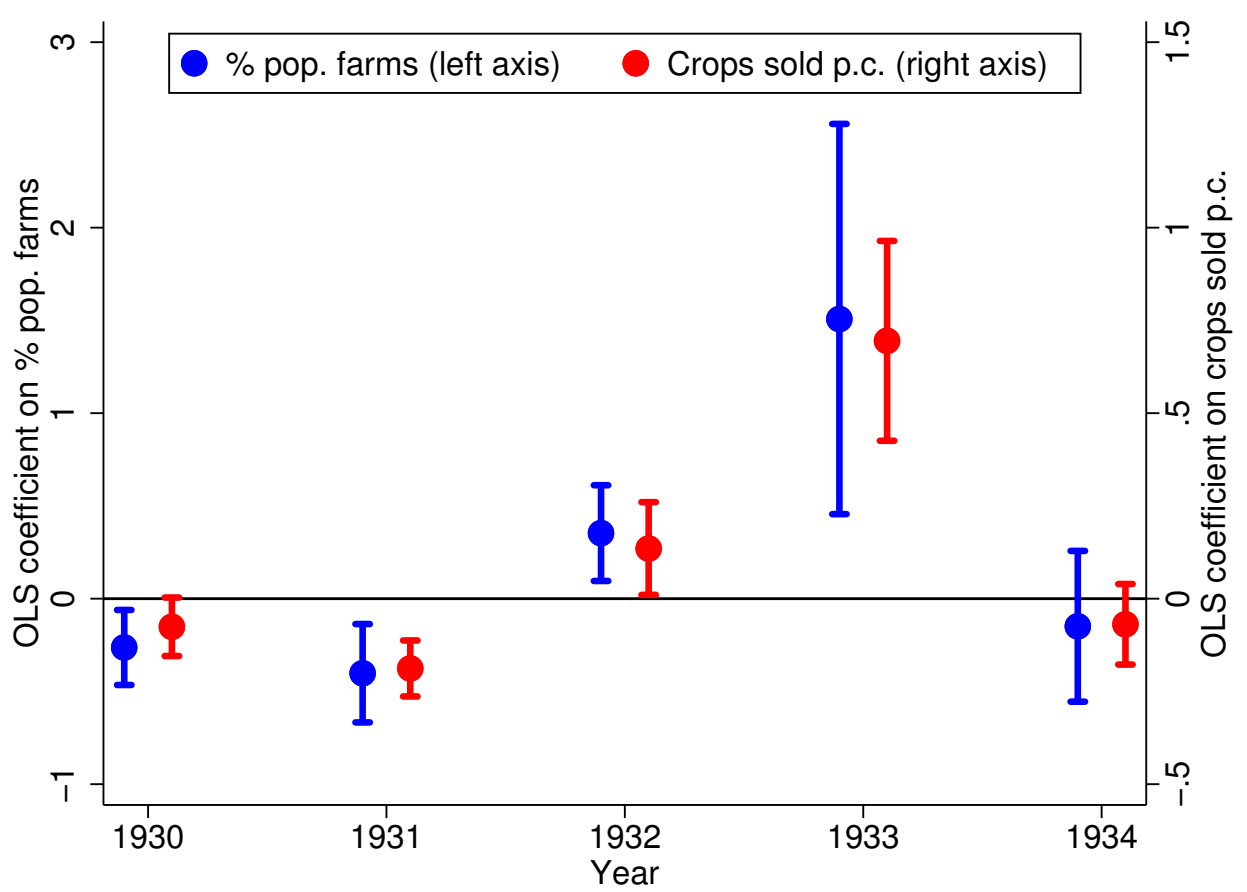

Note: The figure plots the point estimate and 95 percent confidence interval from a regression of the percent change in auto sales from the 1932:Q4-1933:Q1 average to 1933:Q3 on either the farm population share or crops sold per capita. The specification is that in columns (2) and (4) of table 2. Sources: See text.

value is as expected given the mismeasurement of farm product value relative to farm income discussed above, and given the much larger importance of cars in consumption in 1935-36 versus in 1932-33: in 1932 new motor vehicles were 1.2 percent of all consumption; in 1935 they were 2.7 percent.

3.2 Robustness We next address three potential concerns. First, a natural question is whether auto sales always grew more rapidly in spring in states with large populations living on farms or high crop values per person. If farm states saw more rapid auto sales growth in years when there was no dollar devaluation or change in crop prices, then the preceding results would not be evidence about the effects of the farm channel in spring 1933. Figure 8 shows coefficients and two standard error bands from regressions of spring auto sales growth on farm share or crops sold for each year from 1930 to 1934 using the specification in columns (2) and (4) of table 2. The large, positive, and statistically significant effect on auto sales growth is unique to 1933 .

The presence of non-zero effects in years other than 1933 is unsurprising; we would expect 
many shocks to differentially affect farm and nonfarm states, especially during the turbulent Great Depression years. In particular, the negative coefficients in 1930 and 1931 likely reflect the relative decline in farm income in those years. This decline in farm income was not due to an exchange rate movement, but as in 1933, it can be explained by a change in the relative price of farm products; between 1929 and 1931, the CPI fell 11 percent, while farm product prices fell 38 percent (FRED series CPIAUCNS and M04058USM350NNBR). What is reassuring about the results in figure 8 is the relative magnitude of the effect in spring 1933 and the lack of consistently positive effects in other years.

A second potential concern is that the positive relationship between new auto sales and agricultural exposure is only driven by small states. Based on a visual inspection of the scatter plots (figures $6 \mathrm{a}$ and $6 \mathrm{~b}$ ), we noted above that this was unlikely. A more formal test is to estimate specification (1) using population-weighted OLS. Appendix table B.1 reports results: estimates are generally similar or moderately smaller.

Finally, one may be concerned about the effect of seasonal adjustment on our estimates. We have only five years to estimate seasonals (1929-32 and 1934), ${ }^{22}$ and so our estimates of the seasonal factors are imprecise. In appendix table B.2 we report estimates with the dependent variable measured as the percent change in auto sales from the fourth quarter of 1932 to the fourth quarter of 1933 . We see similar or larger effects.

3.3 Cross-county results The state-level regressions establish that there was a strong positive relationship between auto sales growth and farm exposure in spring 1933. But the small cross-state sample inevitably imposes limits on the analysis. In a cross-state sample, we cannot control for all possible state-specific confounders (state fixed effects), nor do we have the statistical power to examine the relationship between farm debt and the spending response. The latter issue will be a focus of the following section. Here we repeat the statelevel analysis of the previous section at the county-level, taking advantage of the much larger sample to both control for more variables and to consider alternative specifications.

County-level data on the percent change in auto sales between 1932 and 1933 are provided

\footnotetext{
${ }^{22}$ We do not have access to monthly data before 1929, and the seasonals are different after 1934, because in 1935 auto manufacturers changed from introducing new models in January to introducing new models in October or November (Cooper and Haltiwanger, 1993).
} 
in Sales Management, 4/20/34, pp. 363-404. Data on the level of 1933 sales are provided in Sales Management, 4/10/35, pp. 418-504. We calculate the level of 1932 sales by applying the percent change from 1932-33 to the level of 1933 sales.

These data allow us to estimate the effect of many covariates in a way that is not possible with the 49 observations in a cross-state regression, but the county data also come with three disadvantages. (1) They are annual rather than monthly, providing only an imperfect window into the crucial March-July 1933 period. (2) They suffer from some reporting error. We know this because uniquely for Wisconsin, we have official data on new car registrations by county to which we can compare the data in Sales Management. Across the 48 Wisconsin counties for which Sales Management provides data on 1932 sales, the correlation between the 1932-33 percent change in Sales Management and that in the official data is 0.85 . This is high enough to reassure us that there is a strong signal in the Sales Management data, but it also indicates substantial reporting error. ${ }^{23}$ Since the change in auto sales will be our dependent variable, not our independent variable, this error is more likely to increase our standard errors than it is to bias our estimates. (3) The third disadvantage of the county relative to the state data is that it is incomplete. Sales Management provided data on 1932

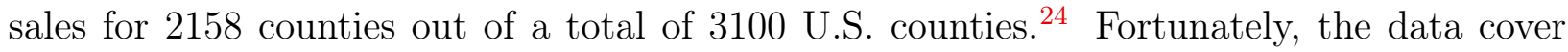
most counties with substantial population and auto sales; they cover 84 percent of 1932 auto sales.

Figure 9a maps the county auto sales data. Blank areas are those with no data, while darker areas are those with more rapid auto sales growth. For comparison, figure 9b maps the change in farm product value across the counties for which we observe auto sales. Farm product value is calculated as in equation 2 , with $\% \Delta$ price $_{j}$ now equal to $\frac{P_{j, 1933}-P_{j, 1932}}{P_{j, 1932}}{ }^{25}$

The correlation is visually obvious: there was a swath of rapid car sales growth and large farm product value increases running north from Texas, with pockets of high car sales

\footnotetext{
${ }^{23}$ Official new car registration data for Wisconsin are from "Report of New Car Registrations for the Year 1932" and "Report of New Car Registrations for the Year 1933." Both are available at the Wisconsin State Historical Society. In our empirical work, we substitute the official data for the Sales Management data for Wisconsin.

${ }^{24}$ With the addition of the official new registrations data from Wisconsin, we cover 2181 counties.

${ }^{25}$ For some crops and counties, we do not observe actual production in 1932 . In these cases, we impute county production of crop $j$ using the formula $Q_{\text {county }, j, 1932}=\left(Q_{\text {county }, j, 1929} / Q_{\text {state }, j, 1929}\right) \times Q_{\text {state }, j, 1932}$. See appendix C.3 for details.
} 
and increasing farm product value through the west. By contrast, in the northeast and mid-atlantic, car sales and farm product value increased only modestly.

Before reporting county-level regression results, as a benchmark the first two columns of table 3 show state level results. In column (1), we repeat the specification in column (7) of table 2. For a direct comparison with the annual county data, in column (2) we rerun this specification using annual data. The dependent variable is now the growth rate of new auto sales from 1932 to 1933. The estimate is larger.

Column (3) reports the same specification with county data. We cluster standard errors at the state level to account for spatial correlation in state-level policies, weather, and other shocks. ${ }^{26}$ The magnitude of the coefficient is similar, but the statistical significance is much higher (t-statistic equal to 2.7). Figure 10 plots a binned scatter plot for this regression. It shows that new auto sales growth tends to rise with the change in farm product value, and that this relationship is not driven by outliers. Column (4) adds controls for population, black population share, democratic vote share in the November 1932 election, rural nonfarm share, car registrations per capita in 1929, average percent of bank deposits suspended between 1930 to 1932, and the percent of farms mortgaged as of 1930. Importantly, in column (4) we also take advantage of the large number of observations to flexibly control for drought. As mentioned in section 2, drought was one factor pushing up grain prices in 1933. Insofar as drought conditions in a county were correlated with exposure to farm product price changes in 1933, this could be a source of bias. To address this, we follow Fishback, Troesken, Kollmann, Haines, Rhode, and Thomasson (2011) and use data from the National Climatic Data Center to construct an indicator for whether or not a county suffered from severe or extreme drought in each month of 1932 and $1933 .^{27}$ We then interact these 24

\footnotetext{
${ }^{26}$ Clustering at the state level does not correct for spatial correlation across state borders due, for instance, to weather shocks. Thus, as an alternative, we calculate standard errors following Conley (1999) as implemented by Hsiang (2010). These allow for arbitrary correlation of errors across counties whose centroids are within a set distance $r$. When $r$ is greater than $200 \mathrm{~km}$, the standard errors from this approach are very similar to our standard errors clustered at the state level, suggesting that the clustered standard errors largely absorb spatial correlation.

${ }^{27}$ Our drought data differ slightly from those in Fishback et al. (2011) for two reasons: (1) a coding error made by the National Climatic Data Center which affected historical data downloaded before 2013 (https://www.ncdc.noaa.gov/sotc/national/2013/3/supplemental/page-7). (2) For counties that span multiple climate divisions, we use GIS to compute the share of the county in each climate division. We then use these shares to compute a weighted average of the drought measure, rather than a simple average as in Fishback et al. (2011).
} 
Figure 9 - Auto sales growth and change in farm product value by county

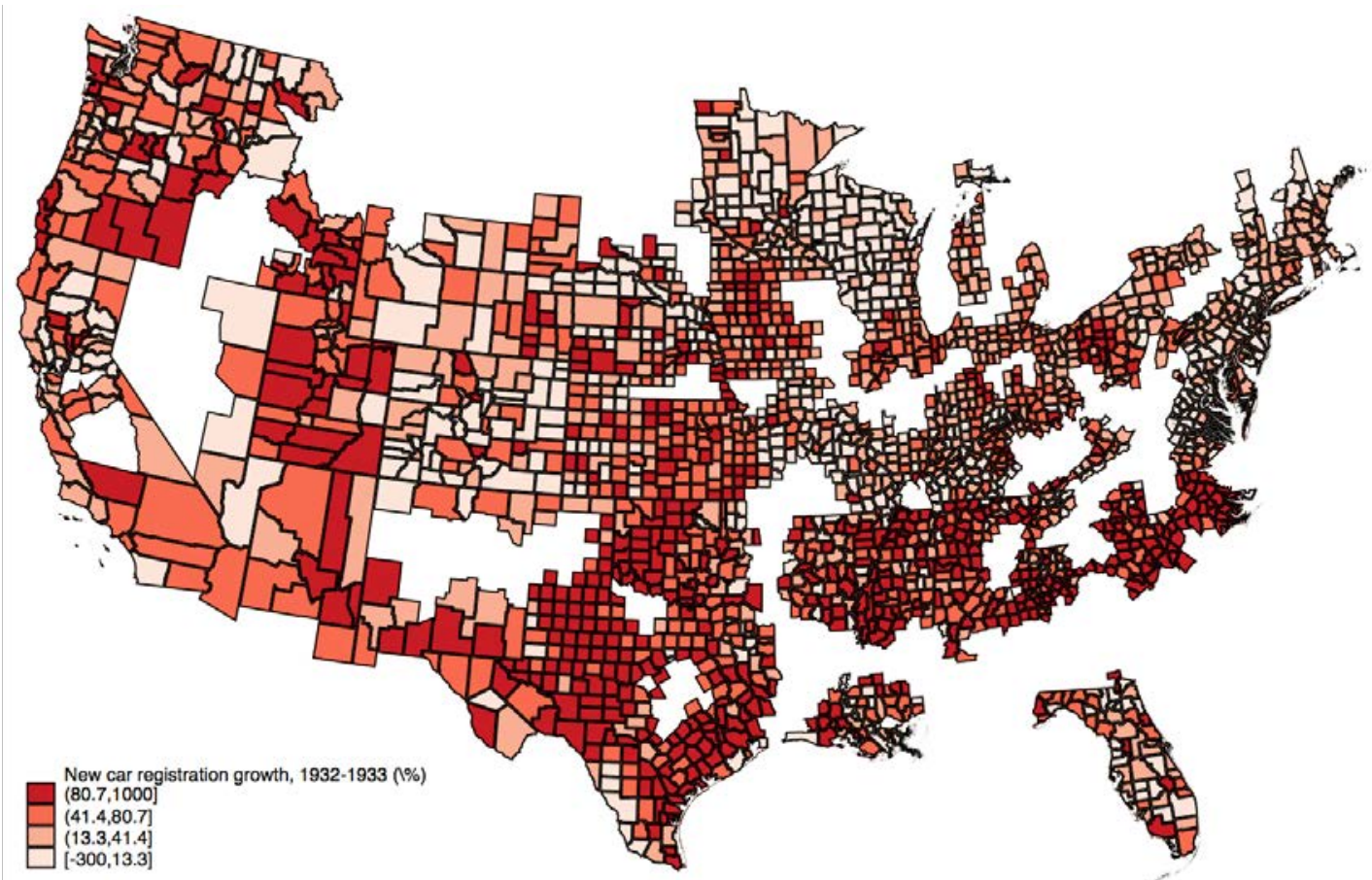

(a) County auto sales growth, 1932-33

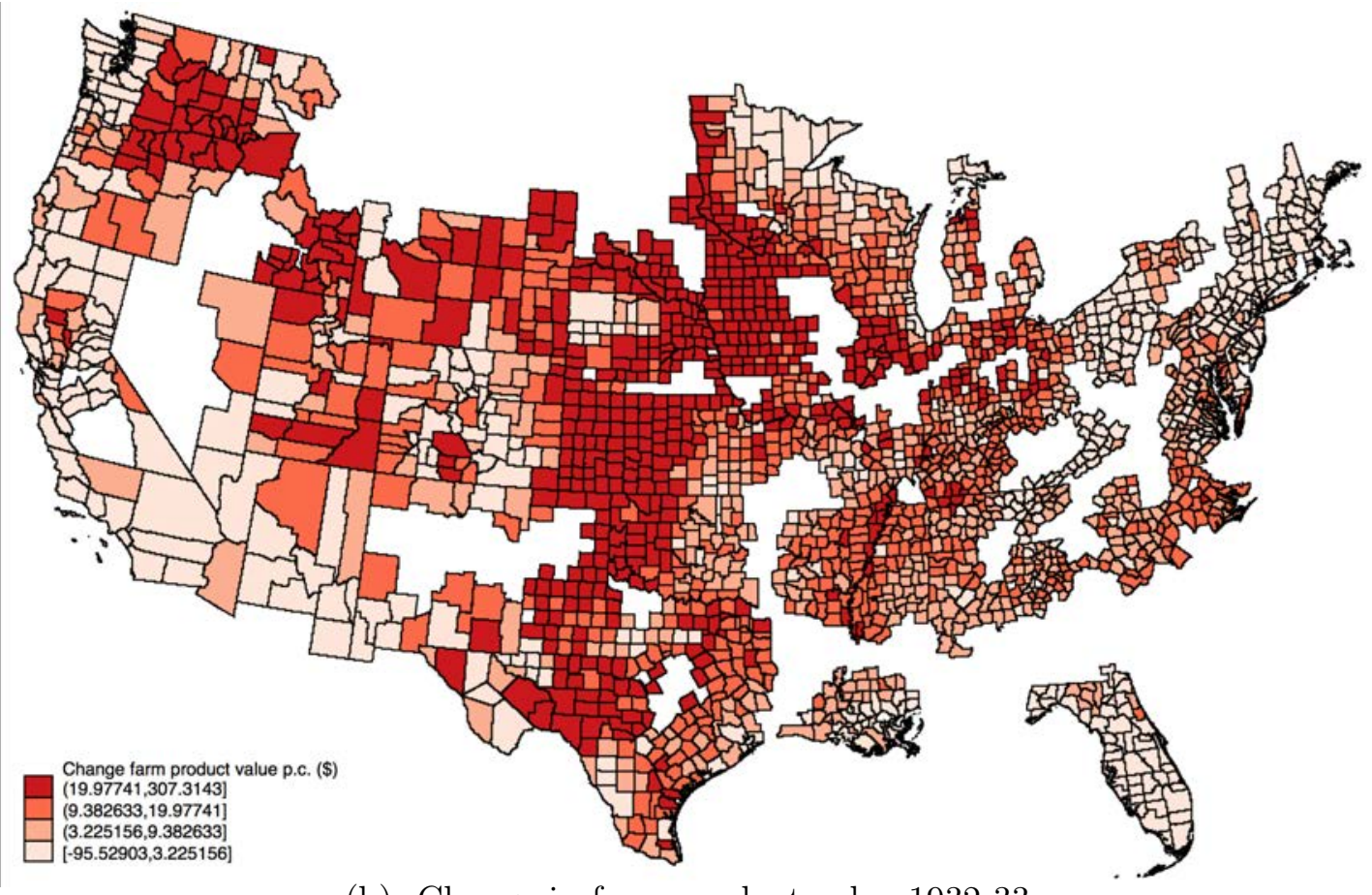

(b) Change in farm product value 1932-33

Note: Blank areas are missing data. Darker colors denote a larger percent change in auto sales or a larger dollar increase in farm product value.

Sources: see text. 
Figure 10 - Percent change in car sales and farm channel exposure at the county level

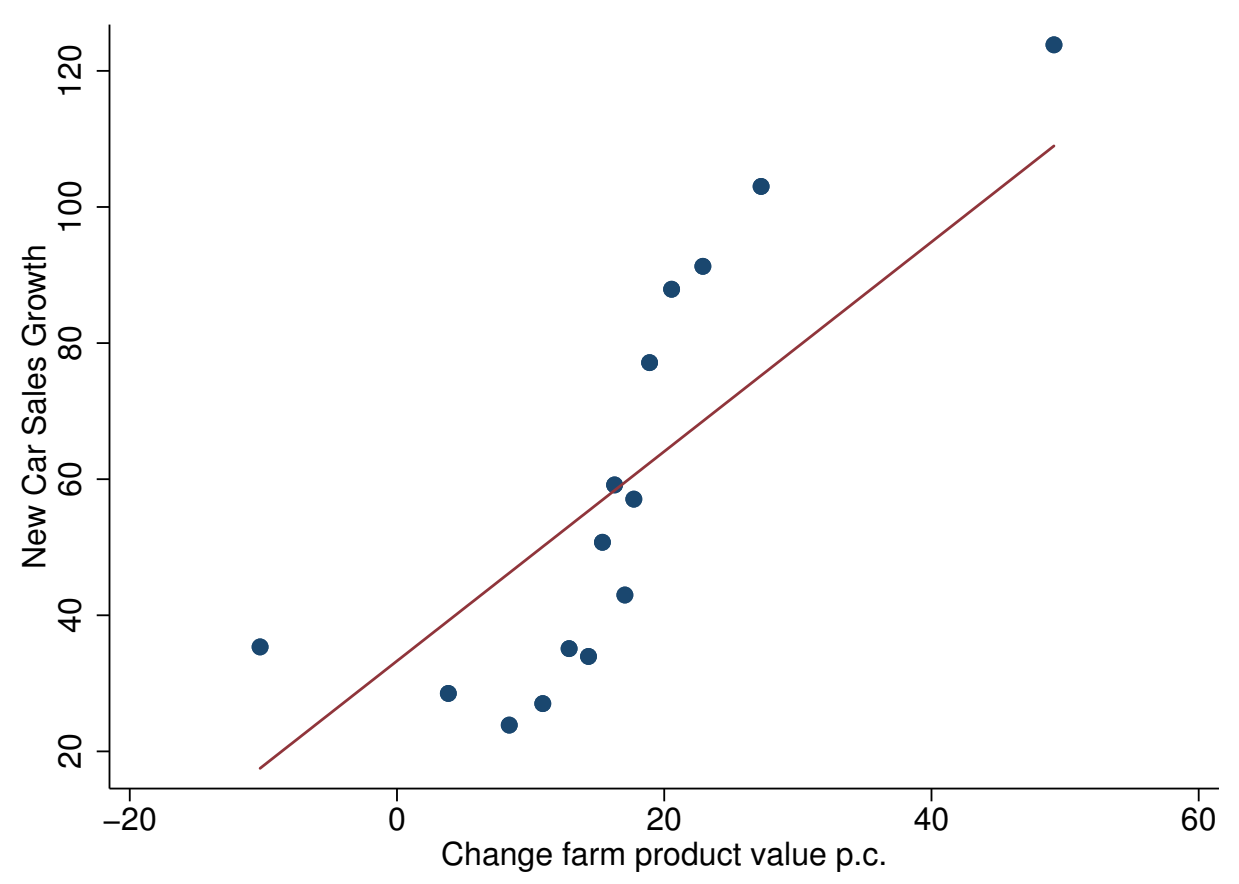

Binned scatter plot of 1932-33 county-level car sales growth against change in farm product value per capita, conditional on 1932 farm product value per capita. This corresponds to column 3 of table 3 . The straight line is the OLS regression line. Each point in the figure shows the mean percent change in auto sales in each bin of change in farm product value per capita after controlling for 1932 farm product value per capita. There are 15 bins. See Stepner (2014) for further details.

indicator variables with both farm product value and the change in farm product value. In doing so, the coefficient reported in column (4) on the change in farm product value shows the effect of a $\$ 1$ increase in farm product value on auto sales in a county that was not suffering from extreme drought. In practice, the addition of the drought and other control variables substantially increases the explanatory power of the regression (as measured by the $R^{2}$ ), but only minimally shrinks the coefficient on the change in farm product value. 
Table 3 - County New Auto Sales 1932-1933

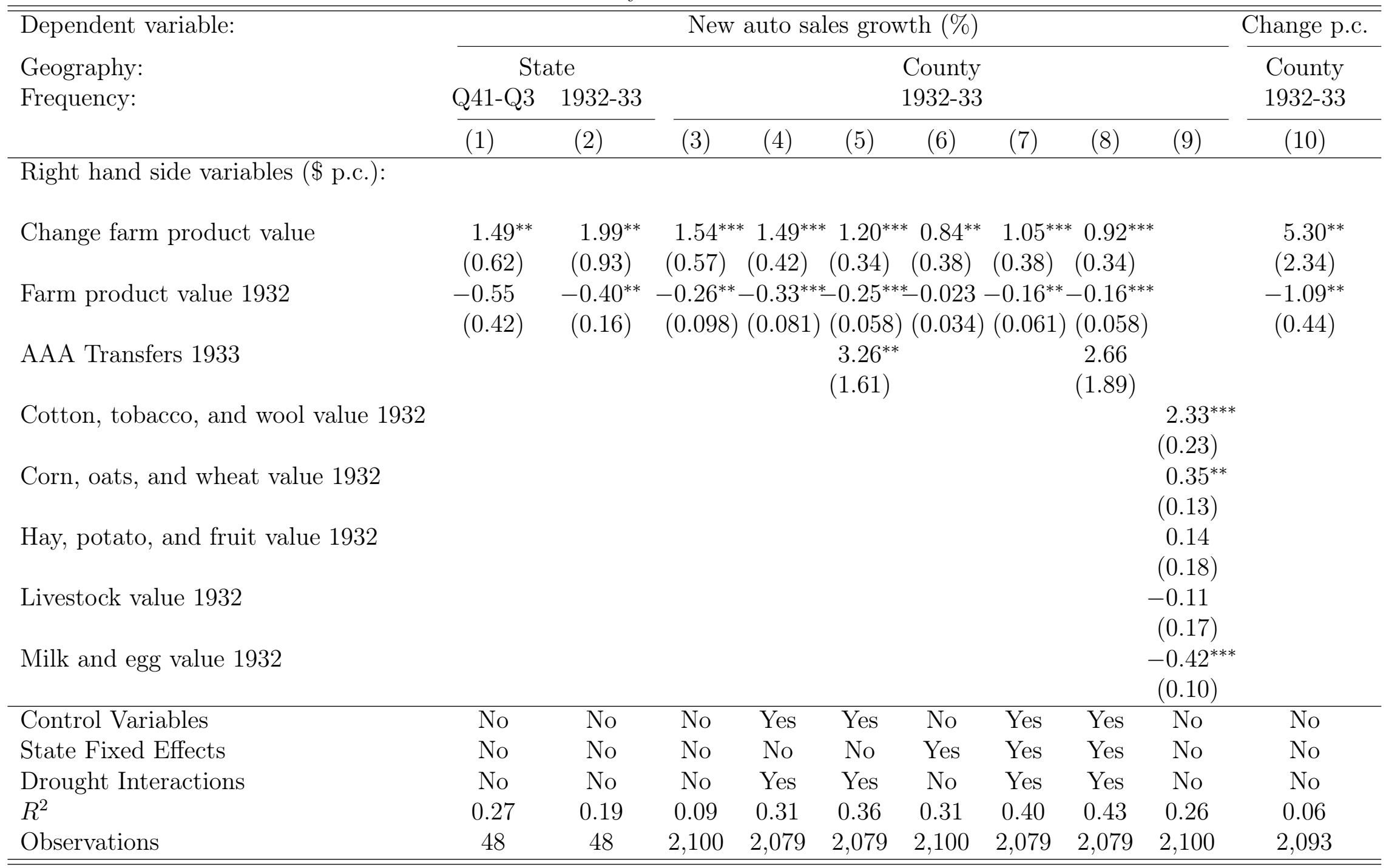

Notes: The dependent variable is the percent growth of new auto sales in columns (1) through (9) and the change in per capita new auto sales multiplied by 100,000 in column (10) over the frequency indicated in the table header. County regressions exclude counties with fewer than 500 car registrations in 1929 . Control variables are population, the FDR vote share, the black population share, the rural nonfarm share, car registrations per capita in 1929, deposits suspended from $1929-1932$ as a fraction of 1929 deposits, and the fraction of farms mortgaged in 1930. Drought interactions are based on monthly dummy variables for 1932 and 1933 for whether a county was in a severe or extreme drought, per the Palmer drought index. These are interacted with both the change in farm product value per capita and farm product value per capita. Standard errors clustered at the state level in parenthesis. ${ }^{*} p<0.1,{ }^{* *} p<0.05,{ }^{* * *} p<0.01$

Sources: New auto sales - see text. Farm product value (total and subcategories) - see text and appendix C.3. Population, and percent of population black - see table 2; 1929 car registrations - Standard Motor List Co, Automotive Statistics 1929; FDR vote percentage - ICPSR (1999) except CQ Voting and Elections Collection for St. Louis and Baltimore cities / counties; percent of population rural nonfarm - the 1930 Census as reported in Haines and ICPSR (2010); 1933 AAA transfers - United States Department of Agriculture (1934a), appendix B, exhibit 10; deposits suspended - Federal Deposit Insurance Corporation (2001); percent of farms mortgaged - Haines et al. (2015); drought indicators for U.S. climate divisions - see text. 
In column (5), we add one further control variable: AAA transfer payments per capita in 1933. In the state data, effects of AAA payments were not a significant concern since monthly data allowed us to end the estimation in the third quarter of 1933, before substantial AAA payments had been made. ${ }^{28}$ But given sizable AAA transfers in late 1933, there is a concern that these, rather than higher crop prices, could be driving our results. In 1933, AAA rental and benefit payments were paid only to farmers of cotton, wheat, and tobacco, ${ }^{29}$ traded crops whose prices rose rapidly in spring 1933. Thus the regression has difficulty fully disentangling the effect of these payments from the increase in farm product value. Nonetheless, in column (5) we still see economically and statistically significant effects of the change in farm product value.

Our estimate of the AAA payments effect is positive and large, though only marginally statistically significant. We suspect that the size is in part explained by the fact that our farm product variables are measured with error, so that the regression attributes part of the farm channel to the better-measured AAA variable. Still, our finding contrasts with Fishback, Horrace, and Kantor (2005) and Fishback and Kachanovskaya (2015), who find small or negative effects of AAA payments on county-level retail sales and state-level income in the 1930s. The difference in results may be explained by our focus on 1933 alone. Relative to the entire decade, in 1933 distortions from the AAA may have been less important and farm debt problems more important.

Columns (6) to (8) add state fixed effects to the specifications of columns (3) to (5). The resulting coefficients are somewhat smaller but statistically indistinguishable. We believe state fixed effects to be unnecessary for identification. But the robustness of the results to their inclusion shows that the farm channel operated within as well as across states.

The results in columns (2) to (8) indicate the importance of traded crops in spring 1933; 96 percent of the variation in the change in farm product value is explained by geographic variation in traded crop intensity. ${ }^{30}$ To see this directly, in column (9) we regress auto sales

\footnotetext{
${ }^{28}$ The Hoover administration used the Federal Farm Board to support grain and cotton markets, but these programs ended by 1932. See Olmstead and Rhode (2000, p. 732) and references therein.

${ }^{29}$ Smaller amounts of AAA spending went to purchasing hogs and dairy products (United States Department of Agriculture, 1934a, p. 277).

${ }^{30}$ This is the R-squared from a regression of the change in farm product value from 1932 to 1933 on the 1932 value of cotton, tobacco, wool, corn, oats, and wheat.
} 
growth on (1) the 1932 value of cotton, tobacco, and wool grown per capita; (2) corn, oats, and wheat value per capita; (3) hay, potato, and fruit value per capita; (4) livestock value per capita; and (5) milk and egg value per capita. In each case, per capita value in county $i$ is measured as $\frac{1}{\text { population }_{i}} \sum_{j} Q_{i, j, 1932} \times P_{j, 1932}$, where the sum is calculated over the crops $j$ in each category (e.g. cotton, tobacco, and wool). Results show that auto sales grew fastest in counties with high per capita production of cotton, tobacco, and / or wool. Although smaller, we also see a significant relationship between the per capita value of grain grown in a county and auto sales growth in that county. By contrast, there is no relationship between auto sales growth and the production of hay, potatoes, and fruit or livestock. This fits with the fact that these were nontraded goods whose prices moved relatively little in 1933 (table 1). The coefficient on milk and egg value per capita is actually negative. This may reflect the decline in milk and dairy prices in 1933 (table 1), and the likely negative impact of higher grain prices on the cost of feeding cows and chickens (United States Department of Agriculture, 1934b, p. 57).

Thus far we have used a specification in which the dependent variable is the percent change in auto sales. A concern is that a high growth rate of auto sales may be driven by small counties with small initial levels of auto sales. For this reason, we already drop counties with fewer than 500 car registrations in 1929. As an additional robustness check, we specify the dependent variable in specification (1) as the change (not percentage change) in auto sales from 1932 to 1933 per 100,000 people. Column (10) shows the result. We again see a positive effect of the change in farm product value. In standard deviation terms, the magnitude is similar to that in column (3). A one-standard-deviation increase in the change in farm product value per capita is associated with a 0.43 standard deviation increase in new auto sales growth and a 0.36 standard deviation increase in the change in new auto sales per 100,000 people.

3.4 Other outcome measures A possible concern is that the behavior of new auto sales in spring 1933 is unrepresentative. Here we compare the auto sales response to changing farm product value with the behavior of other measures of consumption and income. Unfortunately, this comparison is limited by the lower frequency and / or more limited geographical 
Figure 11 - Department store sales and rural general merchandise sales

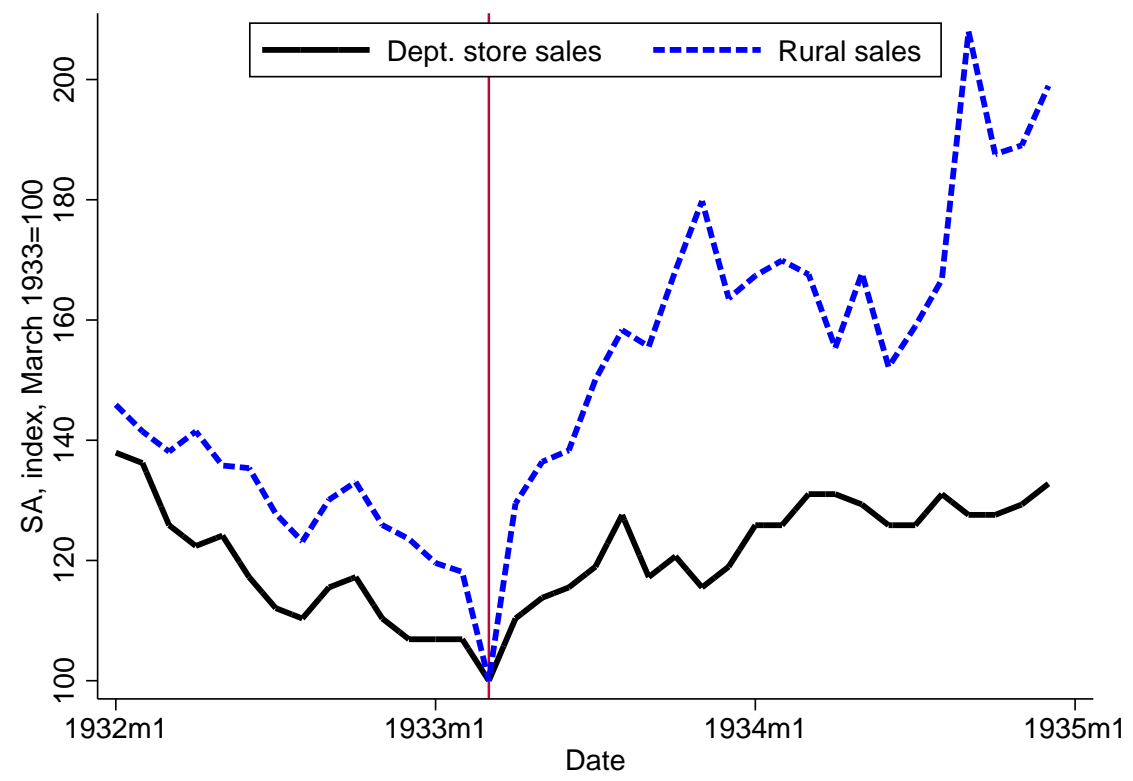

Note: The vertical line indicates the month before devaluation, March 1933. Source: U.S. Department of Commerce (1936), pp. 27-28.

detail of these alternative series.

We start by comparing department store sales to rural and small town sales of general merchandise (figure 11). ${ }^{31}$ We consider department store sales to be a rough proxy for urban consumption, since department stores were located in cities. Both department store and rural retail sales followed a similar downward path in 1932. Department store sales then rose 19 percent between March and July 1933, while rural sales of general merchandise rose 50 percent. The very rapid growth of rural sales was in part driven by a sharp drop in March that was reversed in April. But the relatively more rapid growth of rural sales does not depend on this single observation: February to July, department store sales grew 11 percent while rural sales grew 27 percent; April to July, department store sales grew 8 percent while rural sales grew 16 percent. The relatively rapid increase in rural consumption fits with the argument of this paper that recovery in spring 1933 was in part driven by farm demand.

Other than auto sales, we have no other monthly state-level consumption indicators. But

\footnotetext{
${ }^{31}$ Rural and small town retail sales are a Department of Commerce index that uses data on mail order and chain store sales to measure consumption in small towns (population less than 10,000) and on farms. The underlying data were provided by Chicago Mail Order House, Montgomery Ward \& Co., Sears, Roebuck \& Co., and J. C. Penney Co. For further details, see U.S. Department of Commerce (1934b).
} 
Table 4 - Other state-level outcomes 1932-1933

\begin{tabular}{|c|c|c|c|c|c|c|}
\hline & \multicolumn{3}{|c|}{ Sales Growth } & \multirow{2}{*}{$\begin{array}{c}\text { Empl. Growth } \\
\text { Manuf. } \\
(4)\end{array}$} & \multicolumn{2}{|c|}{ Income Growth } \\
\hline & $\begin{array}{c}\text { Cars } \\
(1)\end{array}$ & $\begin{array}{c}\text { Trucks } \\
(2)\end{array}$ & $\begin{array}{c}\text { Fridges } \\
(3)\end{array}$ & & $\begin{array}{c}\text { Total } \\
(5)\end{array}$ & $\begin{array}{c}\# \text { Tax } \\
(6)\end{array}$ \\
\hline \multicolumn{7}{|c|}{ Right hand side variables (\$ p.c.): } \\
\hline \multirow[t]{2}{*}{ Change farm product value } & $1.99^{* *}$ & $2.29^{*}$ & 1.44 & $0.40^{*}$ & 0.080 & $0.15^{* *}$ \\
\hline & $(0.93)$ & $(1.15)$ & $(1.24)$ & $(0.24)$ & $(0.12)$ & $(0.066)$ \\
\hline \multirow[t]{2}{*}{ Farm product value 1932} & $-0.40^{* *}$ & $-0.46^{* *}$ & -0.19 & $-0.13^{* * *}$ & $-0.087^{* *}$ & $* 0.033^{* * *}$ \\
\hline & $(0.16)$ & $(0.20)$ & $(0.20)$ & $(0.039)$ & $(0.028)$ & $(0.0098)$ \\
\hline$R^{2}$ & 0.19 & 0.13 & 0.07 & 0.26 & 0.35 & 0.01 \\
\hline Observations & 48 & 48 & 47 & 48 & 48 & 2,186 \\
\hline
\end{tabular}

Notes: The dependent variable is indicated in the table header. Column 6 excludes counties with fewer than 50 tax returns filed in 1932. Robust standard errors in parenthesis in columns 1 through 5 , and clustered at the state level in column 6. Sources: Auto sales and farm product value: see text. Truck sales: Automotive Daily News Almanac for 1937, p. 62. Refrigerator sales: Edison Electric Institute Bulletin, March 1936, Volume IV, no. 3, p. 80. Unfortunately, the refrigerator sales data lack documentation, and it is unclear whether they are retail or wholesale sales. Manufacturing employment: Wallis (1989). Total income: Bureau of Economic Analysis state personal income data, table SA04. Tax return counts: IRS Statistics of Income. $* p<.10,{ }^{* *} p<.05,{ }^{* * *} p<.01$.

in table 4 we do analyze annual state-level data on truck sales, electric refrigerator sales, manufacturing employment, and income. We also look at county-level data on the number of tax returns filed, a proxy for the income of the top 5-10 percent. Results in columns (2) and (3) for truck sales and refrigerators are in line with those for auto sales (column 1) in suggesting a large spending response to the change in farm product value. In the employment and income regressions, coefficients are positive but imprecisely estimated. We conjecture that this is due to employment and income leakages outside farm areas. When a farmer in North Dakota bought a car, the car purchase showed up in North Dakota, but the employment and income response might have shown up in Michigan. Therefore, as a general indicator of farm income, we prefer the aggregate numbers shown in figure 5. As discussed in section 2, these numbers show a very large increase in farm income in spring 1933.

\section{Mechanisms}

In 1933 agricultural areas experienced faster consumption growth and income growth. But these cross-sectional effects need not imply that the farm channel was expansionary for the U.S. economy as a whole. Positive effects on farm consumption could have been offset by 
declines in nonfarm consumption. Insofar as higher farm product prices made farmers richer, they ought also to have made others poorer. If higher farm prices were passed through to higher food prices, they made urban workers poorer. If they were not passed through, they lowered the profits of food manufacturers, wholesalers, or retailers. Whether through poorer urban workers or lower profits, higher farm income and consumption demand ought to have been matched by lower urban income and consumption demand. Thus the channel leading from farm prices to farm income could explain the much larger growth in car sales in farm areas without explaining any of the nationwide growth in car sales in spring 1933. Sales could have risen a lot in Iowa and fallen slightly in New York with no net aggregate effect.

In standard international macro models, devaluation is expansionary for the home country in part because foreign economies switch expenditure towards domestic goods. An extensive literature focusses on whether leaving the gold standard had beggar-thy-neighbor effects through such expenditure-switching (see Obstfeld and Rogoff (1996, pp. 626-630) for a survey). But changes in net exports only made small contributions to U.S. growth in 1933 (-0.11 percentage points) and 1934 (0.33 percentage points) (NIPA table 1.1.2). Thus, the farm channel is unlikely to have had large effects on aggregate GDP through this mechanism.

In this section we consider three other mechanisms through which higher crop prices could have been expansionary for the U.S. economy. First, if the increase in farm prices redistributed income from low to high MPC consumers, it would have been expansionary in the aggregate. Second, if higher farm incomes supported rural banks, whose problems were particularly severe, they may have helped the financial system and thus the economy overall. Finally, higher farm product prices may have raised nationwide consumption by creating expectations of higher future prices.

4.1 Differential MPCs Perhaps the most obvious way in which the farm channel would have benefitted the entire economy is if farmers had a higher MPC than the workers and / or businesses (capitalists) paying higher prices for farm products. To understand the plausibility of this mechanism, we compare the debt burden - a likely key indicator of MPCs - of farmers, workers, and capitalists. We then estimate the consumption response to higher farm prices in high versus low debt areas to obtain direct evidence on how debt burdens affected the 
MPC out of higher income. Together, this evidence suggests that higher farm prices in spring 1933 transferred income from low to high-MPC agents.

4.1.1 Debt burdens Standard incomplete market models (Bewley, 1986; Aiyagari, 1994) predict that households in debt have a particularly high MPC out of income shocks. This occurs because consumers subject to a sequence of temporary negative income shocks (e.g., lower crop prices) run up against a borrowing constraint, which prevents them from smoothing consumption. At the borrowing constraint, consumers spend all of any increase in income in order to move closer to the consumption smoothing solution. Consistent with this logic, Mian et al. (2013) estimate significantly higher MPCs for indebted households in the Great Recession. Thus, insofar as the farm channel redistributed from low-debt nonfarmers to high-debt farmers, it could have increased overall aggregate demand.

Data limitations make a precise comparison of farm and nonfarm household and business debt burdens difficult, but a comparison of mortgage debts suggests that debt problems were more severe among farmers. In 1933, agricultural mortgage debt totaled $\$ 7.7$ billion (Goldsmith, Lipsey, and Mendelson (1963), table Ia, pp. 80-81). This was 24 percent of the value of farm structures and land and 270 percent of farm personal income. Nonfarm residential mortgages totaled $\$ 23.1$ billion (Snowden, 2006a) in 1933, or 29 percent of the value of nonfarm residential structures and land (Snowden, 2006d) and 52 percent of nonfarm personal income. ${ }^{32}$

Presumably because of the much more unfavorable debt-to-income ratios, foreclosure problems were far more severe among farmers than among nonfarmers. Between 15 March 1932 and 15 March 1933, foreclosures exceeded voluntary farm sales by a ratio of more than 2 to 1 . There were 38.8 foreclosures per 1000 farms or nearly 100 per 1000 mortgaged farms. ${ }^{33}$ No exact comparison exists for nonfarm residential housing. But among all non-

\footnotetext{
${ }^{32}$ The value of farm structures and land is from Goldsmith et al. (1963), table Ia, pp. 80-81. Farm and nonfarm personal income data are from the Bureau of Economic Analysis, personal income data, table SA4.

${ }^{33}$ Stauber and Regan (1935), table 12, p. 38 document that between 15 March 1932 and 15 March 1933, there were 16.6 "voluntary sales or trades" and 38.8 "foreclosure of mortgages, bankruptcy, etc." per 1000 farms. The foreclosure percentage is approximate, since it uses the 1930 percentage of farms mortgaged (40 percent). Using the 1935 share of farms mortgaged (34 percent) results in a slightly higher ratio of foreclosures per 1000 mortgaged farms. Data on the total number of farms and the number of farms mortgaged are from U.S. Department of Commerce (1975) series K162 and K154. For more on farm foreclosures in the interwar period, see Alston (1983).
} 
farm structures - residential and nonresidential - the foreclosure rate per 1000 mortgaged structures in 1933 was just 13.3, one-eighth that for farms (Snowden, 2006b). ${ }^{34}$

As noted above, redistribution towards farmers could come not only from nonfarm households, but also from businesses. It is not obvious what the appropriate metric is for comparing business debt burdens with household debt burdens. But the available evidence suggests that the debt problems of nonfarm businesses were mild relative to those afflicting households. In his treatment of U.S. debt problems Clark (1933, p. 172) writes: "The facts show that the debt situation in industry, though serious, is not cataclysmic nor is it a mass problem." Quantitative support for this view comes from a comparison of business failures with farm and nonfarm foreclosures. Business failures rose 39 percent between 1929 and 1932; by contrast, over this three-year period, farm foreclosures rose 98 percent, and nonfarm foreclosures rose 84 percent. ${ }^{35}$

4.1.2 Debt and the MPC Our county data give us sufficient power to detect whether, as hypothesized, higher farm debt burdens were associated with higher MPCs and thus a larger local spending response. In that case, the farm channel ought to have been stronger in counties with more farm debt. We measure this exposure using the percent of farms mortgaged in 1930 in a county from the agricultural census (United States Department of Commerce, 1932). ${ }^{36}$ We interact the percent of farms mortgaged with the level and change in farm product value per capita (p.c.). We begin by estimating the linear regression

$\% \Delta$ Auto sales $_{i}=\beta_{0}+\beta_{1} \Delta$ farm product value p.c. $._{i} \times \%$ farms mortgaged $_{i}$

$+\beta_{2}$ farm product value p.c. ${ }_{i} \times \%$ farms $\operatorname{mortgaged}_{i}+\beta_{3} \Delta$ farm product value p.c. ${ }_{i}$

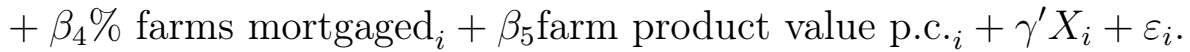

\footnotetext{
${ }^{34}$ Despite this large difference in foreclosure rates, mortgage delinquency rates were if anything higher in urban areas (Clark, 1933, p. 20). This points to the difficulty of making precise comparisons of farm and nonfarm debt burdens.

${ }^{35}$ Data on business failures are from Sutch (2006); farm foreclosures per 1000 farms are from Alston (1983), table 1, p. 888, and the total number of farms are from Olmstead and Rhode (2006a); nonfarm business failures are from Snowden (2006c).

${ }^{36}$ This is the most comprehensive indicator of farm debt available from the Census, since so-called "partowners" only report if they are mortgaged, not the size of their mortgage (United States Department of Commerce, 1932, p. 3). Where mortgage size is available, it correlates with our farm debt variable. Specifically, the average debt level in 1929 per (reporting) farmer across quintiles of \% farms mortgaged was $\$ 465$, $\$ 875, \$ 1509, \$ 2554$, and $\$ 3963$.
} 
The coefficient on the interaction term, $\beta_{1}$, shows how local farm debt conditions affected the strength of the farm channel.

As a second specification we relax the linear structure in equation (4) and instead group counties into quintiles based on the value of the farm debt variable. We then interact the level and change in farm product value per capita with these quintiles,

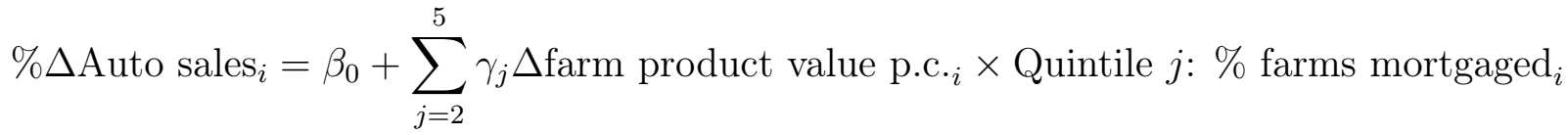

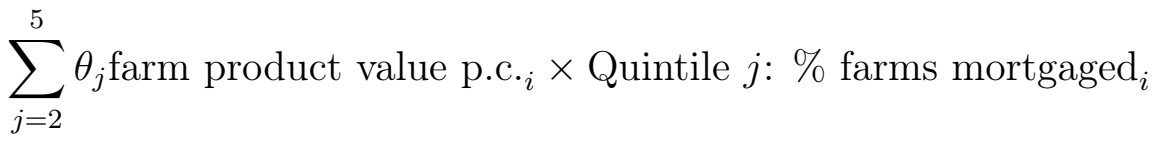

$$
\begin{aligned}
& +\beta_{1} \Delta \text { farm product value p.c. }{ }_{i}+\beta_{2} \text { farm product value p.c. }{ }_{i} \\
& +\sum_{j=2}^{5} \delta_{j} \text { Quintile } j: \% \text { farms } \text { mortgaged }_{i}+\lambda^{\prime} X_{i}+\varepsilon_{i} \text {. }
\end{aligned}
$$

In this specification, the effect of the farm channel is $\beta_{1}$ in the lowest quintile, $\beta_{1}+\gamma_{2}$ in the second quintile, $\beta_{1}+\gamma_{3}$ in the third quintile, and so on. Using quintiles allows us to assess whether the farm channel becomes monotonically weaker or stronger as local farm debt rises, without imposing that this relationship is linear. The cost is less precision if the true relationship is indeed linear.

Panel A of table 5 shows the estimates of the linear interaction (equation (4)) with the percent of farms mortgaged. Panel B shows the estimates using quintiles of percent of farms mortgaged and farm leverage (equation (5)). For percent of farms mortgaged, we find a statistically significant and positive linear interaction coefficient in all specifications. In panel B, without state fixed effects (columns (1) and (3)), quintiles 2 through 5 exhibit stronger effects of the farm channel than quintile 1. However, within these quintiles the effect is not monotonic: quintile 2 shows particularly strong responses. This pattern reflects the following correlation: farmers in cotton counties tended to be less mortgaged but benefitted from a bumper crop in 1933. By contrast, farmers in wheat counties tended to more mortgaged but suffered poor crop yields. This induces a negative correlation between the error term and the interaction of the percent of farms mortgaged quintiles with changes in farm product value, leading to the non-monotonic pattern and weakening the estimate of the linear interaction.

Since no principal wheat producing state was also a principal cotton producing state, 
Table 5 - Auto sales growth in spring 1933 (\% changes) and farm debt

Panel A: Linear interaction with \% farms mortgaged

\begin{tabular}{lcccc}
\hline & $(1)$ & $(2)$ & $(3)$ & $(4)$ \\
\hline Linear Interaction & $0.37^{*}$ & $0.77^{* * *}$ & $0.57^{* *}$ & $0.72^{* * *}$ \\
Change farm product value p.c. $(\$)$ & $(0.19)$ & $(0.24)$ & $(0.23)$ & $(0.24)$ \\
& $1.39^{* *}$ & 0.089 & 0.49 & 0.018 \\
& $(0.61)$ & $(0.50)$ & $(0.52)$ & $(0.51)$ \\
\hline State Fixed Effects & No & Yes & No & Yes \\
Control Variables & No & No & Yes & Yes \\
Drought Interactions & Yes & Yes & Yes & Yes \\
$R^{2}$ & 0.23 & 0.40 & 0.37 & 0.44 \\
Observations & 2,094 & 2,094 & 2,073 & 2,073 \\
\hline
\end{tabular}

Panel B: Interaction with quintiles of \% farms mortgaged

\begin{tabular}{lcccc}
\hline & $(1)$ & $(2)$ & $(3)$ & $(4)$ \\
\hline Change farm product value p.c. $\times$ Quintile 2 & $1.53^{* *}$ & $1.44^{* * *}$ & $1.72^{* * *}$ & $1.32^{* *}$ \\
Change farm product value p.c. $\times$ Quintile 3 & $(0.69)$ & $(0.54)$ & $(0.61)$ & $(0.54)$ \\
& $(1.07)$ & $(0.64)$ & $(0.84)$ & $(0.60)$ \\
Change farm product value p.c. $\times$ Quintile 4 & 0.34 & $2.12^{* *}$ & 1.61 & $2.08^{* * *}$ \\
& $(1.21)$ & $(0.80)$ & $(1.07)$ & $(0.75)$ \\
Change farm product value p.c. $\times$ Quintile 5 & 0.68 & $2.61^{* * *}$ & $1.84^{*}$ & $2.40^{* * *}$ \\
& $(1.07)$ & $(0.76)$ & $(1.01)$ & $(0.64)$ \\
Change farm product value p.c. $(\$)$ & 1.25 & $-1.19^{*}$ & -0.49 & $-1.21^{* *}$ \\
& $(0.96)$ & $(0.63)$ & $(0.96)$ & $(0.59)$ \\
\hline State Fixed Effects & No & Yes & No & Yes \\
Control Variables & No & No & Yes & Yes \\
Drought Interactions & Yes & Yes & Yes & Yes \\
$R^{2}$ & 0.24 & 0.39 & 0.37 & 0.43 \\
Observations & 2,094 & 2,094 & 2,073 & 2,073 \\
\hline \hline
\end{tabular}

Notes: Panel A: \% of farms mortgaged is scaled to be in standard deviation units; the coefficient of 0.37 in column (1) means, for instance, that a 1 standard deviation increase in the $\%$ of farms mortgaged increases the effect on auto sales of the change in farm product value per capita by 0.37 . As in equation 4 , all regressions include controls for the interaction of 1932 farm value per capita with percent of farms mortgaged, the 1932-33 change in farm product value per capita, and the percent of farms mortgaged.

Panel B: As in equation 5, all specifications control for the interaction of each farm mortgage quintile with 1932 farm product value per capita, the 1932-33 change in farm product value per capita, the 1932 farm product value per capita, and a dummy variables for each quintile.

All regressions in panels A and B exclude counties with fewer than 5001929 car registrations and counties with fewer than $50 \%$ of farms reporting their mortgage status. Control variables and drought indicators are the same as those in column (5) of table 3. Standard errors clustered at the state level in parentheses. * $p<.10,{ }^{* *} p<.05,{ }^{* * *} p<.01$. Sources: see table 3 .

state fixed effects will absorb this correlation. Thus, with state fixed effects (columns (2) and (4)), there is a nearly monotonic increase in the farm channel's effect as one moves to higher quintiles of farm debt. The linear interaction estimates consequently become 
larger and more significant. Overall, the results in table 5 imply an important role for farm indebtedness in the propagation of the farm channel.

4.2 The Banking System A second mechanism through which the farm channel could have been expansionary in the aggregate is through the banking sector. Banking problems were particularly severe in rural areas during the Depression (United States Department of Agriculture, 1935, p. 26). Higher farm product prices likely reduced default probabilities, thus improving the prospects of rural banks. As Business Week put it in their first issue after the United States left the gold standard (4/26/33, cover page), "70-cent wheat makes a lot of sick banks well again." ${ }^{37}$ Extensive bank correspondent networks transmitted banking panics during the Depression (Richardson, 2007), and these same networks meant that improving conditions for rural banks may have helped the financial system overall.

Data limitations restrict us to one indicator of bank health: deposits. Monthly data on deposits by Federal Reserve district and annual data by county allow us to measure deposit growth in farm relative to nonfarm areas in spring 1933. To the extent that confidence in farm area banks improved, we would expect individuals to be more willing to deposit funds. Conversely, deposit growth itself likely improved bank health in farm areas by lowering the cost of funds. Thus evidence of relatively more deposit growth in farm areas is likely evidence of a relative improvement in bank health in farm relative to nonfarm areas.

Figure 12 shows the path of average net demand deposits in Federal Reserve member banks in the Kansas City, Minneapolis, Dallas, St. Louis, and Atlanta districts relative to the path of deposits in all other districts. ${ }^{38}$ Kansas City, Minneapolis, Dallas, St. Louis, and Atlanta were the five districts with the largest increase in farm product value per capita in 1933. These five districts are also among the top 6 districts ranked by crops sold per capita and farm share of the population. We focus on net demand deposits since they are a better indicator than time deposits of month-to-month fluctuations in rural financial

\footnotetext{
${ }^{37}$ Wheat prices averaged 52 cents per bushel in March 1933, 63 cents per bushel in April, and 73 cents per bushel in May (NBER macrohistory series m04001a).

${ }^{38}$ We compute averages for each group of districts by first indexing seasonally-adjusted deposits in a district to the October 1932-February 1933 average, and then taking the arithmetic average across districts. According to Wall (1937), p. 3 net demand deposits "included total demand deposits of individuals, corporations, etc., plus the excess, if any, of demand deposits due other banks over items in process of collection and funds held on deposit with other banks."
} 
Figure 12 - Net demand deposits, 1930-33

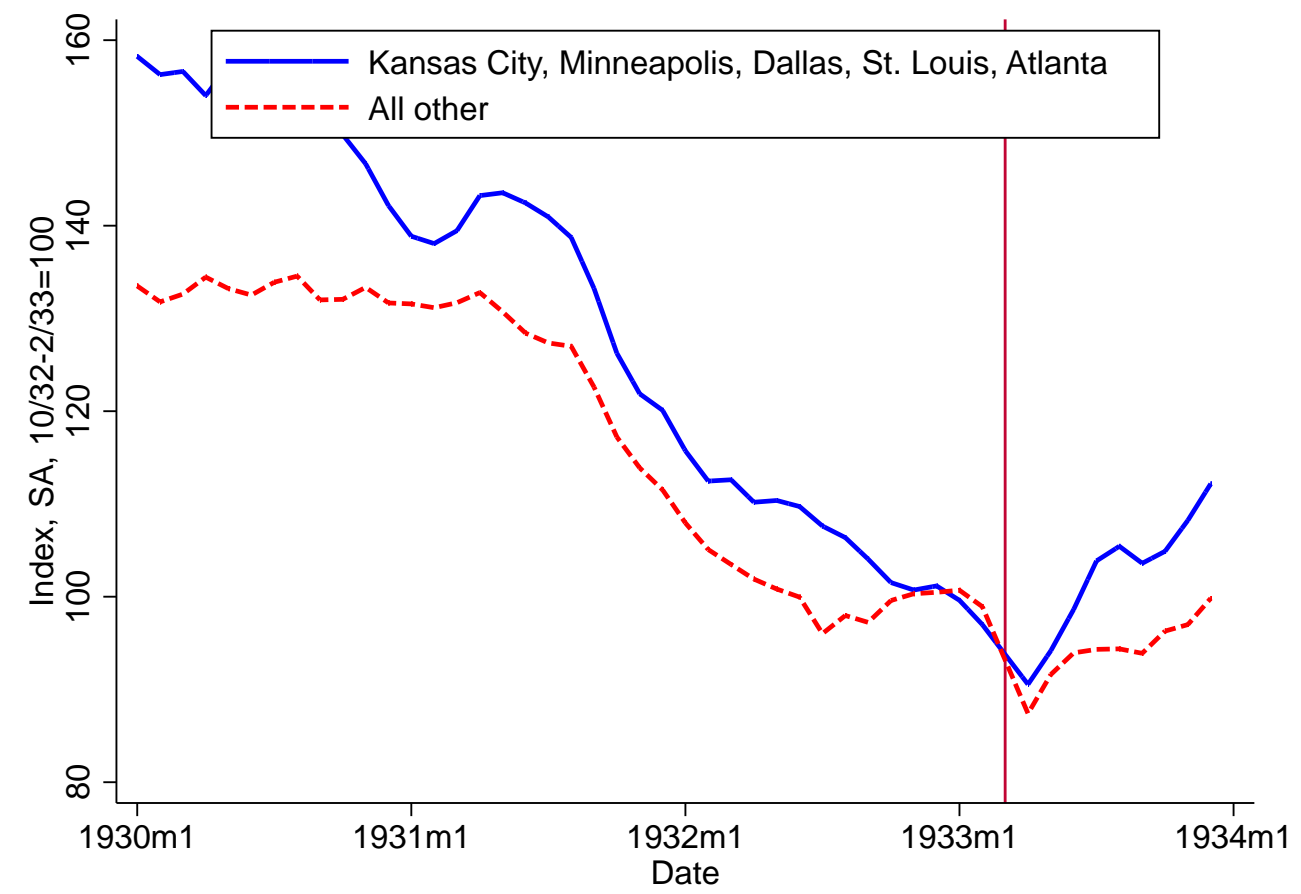

Notes: The vertical line indicates March 1933. Deposit data for March 1933 are missing. For details on the seasonal adjustment, see appendix E. Sources: See appendix E.

conditions (Wall, 1937, p. 2). Figure 12 shows more rapid deposit growth in those areas of the country benefiting most from higher farm prices. From February 1932 to July 1933, the farm district deposit average grew 7.1 percent; that in the remaining districts fell 4.7 percent. Nevertheless, the inference from figure 12 is limited because reserve districts do not neatly split into farm and nonfarm regions, and because pre-trends are not exactly parallel.

Data on bank deposits at the county level allow for a more precise geographic breakdown, but these are only available as of 31 December of each year. So moving to the county level comes at the cost of conflating banking developments during the early 1933 banking crisis with those thereafter. With this caveat, figure 13 shows the binned scatter plot from a regression of 1932-1933 deposit growth on the 1932-33 change in farm product value, controlling for 1932 farm product value. This plot and our regressions below exclude counties with fewer than three banks. ${ }^{39}$ There is a clear positive relationship, with counties experiencing larger increases in farm value also having higher deposit growth.

Unlike the case of new car sales (figure 10), the relationship between change in farm

\footnotetext{
${ }^{39}$ We exclude counties with two or fewer banks, since in these counties the failure of just one bank leads to extreme values of deposit growth.
} 
Figure 13 - Percent change in deposits and farm channel exposure at the county level

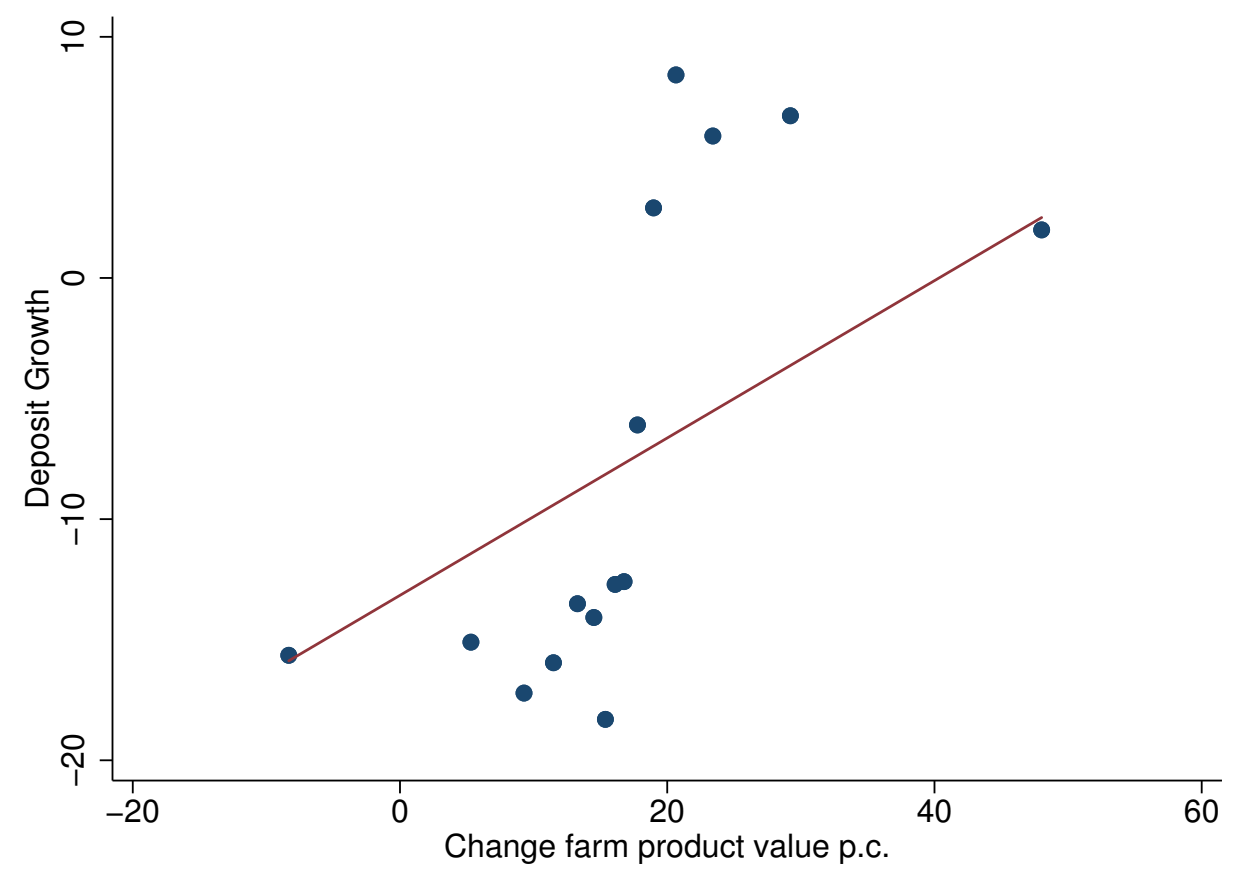

Note: Binned scatter plot of 1932-33 county-level deposit growth against change in farm product value per capita, conditional on 1932 farm product value per capita. The straight line is the OLS regression line. Each point in the figure shows the mean percent change in deposits in each bin of change in farm product value per capita after controlling for 1932 farm product value per capita. Excludes counties with fewer than three banks in 1929. There are 15 bins. See Stepner (2014) for further details.

product value and deposit growth is distinctly non-linear. Therefore, we do not impose a linear structure in our regressions. We instead group counties into quartiles based on their change in farm product value and initial farm product value,

$$
\begin{aligned}
\% \Delta \text { Deposits }_{i, 1932-33}=\beta_{0} & +\sum_{j=1}^{4} \gamma_{j} \text { Quartile } j: \Delta \text { farm product value } 1932-33_{i} \\
& +\sum_{j=1}^{4} \delta_{2} \text { Quartile } j \text { : farm product value } 1932_{i}+\zeta^{\prime} X_{i}+\varepsilon_{i}
\end{aligned}
$$

Table 6 shows results. Column (1) shows that deposit growth increases monotonically along the change in farm product value quartiles. The magnitudes are economically large. In the fourth quartile, deposit growth is 31 percentage points larger than in the first quartile. The estimates become statistically and economically weaker as we add control variables (columns (2) and (3)) and state fixed effects (columns (4) through (6)). Nevertheless, the estimates remain monotonically increasing in the quartiles and are in all cases statistically significant 
Table 6 - Deposit Growth 1932-1933

\begin{tabular}{lcccccc}
\hline \hline & $(1)$ & $(2)$ & $(3)$ & $(4)$ & $(5)$ & $(6)$ \\
\hline Change farm product value p.c. Quartile 2 & $13.0^{* * *}$ & -0.14 & 0.56 & $5.26^{*}$ & 2.52 & 2.77 \\
& $(3.51)$ & $(3.15)$ & $(2.83)$ & $(2.73)$ & $(3.62)$ & $(3.59)$ \\
Change farm product value p.c. Quartile 3 & $19.9^{* * *}$ & 2.33 & 1.40 & $9.93^{* *}$ & 4.27 & 3.70 \\
& $(5.04)$ & $(4.27)$ & $(4.02)$ & $(3.70)$ & $(3.77)$ & $(3.87)$ \\
Change farm product value p.c. Quartile 4 & $31.1^{* * *}$ & $16.8^{* * *}$ & $8.98^{*}$ & $17.7^{* * *}$ & $14.7^{* * *}$ & $9.86^{* *}$ \\
& $(7.95)$ & $(5.30)$ & $(4.63)$ & $(4.09)$ & $(3.96)$ & $(4.39)$ \\
AAA Transfers p.c. 1933 $(\$)$ & & & $1.44^{* * *}$ & & & $1.08^{*}$ \\
& & & $(0.48)$ & & & $(0.55)$ \\
\hline Control Variables & No & Yes & Yes & No & Yes & Yes \\
State Fixed Effects & No & No & No & Yes & Yes & Yes \\
Drought interactions & No & Yes & Yes & No & Yes & Yes \\
Lagged Dependent Variables & No & Yes & Yes & No & Yes & Yes \\
$R^{2}$ & 0.08 & 0.25 & 0.30 & 0.25 & 0.34 & 0.36 \\
Observations & 2,374 & 2,366 & 2,366 & 2,374 & 2,366 & 2,366 \\
\hline \hline
\end{tabular}

Notes: Regressions include controls for quartiles of 1932 farm product value level. Regressions exclude counties with fewer than 3 banks in 1929. Lagged Dependent Variables includes controls for county-level deposit growth from 1931-1932, from 1930-1931, and from 1929-1930. Standard errors clustered at the state level in parenthesis. ${ }^{*} p<0.1,{ }^{* *} p<0.05,{ }^{* * *} p<0.01$

for at least the fourth quartile. For example, our most stringent specification, column 6, suggests that the farm channel contributed 9.9 percentage points to relative deposit growth in the most exposed counties. For comparison, in 1933 nationwide deposit growth was -9.5 percent.

Similar results obtain when we change the number of quantiles or when we use quantiles for our control variables. Overall, these results indicate that deposit funding for banks in areas exposed to the farm channel improved relative to deposit funding for other banks. The increase in deposits may also be indicative of an increase in lending, as loan proceeds were deposited, and as agents deposited funds in advance of loan repayments. ${ }^{40}$ But our crosssectional results do not prove that the farm channel helped the banking system nationwide; perhaps the improvement at banks in farm areas came entirely at the expense of banks in nonfarm areas. But these results at least make it plausible that a bank health channel existed: if deposit growth was more valuable where banking crises had been most severe, then the relative growth of deposits in farm areas was likely positive for the financial system as a whole.

\footnotetext{
${ }^{40}$ We are indebted to Gary Richardson for making this point to us.
} 
Figure 14 - Expected price increases

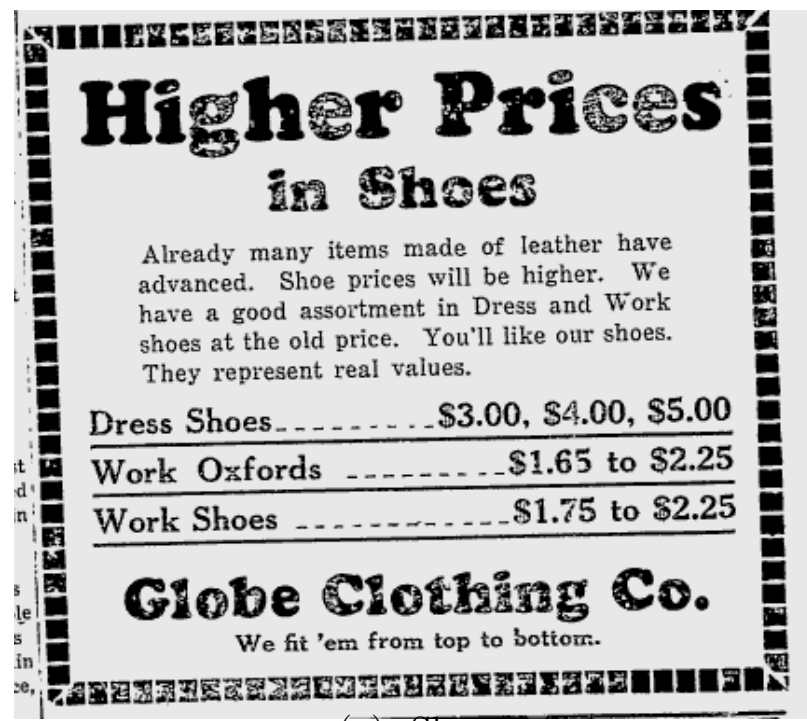

(a) Shoes

\section{Tire Prices Going Higher Buy Now! Save Money! Equip with 7 Tre 10}

TIRE prices have joined the upwand trend. We believe they will advanice again-in fact, increasing prices of rubber and cotton are sure to bring higher tire prices. Get your tire requirements NOW whilewe are selling Firestone Extra Quality Tires at these low prices. BUY TODAY! SAVE MONEY!

$$
\text { (b) Tires }
$$

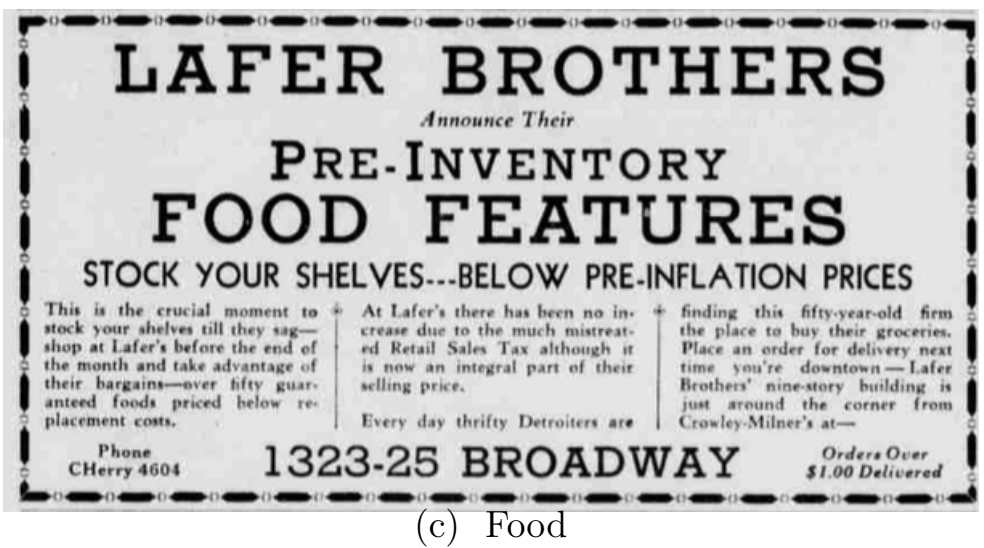

Source: The Warsaw Union, 5/3/33, p. 2; Los Angeles Times, 5/11/33, p. 5; Detroit Free Press, 7/14/33, p. 14. 
4.3 Inflation expectations Narrative evidence suggests that higher farm product price could themselves have been expansionary by creating expectations of higher future prices. For instance, figure $14 \mathrm{a}$ shows an ad that appeared in the Warsaw, Indiana newspaper on

3 May 1933. It tells consumers that "Already many items made of leather have advanced," but that this store still has "shoes at the old price." Similarly, figure 14b shows an ad for Firestone tires that appeared in the Los Angeles Times on 11 May 1933. It announces "Tire Prices Going Higher" so consumers should "Buy Now!" It explains that "increasing prices of rubber and cotton are sure to bring higher tire prices." And figure 14c from the Detroit Free Press on 14 July 1933 tells consumers to buy "foods priced below replacement costs."

While a definitive conclusion awaits more systematic work, these advertisements suggest that higher commodity prices may have caused expected inflation, as retailers facing higher costs delayed raising final goods prices. Since at least Hamilton (1992), economists have known that commodity prices provide information on expected inflation. This narrative evidence points to a stronger hypothesis: in spring 1933 higher commodity prices not only provide evidence of expected inflation, but perhaps were themselves a source of expected inflation. This implies an interpretation of expected inflation in 1933 somewhat different from that in the prior literature (e.g., Jalil and Rua, 2016; Eggertsson, 2008). Whereas the prior literature emphasizes that Roosevelt's words and actions were crucial since they signaled a commitment to higher inflation, this narrative evidence suggests a more mechanical possibility: as the dollar weakened, commodity prices rose. These higher prices were only gradually passed through to final goods prices, leading consumers to expect higher inflation.

\section{Aggregate implications}

The previous section considers several mechanisms through which the farm channel may have been expansionary for the economy as a whole. It gives us no guidance, however, on the quantitative importance of these mechanisms. This requires assumptions about the structure of the economy. In this section, we discuss what assumptions we believe to be reasonable and how these help us to construct a mapping between our cross-sectional estimates and the farm channel's aggregate effect. The formal model guiding our discussion is presented in 
appendix F. It bears emphasis that our conclusions about the aggregate effects of the farm channel are much more speculative than the cross-sectional results of the prior sections.

In considering how to map our cross-sectional estimates to an estimate of the farm channel's aggregate effect, we start with a simple - but wrong- extrapolation. We then show how this extrapolation can be adjusted to be made more accurate. Consider our estimate of $\beta$ from table 2, columns (1) and (2), where we regress new car sales growth on the state-level farm population share. Then a simple extrapolation to the aggregate economy would be to multiply $\beta$ by the national farm population share $\phi^{f}$,

$$
\% \Delta Y=\beta \times \phi^{f}
$$

The implicit counterfactual is predicted auto sales when the farm share of the population is zero, $\% \Delta Y=\beta \times\left(\phi^{f}-0\right)$. This extrapolation is almost surely wrong. We first discuss two mechanical adjustments and then turn to two more substantive considerations.

5.1 Mechanical adjustments As a first, mechanical, adjustment, we need to account for the fact that in our cross-sectional regressions we estimate the effect of farm income on new car sales growth, not local consumption growth. These quantities may differ if car sales responded to income changes differently than other components of consumption. We therefore compare extrapolated aggregate car sales growth from our regression to actual aggregate car sales growth rather than to aggregate consumption growth,

$$
\% \Delta \operatorname{Cars}=\beta \times \phi^{f}
$$

While the marginal propensity to consume on cars may have been higher than that on other goods, there is no obvious bias in the ratio $\frac{\text { extrapolated car sales growth }}{\text { actual car sales growth }}$. Both the numerator and denominator are likely higher than they would be if we were measuring total consumption or output. And car production and car sales exhibited similar, though amplified, movements relative to industrial production as a whole. Over our sample period from 1932:Q4-1933:Q1 to 1933:Q3, seasonally adjusted car sales rose 86.5 percent, car production 84.1 percent, and industrial production 41 percent. ${ }^{41}$ Thus, we take estimates of the fraction of car sales

\footnotetext{
${ }^{41}$ See appendix A for details on the car data sources and seasonal adjustment.
} 
growth explained by the farm channel to be rough estimates of the fraction of overall output growth explained by the farm channel.

We also need to account for the fact that a larger farm share in the cross-section is not the same as a larger farm share in the aggregate. In our model, the importance of the farm channel for an area is a function of the farm income share, the ratio of local farm income to total local income. The higher the farm income share, the greater the fraction of local income "treated" by higher farm prices and the greater the expected consumption growth. The farm population measure (and all our other available measures) only captures this exposure imperfectly. Farm income and population share are linked through the identity Farm income share $\equiv \frac{\text { Farm income per farmer }}{\text { Income per capita }} \times$ Farm population share. Holding relative incomes, $\frac{\text { Farm income per farmer }}{\text { Income per capita }}$, fixed locally and nationally, if the farm population share rises one percentage point in a local area, the local farm income share rises by $\frac{\text { Farm area farm income per farmer }}{\text { Farm area income per capita }} \times 1 \%$. If the farm population share rises by one percentage point nationally, the national farm income share increases by $\frac{\text { National farm income per farmer }}{\text { National income per capita }} \times 1 \%$. In 1933, the relative income of farmers was higher in farm areas than it was nationwide $\frac{\text { Farm area farm income per farmer }}{\text { Farm area income per capita }}>\frac{\text { National farm income per farmer }}{\text { National income per capita }} ;{ }^{42}$ therefore, our cross-sectional estimates reflect that a one percentage point change in the local farm population share implies a larger change to local farm income shares than to the national farm income share.

We can bound this bias because income per farmer was no higher in (poorer) farm areas than it was nationally, Farm area farm income per farmer $\leq 1$. In other words, while farmers were richer relative to the general population in farm areas (e.g. the south) than they were nationally, average farm income per farmer was not in absolute dollar terms higher in farm areas than it was nationally. ${ }^{43}$ So we can bound the relative difference in national treatment intensity with $\frac{\frac{\text { National farm income per farmer }}{\text { National income per capita }}}{\frac{\text { Farm area farm income per farmer }}{\text { Farm area income per capita }}} \leq \frac{\text { Farm area income per capita }}{\text { National income per capita }}$. Thus, we pare back our crosssectional coefficient by the ratio of farm area income per capita to income in the country as

\footnotetext{
${ }^{42}$ This statement is based on 1930 census population data as reported in Haines and ICPSR (2010) and 1932 income data as reported in BEA table SA4.

${ }^{43}$ For example, $\frac{\text { Alabama farm income per farmer }}{\text { Alabama income per capita }}$ was 0.28 , while nationwide it was 0.19 ; but absolute farm income per farmer was $\$ 44$ in Alabama, and $\$ 80$ dollar nationwide. (These figures are calculated with 1930 Census population data from Haines and ICPSR (2010) and 1932 income data from BEA table SA4.)
} 
a whole:

$$
\% \Delta \text { Cars }=\beta \times \phi^{f} \times \frac{\text { Farm area income per capita }}{\text { National income per capita }} .
$$

This adjustment reduces our estimate of the farm channel's aggregate effect, since farm areas of the United States, in particular the South, tended to be poorer than the country as a whole.

5.2 Redistribution and Pass-Through A more substantive issue is that farmers' gains came at the expense of nonfarmers. In section 4, we argued that farmers' large debt burdens indicate a high MPC. Thus, redistribution to farmers would have been expansionary if farmers received income from low MPC consumers or firms. The strength of this effect was determined by the relative MPCs of farmers and nonfarmers. If higher farm prices transferred income from consumers with a low MPC, then aggregate output would have increased substantially. This could have occurred, for instance, if the cost of higher farm prices was largely borne by businesses with low debt burdens and low MPCs. (In the following discussion and in the model of appendix F, we assume that firms (capitalists) are permanent income consumers with a MPC of 0.) By contrast, if the cost of higher farm prices primarily fell on nonfarm workers with a high MPC, then redistribution would not have raised the aggregate MPC and aggregate output.

A high, positive $\beta$ is a necessary, though not a sufficient, condition for a large aggregate effect of the farm channel. It is necessary, because if $\beta$ is small then the income transfer to farmers was small and / or farmers' MPC out of the transfer was small. In either case, the aggregate effect would have been small. A high $\beta$ is not sufficient for large aggregate effects, since $\beta$ can be large because farmers had a high MPC or because losses from higher farm prices were borne by high-MPC consumers in the nonfarm area. Both cases would result in substantial cross-sectional consumption differences, but only in the first case would the aggregate output effect be large.

We suspect that the most important channel through which losses accrued to high-MPC consumers in the nonfarm area was via pass-through from higher farm prices to urban food prices. We embed this effect in our model in appendix F, which suggests that we apply the 
following, approximate, correction factor to equation (7):

$$
1-\xi \frac{\theta^{w}}{\theta^{f}} .
$$

$\theta^{f}$ is the fraction of borrowing-constrained (high-MPC) farmers, $\theta^{w}$ is the fraction of borrowingconstrained (high-MPC) consumers (workers), and $\xi$ is the share of losses from higher farm product prices borne by workers. Thus, our estimate of the aggregate effect shrinks when more losses are borne by workers ( $\xi$ is high), and when they have a relatively high MPC compared to farmers $\left(\frac{\theta^{w}}{\theta^{f}}\right.$ is high). $\xi$ depends on how higher farm product prices affected real wages, i.e., (1) how higher farm prices changed workers' nominal wages, and (2) how higher farm prices affected final goods prices. We suspect that (1) is positive; insofar as higher farm prices were expansionary, they likely put upward pressure on nominal wages. Indeed, over our sample period from the 1932:Q4-1933:Q1 average to 1933:Q3, nominal wages in the manufacturing sector increased by 7.2 percent. ${ }^{44}$ Unfortunately, quantifying the contribution of higher farm prices to this increase is difficult, since we do not observe the counterfactual behavior of wages.

Precise conclusions about the degree of pass-through are also difficult. But the available data paint a picture of incomplete retail price adjustment. From the 1932:Q4-1933:Q1 average to 1933:Q3, the CPI rose a modest 1.5 percent. It was completely flat between March and May 1933. The BLS index of the price of food in urban areas first declined 1.1 percent from 1932:Q4-1933:Q1 to 1933:Q2 and then rose 14.6 percent in 1933:Q3. ${ }^{45}$

These aggregates mask substantial heterogeneity. Some items have sticky prices and limited pass-through in the initial months after devaluation. For instance, between March and July 1933, the price of cornflakes was unchanged at 8.1 cents per 8-oz package despite a doubling of the cost of the corn input from 0.25 cents to 0.68 cents. ${ }^{46}$ This sort of incomplete pass-through is also visible in the advertisements we discussed in section 4, warning consumers of coming price increases. In other cases, there were rapid increases in food prices.

\footnotetext{
${ }^{44}$ FRED series M08142USM055NNBR.

${ }^{45}$ The CPI is FRED series CPIAUCNS. The urban food price index is FRED series M04071USM350NNBR. This is an index of the retail price of food at home for wage earners and clerical workers.

${ }^{46}$ Retail price data (for urban areas) are from United States Department of Labor (1938), table 7, p. 79; data on the cost of the corn input to an 8-oz box of cornflakes are from United States Department of Agriculture (1945), table 40, p. 188.
} 
For instance, the price of flour rose 54 percent from 1932:Q4-1933:Q1 to 1933:Q3 (United States Department of Labor, 1938, table 7, pp. 78-79). It is difficult to know to what extent higher retail food prices were caused by pass-through of higher farm product prices versus by other factors. Some food (like flour) was itself traded meaning that devaluation may have put direct upward pressure on prices independent of pass-through from farm products. And the National Industrial Recovery Act (signed into law on 16 June 1933), a new processing tax, rising wages, and increased product demand likely also contributed to higher prices. We can be fairly confident that higher farm product costs were not the only driver of higher food prices, since some food prices rose by much more than the change in the farm input cost. From 1932:Q4-1933:Q1 to 1933:Q3, for instance, the retail price of chicken rose one cent per pound, while the farm-gate price rose 0.3 cents. $^{47}$

Food production was not the only sector affected by higher farm prices. Most obviously, cotton was used in textile production and tobacco in cigarette production. Even heavy industry used farm products. For instance, a small car contained roughly 90 pounds of cotton (Ward's Reports Inc., 1938). Unfortunately, we lack the monthly data needed to examine pass-through for these non-food goods. We suspect that given higher levels of processing, pass-through was if anything lower than in the food sector. We know that the prices of popular clothing items and tobacco fell or were flat between December 1932 and June $1933{ }^{48}$ And car prices were essentially unchanged between February 1933 and January $1934 . .^{49}$

Taken together, we believe the evidence suggests that pass-through was incomplete. And

\footnotetext{
${ }^{47}$ These figures are from United States Department of Agriculture (1945), table 28, p. 128. This is the change in the farm price of 1.136 pounds of chicken, since United States Department of Agriculture (1945), pp. 117-118 finds that 1.136 pounds of chicken from the farm was needed to produce 1 pound of chicken for retail sale.

${ }^{48}$ United States Department of Labor (1936a) (table 7, p. 1052) provides data on the prices of men's shirts, pajamas, and overalls, and women's housedresses and nightgowns. All these prices fell between December 1932 and June 1933, except for the price of men's pajamas, which rose from $\$ 1.63$ to $\$ 1.65$. United States Department of Labor (1936b) (table 13, p. 241) provides data on the retail price of cigarettes, cigars, cigarette tobacco, pipe tobacco, and plug tobacco. These prices all declined between December 1932 and June 1933. Unfortunately, these retail price data for textiles and tobacco are only available at 6-month intervals (June and December). So we do not know what happened to these prices in the third quarter of 1933.

${ }^{49}$ This refers to the BLS index of wholesale car prices, NBER macrohistory series m04180b. The constancy of car prices over this period likely reflects the industry pattern of changing car prices only when new models were introduced, which occurred in January (Cooper and Haltiwanger, 1993; Hausman, 2016b).
} 
higher nominal wages mean that the degree of pass-through may itself be an overestimate of the losses borne by high-MPC urban workers. Since the precise incidence of redistribution is difficult to discern from the available data, in our quantification below we consider a wide range of possible values.

5.3 General Equilibrium The cross-sectional coefficient $\beta$ does not capture aggregate general equilibrium effects. These are differenced out in the cross-section because they affected farm and nonfarm areas equally. We believe that general equilibrium effects operating in spring 1933 likely amplified the impact of the farm channel. This view aligns with Nakamura and Steinsson (2014) and Chodorow-Reich (2017) who argue that offsetting general equilibrium forces are limited at the zero lower bound.

Our cross-sectional regressions do not measure the possible effects of monetary policy and expected inflation. The aggregate effect could be small and the cross-sectional effect large if the Federal Reserve had raised nominal interest rates in response to devaluation and rapid output growth. But short-term interest rates were at the zero lower bound in spring 1933, and long-term rates were flat or slightly falling. That interest rates did not rise meant that any increase in expected inflation due to higher farm prices would have lowered expected real interest rates. And intertemporal substitution would have then led to higher aggregate consumption and output. This is a positive general equilibrium effect that our cross-sectional results miss. In section 4, we provided qualitative evidence for this effect.

Our cross-sectional estimates also do not capture the fact that spending by a farmer on goods produced outside her state / county benefited the entire U.S. economy. When a farmer bought a car, this increased income and consumption in manufacturing areas (e.g. Michigan), reducing the cross-sectional consumption differences across U.S. states and counties. This difference between the cross-sectional and aggregate effect is captured in the aggregate spending multiplier.

A final aggregate effect not measured by the cross-sectional regressions is that of bank health. As discussed in the previous section, by redistributing deposits towards troubled banks, the farm channel could have been expansionary for the economy as a whole. But our cross-sectional estimates only pick up the improvement in farm areas relative to that in 
nonfarm areas.

5.4 Quantifying the aggregate effect Putting together the factors discussed in this section, our model implies an expanded version of equation (7),

$$
\begin{aligned}
\% \Delta \text { Cars }= & \underbrace{\beta \times \phi^{f}}_{\begin{array}{c}
\text { "naive" } \\
\text { extrapolation }
\end{array}} \times \underbrace{\frac{\text { Farm area income per capita }}{\text { National income per capita }}}_{\text {Relative income p.c. }} \times \underbrace{\left(1-\xi \frac{\theta^{w}}{\theta^{f}}\right)}_{\begin{array}{c}
\text { Redistribution from } \\
\text { high-MPC consumers }
\end{array}} \times \underbrace{\mu_{t}}_{\begin{array}{c}
\text { Aggregate } \\
\text { spending } \\
\text { multiplier }
\end{array}} \\
& +\underbrace{-\sigma d \ln \left(1+r_{t}\right)}_{\text {Intertemporal Substitution }} .
\end{aligned}
$$

The first line combines all elements of the redistribution effect. The second line does the same for the intertemporal substitution effect, in other words the positive effect on output of higher inflation expectations and resulting lower real interest rates. $d \ln \left(1+r_{t}\right)$ is the change in the real interest rate due to the farm channel, and $\sigma$ is the intertemporal elasticity of substitution. Our model omits any effect of the farm channel on bank health, so any such effect is absent from equation 8 .

We quantify the overall effect as follows. The nationwide farm population share in 1930 was $\phi^{f}=24.8 \%$ (U.S. Bureau of the Census, 1933, table 2, p. 8). We set the ratio of per-capita income in farm areas relative to nationwide per capita income to be $\frac{Y_{p . c ., a}}{Y_{p . c .}}=0.63$. Per-capita income in farm states is that in states with farm population share greater than or equal to the national average. ${ }^{50}$ Seventy-seven percent of the farm population lived in these states.

We consider a range of values from the literature for the aggregate multiplier. Gordon and Krenn (2014) (p. 24) estimate an aggregate multiplier of 3.1-3.3 in 1940-41, before supply constraints were binding. Using international data, Almunia, Benetrix, Eichengreen, O'Rourke, and Rua (2010) estimate a multiplier in the 1930s of 2.5. And Hausman (2016a) estimates an MPC ranging from 0.6 to 0.75 among veterans in 1936, consistent with a multiplier $\left(\mu=\frac{1}{1-M P C}\right)$ of 2.5 or larger. In contrast, Ramey and Zubairy (2018) generally estimate multipliers below one, though at the zero lower bound and without rationing, they find a multiplier of roughly 1.5. We therefore consider multipliers ranging from 1 to 3 .

\footnotetext{
${ }^{50}$ Income data are from BEA regional data, table SA4, and population data are from Haines and ICPSR (2010).
} 
Table 7 - Implied aggregate effect

\begin{tabular}{|c|c|c|c|c|c|c|}
\hline \multirow{3}{*}{$\begin{array}{l}\text { Redistribution from high } \\
\text { MPC consumers, } \xi \frac{\theta^{w}}{\theta^{f}}\end{array}$} & \multicolumn{3}{|c|}{ Predicted $\% \Delta$ Cars } & \multicolumn{3}{|c|}{ Fraction of actual $\% \Delta$ Cars } \\
\hline & \multicolumn{3}{|c|}{ Aggregate Multiplier } & \multicolumn{3}{|c|}{ Aggregate Multiplier } \\
\hline & $\mu=1$ & $\mu=2$ & $\mu=3$ & $\mu=1$ & $\mu=2$ & $\mu=3$ \\
\hline 0.7 & 8.0 & 15.9 & 23.9 & 9.2 & 18.4 & 27.6 \\
\hline 0.6 & 10.6 & 21.2 & 31.9 & 12.3 & 24.6 & 36.8 \\
\hline 0.5 & 13.3 & 26.6 & 39.8 & 15.4 & 30.7 & 46.1 \\
\hline 0.4 & 15.9 & 31.9 & 47.8 & 18.4 & 36.8 & 55.3 \\
\hline 0.3 & 18.6 & 37.2 & 55.8 & 21.5 & 43.0 & 64.5 \\
\hline
\end{tabular}

Notes: Columns 2-4 display the implied new car sales growth rate from equation (8) given the indicated parameter values, and $\beta=1.7, \phi^{f}=0.248, \frac{Y_{p . c ., a}}{Y_{p . c .}}=0.63$. Columns 5-7 show the fraction of actual new car sales growth $(86.5 \%)$ explained.

The amount of redistribution from high-MPC consumers $\left(\xi \frac{\theta^{w}}{\theta^{f}}\right)$ to farmers is likely the most uncertain element in the first line of equation 8. There was certainly some pass-through from farm prices to urban food prices, so $\xi>0$. And some workers did have high MPCs, $\theta^{w}>0$. On the other hand, we noted cases in which pass-through appears to have been close to zero, and we argued that farmers likely had more severe debt problems and associated higher MPCs than nonfarmers, implying $\frac{\theta^{w}}{\theta^{f}}<1$. These considerations suggest a range of the correction factor of 0.3 to $0.7 .^{51}$

Unfortunately, the size of the intertemporal substitution channel and the bank health channel are too uncertain to quantify given the available information. Since these channels added to the farm channel's aggregate effect, ignoring them makes our estimates a lower bound.

Columns 2 through 4 of table 7 show predicted growth rates for aggregate car sales from equation (8) for given combinations of the multiplier and redistribution from highMPC consumers. These range from 8 percent for the smallest value of the multiplier and the largest redistribution correction factor to 56 percent for the highest multiplier and the lowest redistribution correction factor. Columns 5 through 7 express this predicted growth rate as a fraction of actual aggregate new car sales growth, which was 86.5 percent between the 1932:Q4-1933:Q1 average and 1933:Q3. ${ }^{52}$

While table 7 displays a range of outcomes, it shows that the farm channel makes a

\footnotetext{
${ }^{51}$ The correction factor would be 0.3 if pass-through $(\xi)$ were 0.4 , the share of constrained workers $\left(\theta^{w}\right)$ were 0.6 , and the share of constrained farmers $\left(\theta^{f}\right)$ were 0.8 . The correction factor would be 0.7 if passthrough $(\xi)$ were 0.8 , the share of constrained workers $\left(\theta^{w}\right)$ were 0.7 , and the share of constrained farmers $\left(\theta^{f}\right)$ were 0.8 .

${ }^{52}$ See appendix A for the source and seasonal adjustment details.
} 
negligible contribution to aggregate car sales only if all of the following three conditions hold: first, losses from higher farm product prices fall primarily on consumers with MPCs nearly as high as those of farmers. Second, the aggregate multiplier is around 1 or lower at the trough of the Great Depression. Third, any inflation expectations or bank health effects, which are not included in the table's figures, are negligible. In our view, it is unlikely that all three of these conditions were met. If one excludes such combinations - the top left corner of table 7 - one obtains a range of 20-60 percent for the proportion of actual car sales growth explained by the farm channel.

\section{Conclusion}

This paper provides evidence on the sources of U.S. recovery in spring 1933. We document the importance of the farm channel: devaluation raised prices of traded crops and close substitutes, raising income and consumption in agricultural areas. We estimate the importance of the farm channel for recovery using state and county auto sales data. Our estimates imply that a one-standard-deviation increase in the share of a state's population living on farms was associated with a 25-30 percentage point increase in auto sales growth between the October 1932 - March 1933 average and the July - September 1933 average. These cross-sectional effects explain a substantial fraction of cross-state variation in auto sales growth and are concentrated in areas growing traded crops or close substitutes. The additional statistical power of the county data reveals that the spending effects from a given increase in farm product value were larger in counties with more farm debt.

Together with evidence that farmers were among the most indebted agents in the economy, this suggests that higher crop prices could have been expansionary for the U.S. economy as a whole by redistributing income to indebted, high-MPC farmers. We argue that redistribution to farmers significantly increased economy-wide spending, because pass-through of higher farm product prices to final goods prices was incomplete, and business debt burdens and MPCs were likely relatively low. Coupled with a plausible aggregate multiplier, and evidence of positive effects of higher farm prices on bank health and inflation expectations, we conclude that the farm channel explains a substantial share, in the range of 20-60 percent, 
of spring 1933 growth.

To the extent that the farm channel contributed to overall recovery in the United States, the lessons of 1933 for macroeconomic policy are more nuanced than often assumed. In particular, our work points to the importance of redistribution as a channel for macroeconomic policy. Japan's recent efforts to raise inflation expectations and end two decades of output stagnation (so-called "Abenomics") provide an illustrative example. When Japan embarked on Abenomics, the U.S. success in 1933 was invoked to predict success in Japan (Romer, 2014; Kuroda, 2013). Just like the United States in 1933, Japan in 2013-14 weakened its currency and raised inflation expectations. But whereas devaluation in 1933 redistributed income to indebted farmers with a high MPC, the weakening of the yen may have redistributed income from workers to large, exporting businesses with a low marginal propensity to spend. ${ }^{53}$ Thus an appreciation of the farm channel may help economists understand why Abenomics failed to quickly produce rapid growth.

\section{References}

Aiyagari, S. Rao, "Uninsured Idiosyncratic Risk and Aggregate Saving," Quarterly Journal of Economics, 1994, 109 (3), 659-684.

Almunia, Miguel, Agustin Benetrix, Barry Eichengreen, Kevin H. O’Rourke, and Gisela Rua, "From Great Depression to Great Credit Crisis: Similarities, Differences and Lessons," Economic Policy, 2010, 25 (62), 220-265.

Alston, Lee J., "Farm Foreclosures in the United States During the Interwar Period," Journal of Economic History, 1983, 43 (4), 885-903.

Auclert, Adrien, "Monetary Policy and the Redistribution Channel," 2017. NBER Working Paper 23451.

Bessler, David A., "Agricultural Prices, the Gold-Exchange Standard, and the Great Depression," Agricultural Finance Review, 1996, 56, 47-67.

Bewley, Truman, "Stationary Monetary Equilibrium with a Continuum of Independently Fluctuating Consumers," Contributions to Mathematical Economics in Honor of Gérard Debreu, 1986, 79 .

Bordo, Michael David, "The Effects of Monetary Change on Relative Commodity Prices and the Role of Long-Term Contracts," Journal of Political Economy, 1980, 88 (6), 1088-1109.

\footnotetext{
${ }^{53}$ Hausman and Wieland $(2014,2015)$ document a decline in real wages in Japan under Abenomics. Kato and Kawamoto (2016) argue that the weakening of the yen contributed to record high corporate profits, but that these higher corporate profits translated into little business investment.
} 
Broer, Tobias, Niels-Jakob H. Hansen, Per Krusell, and Erik Öberg, "The New Keynesian Transmission Mechanism: A Heterogenous-Agent Perspective," 2016. NBER Working Paper 22418.

Chodorow-Reich, Gabriel, "Geographic Cross-Sectional Fiscal Spending Multipliers: What Have We Learned?," 2017. NBER Working Paper 23577.

Clark, Evans, The Internal Debts of the United States, Macmillan Company, 1933.

Cloyne, James, Clodomiro Ferreira, and Paolo Surico, "Monetary Policy when Households have Debt: New Evidence on the Transmission Mechanism," 2016. Bank of England Staff Working Paper No. 589.

Conley, Timothy G., "GMM Estimation with Cross Sectional Dependence," Journal of Econometrics, 1999, 92 (1), 1-45.

Cooper, Russell W. and John C. Haltiwanger, "Automobiles and the National Industrial Recovery Act: Evidence on Industry Complementarities," Quarterly Journal of Economics, 1993, 108 (4), 1043-1071.

Davis, Joseph Stancliffe, Wheat and the AAA, The Brookings Institution, 1935.

Diaz Alejandro, Carlos F., Exchange-Rate Devaluation in a Semi-Industrialized Country, M.I.T. Press, 1965.

Edwards, Sebastian, "Academics as Economic Advisers: Gold, the 'Brains Trust,' and FDR," 2015. NBER Working Paper 21380.

_, "The London Monetary and Economic Conference of 1933 and the End of the Great Depression," Open Economies Review, 2017, 28 (3), 431-459.

_, American Default: The Untold Story of FDR, the Supreme Court, and the Battle over Gold, Princeton University Press, 2018.

Eggertsson, Gauti B., "Great Expectations and the End of the Depression," American Economic Review, 2008, 98 (4), 1476-1516.

Federal Deposit Insurance Corporation, "Federal Deposit Insurance Corporation Data on Banks in the United States, 1920-1936," ICPSR Study 7 2001. Ann Arbor, MI: Interuniversity Consortium for Political and Social Research [Editor, Producer, and Distributer].

Federal Reserve, "Review of the Month," Federal Reserve Bulletin, October 1935, 21 (10), 641-645.

_ , "New Federal Reserve Index of Industrial Production," Federal Reserve Bulletin, August 1940 .

_, Federal Reserve Bulletin, June 1941.

Federal Reserve Board, Fourteenth Annual Report of the Federal Reserve Board Covering Operations for the Year 1927, Government Printing Office, 1928.

_, Fifteenth Annual Report of the Federal Reserve Board Covering Operations for the Year 1928, Government Printing Office, 1929.

_, Sixteenth Annual Report of the Federal Reserve Board Covering Operations for the Year 1929, Government Printing Office, 1930.

- , Seventeenth Annual Report of the Federal Reserve Board Covering Operations for the 
Year 1930, Government Printing Office, 1931.

_, Eighteenth Annual Report of the Federal Reserve Board Covering Operations for the Year 1931, Government Printing Office, 1932.

_, Nineteenth Annual Report of the Federal Reserve Board Covering Operations for the Year 1932, Government Printing Office, 1933.

_, Twentieth Annual Report of the Federal Reserve Board Covering Operations for the Year 1933, Government Printing Office, 1934.

_, Twenty-First Annual Report of the Federal Reserve Board Covering Operations for the Year 1934, Government Printing Office, 1935.

_, Twenty-Second Annual Report of the Federal Reserve Board Covering Operations for the Year 1935, Government Printing Office, 1936.

Fishback, Price V. and Valentina Kachanovskaya, "The Multiplier for Federal Spending in the States During the Great Depression," Journal of Economic History, 2015, 75 (1), $125-162$.

-, Werner Troesken, Trevor Kollmann, Michael Haines, Paul W. Rhode, and Melissa Thomasson, "Information and the Impact of Climate and Weather on Mortality Rates during the Great Depression," in Gary D. Libecap and Richard H. Steckel, eds., The Economics of Climate Change: Adaptations Past and Present, University of Chicago Press, 2011, pp. 131-167.

_ , William C. Horrace, and Shawn Kantor, "Did New Deal Grant Programs Stimulate Local Economies? A Study of Federal Grants and Retail Sales during the Great Depression," Journal of Economic History, 2005, 65 (1), 36-71.

Fisher, Irving, Booms and Depressions, Adelphi, 1932.

_, "The Debt-Deflation Theory of Great Depressions," Econometrica, 1933, 1 (4), 337-357.

Friedman, Milton and Anna Jacobson Schwartz, A Monetary History of the United States, 1867-1960, Princeton University Press, 1963.

Goldsmith, Raymond W., Robert E. Lipsey, and Morris Mendelson, Studies in the National Balance Sheet of the United States, Vol. 2, Princeton University Press, 1963.

Gordon, Robert J. and Robert Krenn, "The End of the Great Depression 1939-41: Fiscal Multipliers, Capacity Constraints, and Policy Contributions," Unpublished Manuscript, 2014.

Haines, Michael and ICPSR, "Historical, Demographic, Economic, and Social Data: The United States, 1790-2002," ICPSR Study 02896-v3 2010. Ann Arbor, MI: Inter-university Consortium for Political and Social Research [Distributer].

_ , Price Fishback, and Paul Rhode, "United States Agricultural Data, 1840-2010," ICPSR Study 35206-v2 2015. Ann Arbor, MI: Inter-university Consortium for Political and Social Research [Distributer].

Hamilton, James D., "Monetary factors in the Great Depression," Journal of Monetary Economics, 1987, 19 (2), 145-169.

_, "Was the Deflation During the Great Depression Anticipated? Evidence from the Commodity Futures Market," American Economic Review, 1992, 82 (1), 157-178. 
Hausman, Joshua K., "Fiscal Policy and Economic Recovery: The Case of the 1936 Veterans' Bonus," American Economic Review, 2016a, 106 (4), 1100-1143.

_, "What was Bad for General Motors was Bad for America: The Auto Industry and the 1937-38 Recession," Journal of Economic History, 2016b, 76 (2), 427-477.

- and Johannes F. Wieland, "Abenomics: Preliminary Analysis and Outlook," Brookings Papers on Economic Activity, 2014, 2014 (1), 1-63.

_ and _ , "Overcoming the Lost Decades? Abenomics after Three Years," Brookings Papers on Economic Activity, 2015, 2015 (2), 385-413.

Hsiang, Solomon M., "Temperatures and Cyclones Strongly Associated with Economic Production in the Caribbean and Central America," Proceedings of the National Academy of sciences, 2010, 107 (35), 15367-15372.

ICPSR, "United States Historical Election Returns, 1824-1968," ICPSR00001-v3 1999. Ann Arbor, MI: Inter-university Consortium for Political and Social Research [Distributer].

Illinois Cooperative Crop Reporting Service, Illinois Agricultural Statistics, Illinois Department of Agriculture and U.S. Department of Agriculture, 1951. Circular 446.

Jalil, Andrew J. and Gisela Rua, "Inflation Expectations and Recovery in Spring 1933," Explorations in Economic History, 2016, 62, 26-50.

Kaplan, Greg, Benjamin Moll, and Giovanni L. Violante, "Monetary Policy According to HANK," American Economic Review, 2018, 108 (3), 697-743.

Kato, Naoya and Takuji Kawamoto, "Corporate Profits and Business Fixed Investment: Why are Firms So Cautious about Investment?," Bank of Japan Review, April 2016.

Krugman, Paul and Lance Taylor, "Contractionary Effects of Devaluation," Journal of International Economics, 1978, 8 (3), 445-456.

Kuroda, Haruhiko, "Overcoming Deflation and After," 2013. Speech at the Meeting of Councillors of Nippon Keidanren (Japan Business Federation), Tokyo, December 25.

_ , "At the Turning Point," 2015. Speech at the Meeting of Councillors of Nippon Keidanren (Japan Business Federation), Tokyo, December 24.

McKay, Alisdair, Emi Nakamura, and Jón Steinsson, "The Power of Forward Guidance Revisited," American Economic Review, 2016, 106 (10), 3133-3158.

Mian, Atif, Kamalesh Rao, and Amir Sufi, "Household Balance Sheets, Consumption, and the Economic Slump," Quarterly Journal of Economics, 2013, 128 (4), 1687-1726.

Mishkin, Frederic S., "The Household Balance Sheet and the Great Depression," Journal of Economic History, 1978, 38 (4), 918-937.

Nakamura, Emi and Jón Steinsson, "Five Facts about Prices: A Reevaluation of Menu Cost Models," Quarterly Journal of Economics, 2008, 123 (4), 1415-1464.

_ and _ , "Fiscal Stimulus in a Monetary Union: Evidence from US Regions," American Economic Review, 2014, 104 (3), 753-792.

Nourse, Edwin G., Joseph S. Davis, and John D. Black, Three Years of the Agricultural Adjustment Administration, The Brookings Institution, 1937.

Obstfeld, Maurice and Kenneth Rogoff, Foundations of International Macroeconomics, MIT Press, 1996. 
Olmstead, Alan L. and Paul W. Rhode, "The Transformation of Northern Agriculture, 19101990," in Stanley L. Engerman and Robert E. Gallman, eds., The Cambridge Economic History of the United States, Cambridge University Press, 2000, pp. 693-742.

_ and _ , "Farms - Number, Population, Land, and Value of Property: 1910-1999 [Annual]," in Susan B. Carter, Scott Sigmund Gartner, Michael R. Haines, Alan L. Olmstead, Richard Sutch, and Gavin Wright., eds., Historical Statistics of the United States, Earliest Times to the Present: Millennial Edition, Cambridge University Press, 2006. Table Da1-13, series Da4.

_ and _ , "Grapefruit, Oranges, Lemons, and Limes - Acreage, Production, and Price: 19101999," in Susan B. Carter, Scott Sigmund Gartner, Michael R. Haines, Alan L. Olmstead, Richard Sutch, and Gavin Wright., eds., Historical Statistics of the United States, Earliest Times to the Present: Millennial Edition, Cambridge University Press, 2006. Table Da806820.

Pirtle, Thomas Ross and Rob Roy Slocum, Handbook of Poultry and Egg Statistics number 158, Government Printing Office, 1937.

Ramey, Valerie A. and Sarah Zubairy, "Government Spending Multipliers in Good Times and in Bad: Evidence from US Historical Data," Journal of Political Economy, 2018, 126 (2), 850-901.

Rauchway, Eric, The Money Makers: How Roosevelt and Keynes Ended the Depression, Defeated Fascism, and Secured a Prosperous Peace, Basic Books, 2015.

Richardson, Gary, "The Check is in the Mail: Correspondent Clearing and the Collapse of the Banking System, 1930 to 1933," Journal of Economic History, 2007, 67 (3), 643-671.

Rigobon, Roberto, "Identification through Heteroskedasticity," Review of Economics and Statistics, 2003, 85 (4), 777-792.

Romer, Christina D., "It Takes a Regime Shift: Recent Developments in Japanese Monetary Policy Through the Lens of the Great Depression," NBER Macroeconomics Annual 2013, 2014, 28 (1), 383-400.

Snowden, Kenneth A., "Debt on Nonfarm Structures, by Type of Debt, Property, and Holder: 1896-1952," in Susan B. Carter, Scott Sigmund Gartner, Michael R. Haines, Alan L. Olmstead, Richard Sutch, and Gavin Wright., eds., Historical Statistics of the United States, Earliest Times to the Present: Millennial Edition, Cambridge University Press, 2006. Table Dc903-928, series Dc906.

_., "Mortgage Foreclosures and Delinquencies: 1926-1979," in Susan B. Carter, Scott Sigmund Gartner, Michael R. Haines, Alan L. Olmstead, Richard Sutch, and Gavin Wright., eds., Historical Statistics of the United States, Earliest Times to the Present: Millennial Edition, Cambridge University Press, 2006. Table Dc1255-1270, series Dc1257.

_ , "Mortgage Foreclosures and Delinquencies: 1926-1979," in Susan B. Carter, Scott Sigmund Gartner, Michael R. Haines, Alan L. Olmstead, Richard Sutch, and Gavin Wright., eds., Historical Statistics of the United States, Earliest Times to the Present: Millennial Edition, Cambridge University Press, 2006. Table Dc1255-1270, series Dc1255.

_, "Residential Capital Formation and Wealth - Nonfarm Housekeeping Structures and Land: 1889-1953," in Susan B. Carter, Scott Sigmund Gartner, Michael R. Haines, Alan L. 
Olmstead, Richard Sutch, and Gavin Wright., eds., Historical Statistics of the United States, Earliest Times to the Present: Millennial Edition, Cambridge University Press, 2006. Table Dc879-888, series Dc884.

Stauber, B. R. and M. M. Regan, "The Farm Real Estate Situation, 1934-35," United States Department of Agriculture Circular number 3821935.

Stepner, Michael, "binscatter: Binned Scatterplots in Stata," Slide deck online at https://michaelstepner.com/binscatter/binscatter-StataConference2014.pdf 2014.

Strauss, Frederick and Louis Hyman Bean, Gross Farm Income and Indices of Farm Production and Prices in the United States, 1869-1937 number 703, Department of Agriculture, 1940.

Suits, Daniel B., "The Demand for New Automobiles in the United States 1929-1956," Review of Economics and Statistics, 1958, 40 (3), 273-280.

Sumner, Scott B., The Midas Paradox: Financial Markets, Government Policy Shocks, and the Great Depression, Independent Institute, 2015.

Sutch, Richard, "Business Incorporations and Failures - Number and Liabilities: 1857-1998," in Susan B. Carter, Scott Sigmund Gartner, Michael R. Haines, Alan L. Olmstead, Richard Sutch, and Gavin Wright., eds., Historical Statistics of the United States, Earliest Times to the Present: Millennial Edition, Cambridge University Press, 2006. Table Ch408-413, series Ch411.

Taylor, Alonzo E., Corn and Hog Surplus of the Corn Belt, Stanford University Press, 1932. Food Research Institute Miscellaneous Publication number 6.

Taylor, Jason E. and Todd C. Neumann, "Recovery Spring, Faltering Fall: March to November 1933," Explorations in Economic History, 2016, 61, 54-67.

Temin, Peter and Barrie Wigmore, "The End of One Big Deflation," Explorations in Economic History, 1990, 27 (4), 483-502.

United States Department of Agriculture, Agricultural Adjustment: A Report of Administration of the Agricultural Adjustment Act May 1933 to February 1934, Government Printing Office, 1934.

_, Yearbook of Agriculture, Government Printing Office, 1934.

_, Yearbook of Agriculture, Government Printing Office, 1935.

_ , Agricultural Statistics, Government Printing Office, 1936.

_, Price Spreads Between Farmers and Consumers for Food Products 1913-44 1945. From the Bureau of Agricultural Economics, Miscellaneous Publication number 576.

United States Department of Commerce, Fifteenth Census of the United States: 1930. Agriculture, Vol. II, Government Printing Office, 1932.

United States Department of Labor, "Retail Prices," Monthly Labor Review, 1936, 43 (4), 1041-1055.

_ , "Retail Prices," Monthly Labor Review, 1936, 43 (1), 219-244.

_, Retail Prices of Food, 1923-36, Government Printing Office, 1938. Bulletin, number 635.

U.S. Bureau of the Census, Fifteenth Census of the United States: 1930; Population, Volume II, Government Printing Office, 1933. 
U.S. Department of Commerce, "Index of Cash Income from Farm Marketings," Survey of Current Business, May 1934, 14 (5), 16-19.

_., "Index of Sales of General Merchandise in Small Towns and Rural Areas," Survey of Current Business, December 1934, 14 (12), 20.

_, Survey of Current Business: 1936 Supplement, Government Printing Office, 1936.

_ , Historical Statistics of the United States, Government Printing Office, 1975.

Wall, Norman J., "Demand Deposits of Country Banks," 1937. United States Department of Agriculture Technical Bulletin number 575.

Wallis, John Joseph, "Employment in the Great Depression: New Data and Hypotheses," Explorations in Economic History, 1989, 26, 45-72.

Ward's Reports Inc., Ward's 1938 Automotive Year Book, Ward's Reports Inc., 1938.

Warren, George F. and Frank A. Pearson, Gold and Prices, John Wiley \& Sons, 1935.

Werning, Iván, "Managing a Liquidity Trap: Monetary and Fiscal Policy," 2011. NBER Working Paper 17344.

_ , "Incomplete Markets and Aggregate Demand," 2015. NBER Working Paper 21448.

Wieland, Johannes, "Are Negative Supply Shocks Expansionary at the Zero Lower Bound?," 2017.

Wood, Howard, "Pit has Biggest Day Since Opening of New Building," Chicago Tribune, April 1933, pp. 1-2.

Woodford, Michael, "Methods of Policy Accommodation at the Interest-Rate Lower Bound," in "The Changing Policy Landscape: 2012 Jackson Hole Symposium" Federal Reserve Bank of Kansas City 2012.

Woytinsky, W.S. and E.S. Woytinsky, World Population and Production: Trends and Outlook, Twentieth Century Fund, 1953. 


\section{A Checking data consistency in spring 1933}

Rapid growth rates over a short period naturally lead to questions of data quality: should one believe that seasonally adjusted industrial production rose 57 percent in spring 1933 or might this reported increase be a result of data construction problems? We argue the former. Since our conclusion is in line with Taylor and Neumann (2016), our analysis in this appendix is brief.

The first check is to consider the behavior of non-seasonally adjusted production. This is shown in figure A.1a. The rapid increase in industrial production is also present in the raw, non-seasonally adjusted data and is not a regular seasonal phenomena. Only in 1933 does one see such a dramatic increase in spring. A second check on data quality is to see whether the rapid production increase is driven by outliers. It appears not. Of the 19 individual industry production series comprising durable manufacturing published in Federal Reserve (1940), eight saw seasonally adjusted production rise more than 100 percent between March and July 1933; all but one (railroad car production) of the 19 saw production rise more than 20 percent.

A.1 Other production indicators A further check on the industrial production data is to consider alternative indicators of economic activity. Figure A.1b shows two such indicators: the Federal Reserve index of freight car loadings and nonagricultural employment (Federal Reserve, 1941). Freight car loadings measure the real quantity of shipments by rail, with underlying data from the railroads themselves. The broad picture is similar to that for industrial production. After reaching a trough in March 1933, seasonally adjusted freight car loadings grew rapidly through July. In these four months, the seasonally adjusted series rose 40 percent.

It is also natural to examine the evolution of employment. Caution is necessary since the employment data are not entirely independent of the industrial production data. For some industries, the industrial production figures rely heavily on the Bureau of Labor Statistics establishment survey, which is the employment data's source (Federal Reserve, 1940, p. 761). Nonetheless, it is reassuring that, like industrial production, employment rose rapidly in spring 1933. Total, seasonally adjusted, nonagricultural employment grew from 26.7 million in March 1933 to 28.4 million in July. ${ }^{54}$ Seventy-three percent of this employment increase was accounted for by an astonishing 20 percent increase in manufacturing employment. ${ }^{55}$

A.2 Sales Together, the data on industrial production, employment, and freight car loadings leave little doubt that output rose rapidly in spring 1933. But was the recovery of production due to contemporaneous consumer demand or to expectations of future demand? If the former, the historians' task is to explain the increase in consumption. If the latter, to explain why firms expected higher future sales. Therefore we examine the behavior of sales in spring 1933. Figure A.1c shows seasonally adjusted passenger car sales and production

\footnotetext{
${ }^{54}$ Note that these employment data exclude relief workers. Data are from Federal Reserve (1941) p. 534.

${ }^{55}$ Manufacturing employment rose from 6.12 million in March to 7.36 million in July (Federal Reserve, 1941, p. 534).
} 

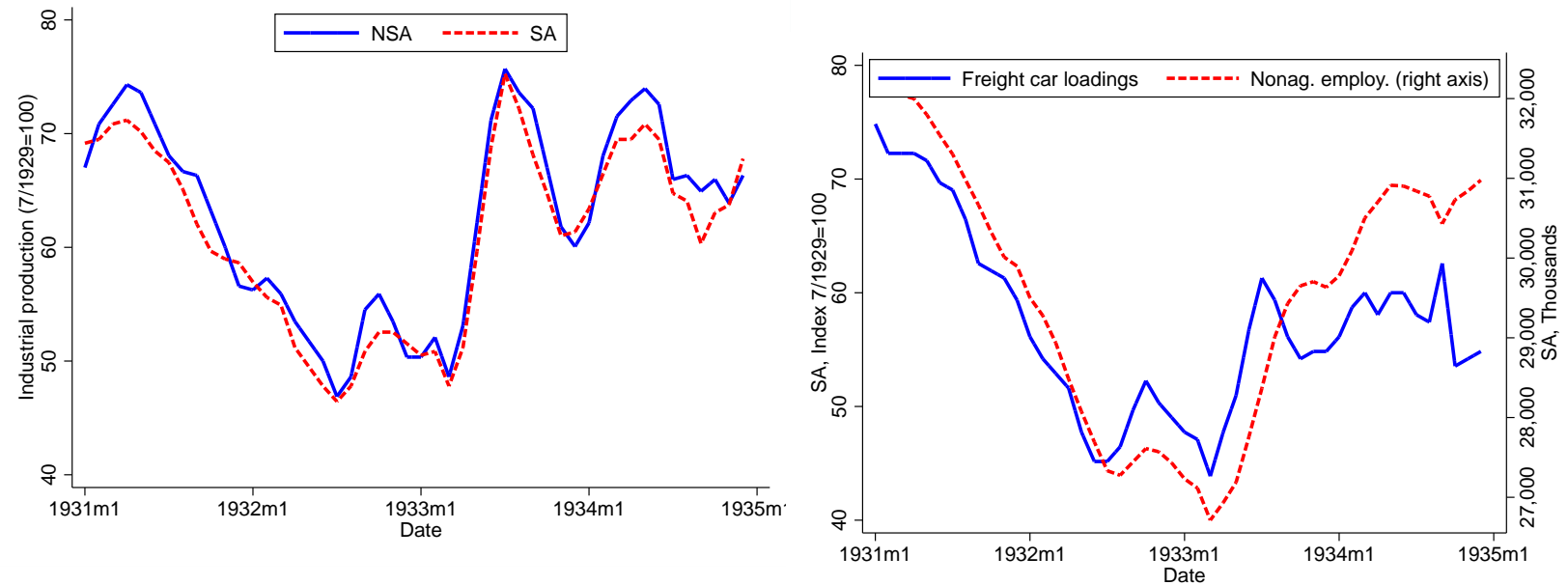

(a) Non-seasonally adjusted and seasonally adjusted industrial production

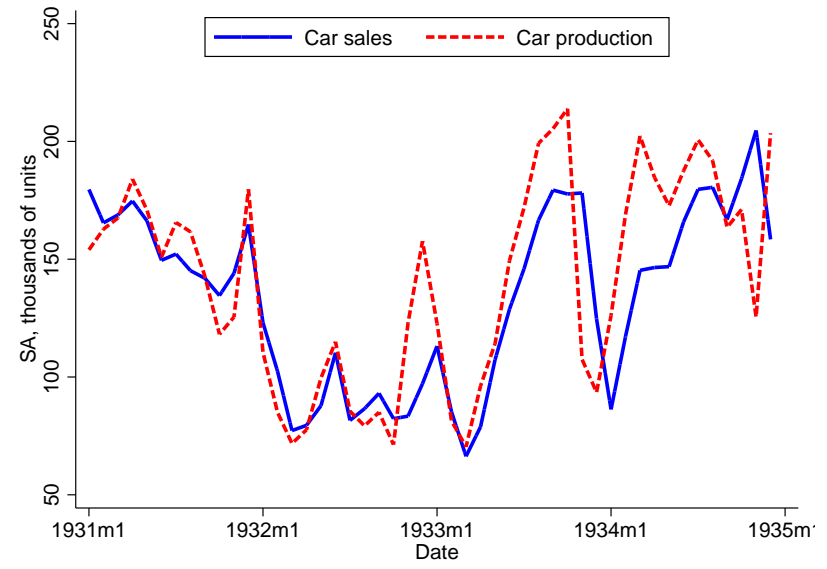

(c) Car sales and production (b) Freight car loadings and employment

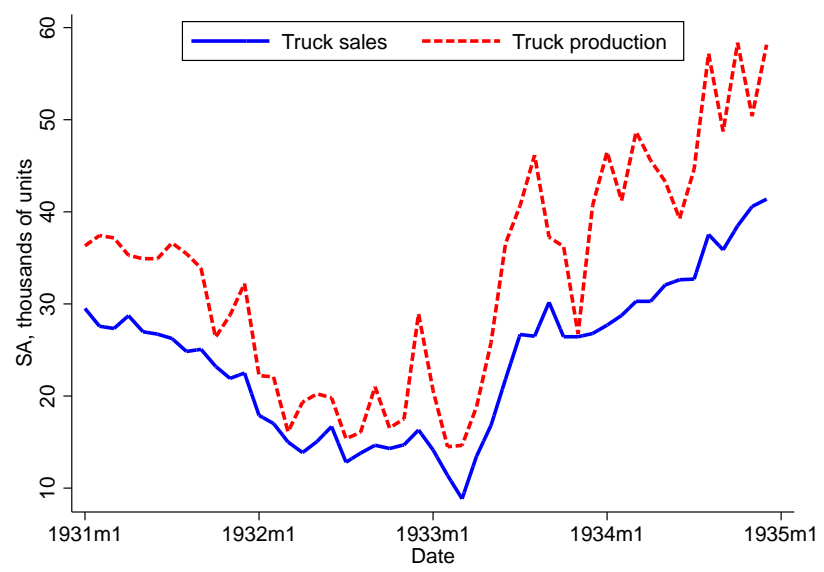

(d) Truck sales and production

Figure A.1 - Notes: See text for details on the seasonal adjustment of car and truck sales / production. Sources: Industrial production: Federal Reserve Board, G.17 data release. Freight car loadings and employment: Federal Reserve (1941). Cars: Sales data are from NBER macrohistory series m01109; production data are from NBER series m01107a. Trucks: Sales data are from NBER macrohistory series m01146a; production data are from NBER series m01144a. 
from 1931 through $1934 .{ }^{56}$ Seasonally adjusted sales behave similarly to production in spring 1933, roughly doubling from March to July. Figure A.1d presents the analogous data for trucks. Interestingly, the recovery of truck sales is even more rapid than that of car sales in spring 1933: they rise 202 percent from March to July. ${ }^{57}$

As with cars, the difference between truck production and sales is not obviously anomalous in spring 1933. Figures A.1c and A.1d suggest a roughly parallel movement in production and sales of cars and trucks. This mirrors the finding of Taylor and Neumann (2016) that manufacturing inventories behaved normally in spring 1933.

\section{B Appendix Tables}

\footnotetext{
${ }^{56}$ Sales data are from NBER macrohistory series m01109; production data are from NBER series m01107a. Neither series was seasonally adjusted by the source. We seasonally adjust the series by regressing the natural logarithm of each series on monthly dummies for the period January 1929-December 1934, excluding 1933. We use this narrow sample to align with the seasonal adjustment procedure used for the monthly state auto sales. The series graphed in figure A.1c is $e^{\hat{\varepsilon_{t}}} \times \frac{\bar{y}}{\bar{x}}$, where $\hat{\varepsilon_{t}}$ are the residuals from the regression of the natural $\log$ of sales or production on the monthly dummies, $\bar{y}$ is the mean of non-seasonally adjusted sales over the period, and $\bar{x}$ is the mean of $e^{\hat{\varepsilon} t}$.

${ }^{57}$ Sales data are from NBER macrohistory series m01146a; production data are from NBER series m01144a. The seasonal adjustment procedure is identical to that for passenger cars. See footnote above.
} 
Table B.1 - New auto sales growth in spring 1933 (\%, SA), population weighted

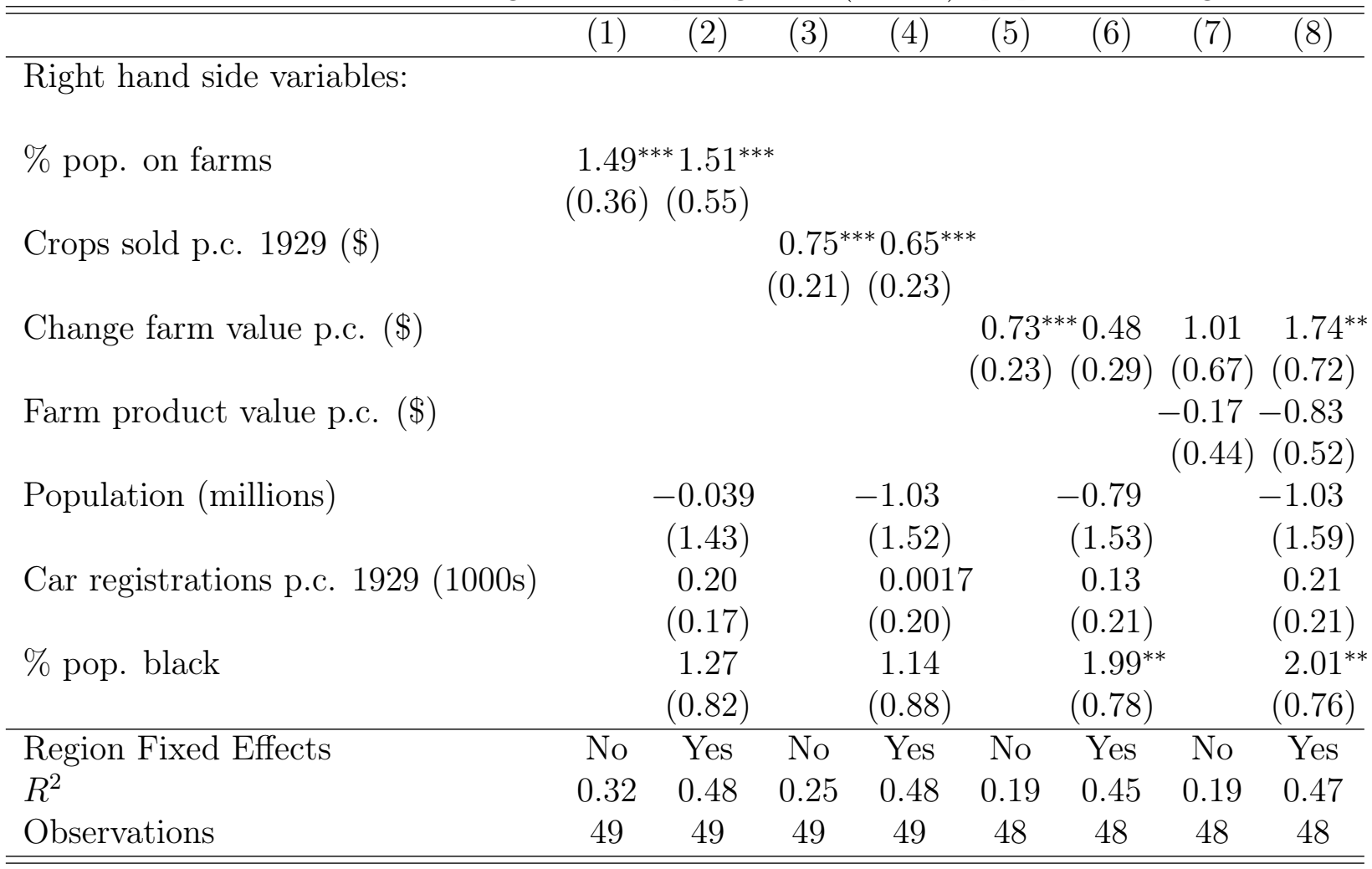

Notes: The dependent variable is the percent change in seasonally adjusted auto sales from the October 1932-March 1933 average to the July-September 1933 average. "p.c." means per capita. Robust standard errors in parenthesis. ${ }^{*} p<0.1,{ }^{* *} p<0.05,{ }^{* * *} p<0.01$

Sources: see text. 
Table B.2 - New auto sales growth Q4 1932 to Q4 1933 (\%, NSA)

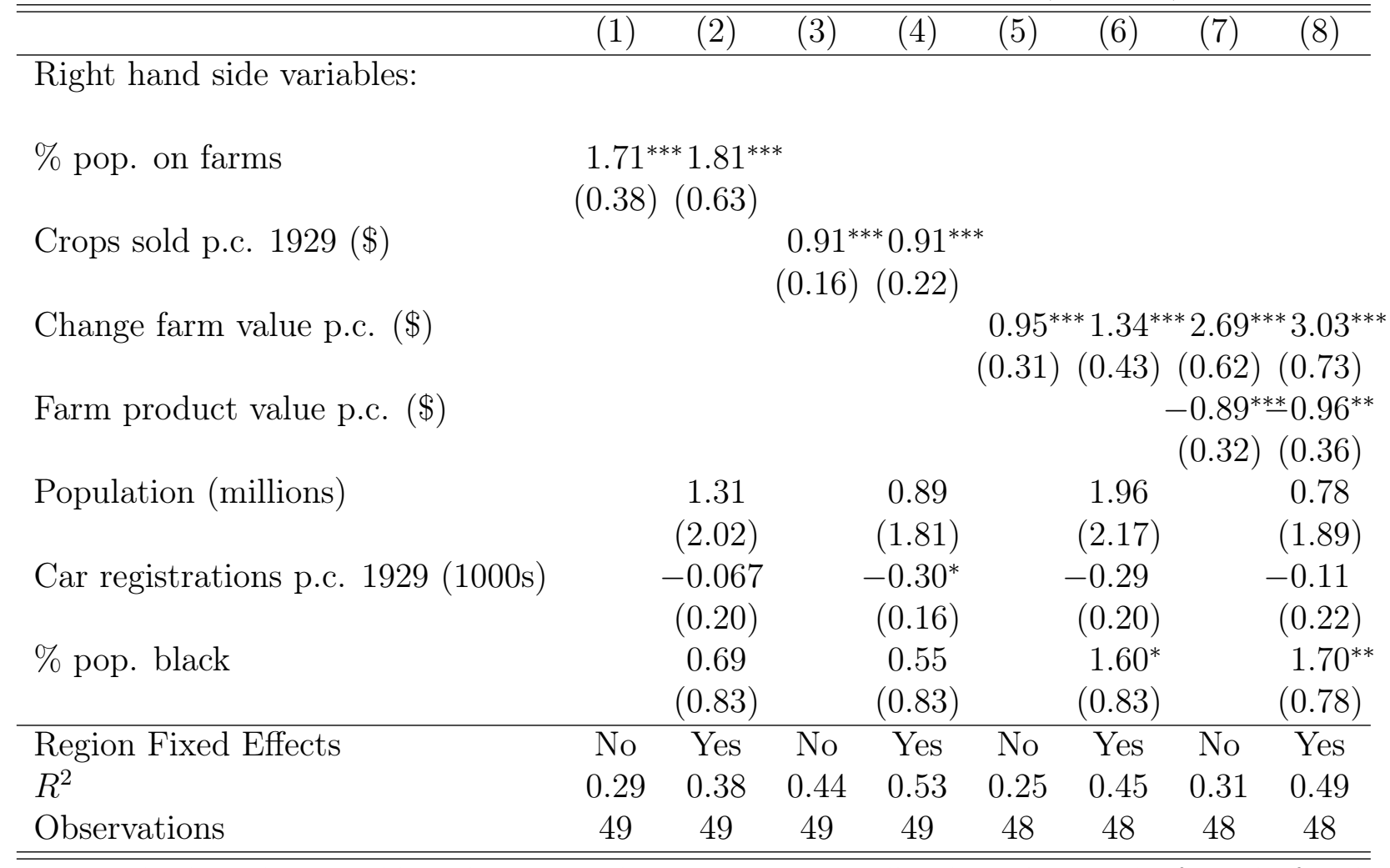

Notes: The dependent variable is the percent change in non-seasonally adjusted auto sales from the fourth quarter of 1932 to the fourth quarter of 1933. "p.c." means per capita. Robust standard errors in parenthesis. ${ }^{*} p<0.1,{ }^{* *} p<0.05,{ }^{* * *} p<0.01$

Sources: see text. 


\section{Notes and sources for farm product data}

\section{C.1 Table 1}

- The exchange rate: The source is Survey of Current Business, 12/32 p. 32, 12/33 p. $31,12 / 34$ p. $32,12 / 35$ p. 33.

- Wheat: Monthly U.S. producer prices are from United States Department of Agriculture (1936), table 15, p. 19. We seasonally adjust these prices using the same procedure as for auto sales (footnote 14). The seasonal adjustment is done on data from July 1926 through December 1935, excluding 1933. Production, farm product value, and trade data are from United States Department of Agriculture (1936), table 1, p. 6. Trade quantities are for the trade year beginning July.

- Corn: Monthly U.S. producer prices are from United States Department of Agriculture (1936), table 45, p. 39. We seasonally adjust these prices using the same procedure as for auto sales (footnote 14). The seasonal adjustment is done on data from October 1926 through December 1935, excluding 1933. Production, farm product value, and trade data are from United States Department of Agriculture (1936), table 37, p. 33. Trade quantities are for the trade year beginning July.

- Oats: Monthly U.S. producer prices are from United States Department of Agriculture (1936), table 60, p. 50. We seasonally adjust these prices using the same procedure as for auto sales (footnote 14). The seasonal adjustment is done on data from July 1926 through December 1935, excluding 1933. Production, farm product value, and trade data are from United States Department of Agriculture (1936), table 53, p. 44. Trade quantities are for the trade year beginning July.

- Cotton: Monthly U.S. producer prices are from United States Department of Agriculture (1936), table 106, p. 82. We seasonally adjust these prices using the same procedure as for auto sales (footnote 14). The seasonal adjustment is done on data from August 1926 through December 1935, excluding 1933. Production, farm product value, and trade data are from United States Department of Agriculture (1936), table 98, p. 76. Trade quantities are for the trade year beginning August.

- Tobacco: Annual calendar year U.S. producer prices are from Strauss and Bean (1940), p. 69, table 27. Production, farm product value, and trade data are from United States Department of Agriculture (1936), table 143, p. 104. Trade quantities are for the trade year beginning July.

- Hay: Monthly U.S. producer prices are from United States Department of Agriculture (1936), table 274, p. 190. We seasonally adjust these prices using the same procedure as for auto sales (footnote 14). The seasonal adjustment is done on data from July 1926 through December 1935, excluding 1933. Production and trade data are from United States Department of Agriculture (1936), table 270, p. 187. Trade quantities are for the trade year beginning July. Production of hay is the sum of tame hay and wild hay production. Farm product value is tame hay production multiplied by the December 1 price (given in United States Department of Agriculture (1936), table 270, 
p. 187) plus wild hay production multiplied by the December 1 price (also given in United States Department of Agriculture (1936), table 270, p. 187).

- Potatoes: Monthly U.S. producer prices are from United States Department of Agriculture (1936), table 229, p. 162. We seasonally adjust these prices using the same procedure as for auto sales (footnote 14). The seasonal adjustment is done on data from July 1926 through December 1935, excluding 1933. Production, farm product value, and trade data are from United States Department of Agriculture (1936), table 222 , p. 157. Trade quantities are for the trade year beginning July.

- Cattle: Monthly U.S. producer prices are from United States Department of Agriculture (1936) table 307, p. 213. We seasonally adjust these prices using the same procedure as for auto sales (footnote 14). The seasonal adjustment is done on data from January 1926 through December 1935, excluding 1933. Production data are from United States Department of Agriculture (1934b), table 324, pp. 590-591, and United States Department of Agriculture (1935), table 327, pp. 562-563. We calculate farm product value as production multiplied by the weighted-average calendar year producer price (United States Department of Agriculture (1936) table 307, p. 213). Trade data are from United States Department of Agriculture (1936) table 312, p. 217. Trade quantities are for the calendar year. The trade data are for beef and beef products.

- Hogs: Monthly U.S. producer prices are from United States Department of Agriculture (1936), table 321, p. 224. Production data are from United States Department of Agriculture (1934b), table 340, p. 601, and United States Department of Agriculture (1935), table 342, p. 572. We seasonally adjust these prices using the same procedure as for auto sales (footnote 14). The seasonal adjustment is done on data from January 1926 through December 1935, excluding 1933. Farm product value is from United States Department of Agriculture (1934b), table 340, p. 601. Trade data are from United States Department of Agriculture (1936) table 331, p. 229. Trade quantities are for the calendar year. The trade data are for hog products; thus they are an upper bound on trade in pork itself.

- Milk: Monthly U.S. producer prices are from United States Department of Agriculture (1936), table 376, p. 267. Production data are from United States Department of Agriculture (1934b), table 383, p. 628, and United States Department of Agriculture (1936), table 368, p. 259. We seasonally adjust these prices using the same procedure as for auto sales (footnote 14). The seasonal adjustment is done on data from January 1926 through December 1935, excluding 1933. Farm product value is production multiplied by the weighted-average calendar year producer price (United States Department of Agriculture (1936), table 376, p. 267). These USDA publications provide no trade data, presumably because little milk was traded. (There was trade in some milk by-products, such as condensed and evaporated milk.)

- Chickens: Monthly U.S. producer prices are from United States Department of Agriculture (1936), table 410, p. 286. We seasonally adjust these prices using the same procedure as for auto sales (footnote 14). The seasonal adjustment is done on data from January 1926 through December 1935, excluding 1933. Production and farm product 
value data refer to the number of chickens raised; data are from United States Department of Agriculture (1936), table 403, p. 281. United States Department of Agriculture (1936) provides no trade data, presumably because little chicken was traded.

- Eggs: Monthly U.S. producer prices are from United States Department of Agriculture (1936), table 419, p. 291. We seasonally adjust these prices using the same procedure as for auto sales (footnote 14). The seasonal adjustment is done on data from January 1926 through December 1935, excluding 1933. Production and farm product value data are from United States Department of Agriculture (1936), table 403, p. 281. Trade data are from United States Department of Agriculture (1936), table 423, p. 293. They are for the period July 1932 to June 1933 and are reported in dollar terms; therefore, we calculate the trade output share as imports plus exports (in dollars) divided by total farm value (in dollars).

C.2 Farm product value for U.S. states Except as noted below, we compute the price for 1932 production using a weighted average of monthly, non-seasonally adjusted prices. We compute the percent change in prices from the October 1932 - March 1933 average to the July-September 1933 average using seasonally adjusted, unweighted monthly prices.

- Wheat: Raw and seasonally adjusted monthly price data are the same as listed in section C.1. To compute annual 1932 and 1933 prices, we weight the monthly prices using monthly wheat receipts, United States Department of Agriculture (1936), table 11, p. 15. Production data for 1932 by state are from United States Department of Agriculture (1934b), table 4, p. 389. For the states Colorado, Illinois, Indiana, Kansas, Maryland, Missouri, Montana, North Dakota, Ohio, Oklahoma, South Dakota, Virginia, and Wyoming we use 1932 production data from the National Agricultural Statistics Service (NASS). ${ }^{58}$ For Illinois, we take data on winter wheat only from NASS and add to it the data on spring wheat production reported in Illinois Cooperative Crop Reporting Service (1951).

- Corn: Raw and seasonally adjusted monthly price data are the same as listed in section C.1. To compute annual 1932 and 1933 prices, we weight the monthly prices using monthly marketings by farmers, United States Department of Agriculture (1935), table 48, p. 385. Production data for 1932 by state are from United States Department of Agriculture (1934b), table 41, p. 415. For the states Delaware, Illinois, Indiana, Iowa, Kentucky, Maryland, Missouri, Nebraska, North Carolina, Ohio, and Wisconsin we use 1932 production data from NASS.

- Oats: Raw and seasonally adjusted monthly price data are the same as listed in section C.1. To compute annual 1932 and 1933 prices, we weight the monthly prices using monthly marketings by farmers, United States Department of Agriculture (1935), table 64, p. 396. Production data for 1932 by state are from United States Department of Agriculture (1934b), table 59, p. 427. For the states Illinois, Minnesota, Montana,

\footnotetext{
${ }^{58}$ This and all other NASS data were downloaded on June 10, 2007. See https://www.nass.usda.gov/Quick_Stats/.
} 
North Dakota, Ohio, South Dakota, and Wisconsin we use 1932 production data from NASS.

- Cotton: Raw and seasonally adjusted monthly price data are the same as listed in section C.1. To compute annual 1932 and 1933 prices, we weight the monthly prices using monthly marketings by farmers, United States Department of Agriculture (1935), table 117, p. 429. Production data for 1932 by state are from United States Department of Agriculture (1934b), table 112, p. 460. For the states California, Georgia, Mississippi, and North Carolina we use 1932 production data from NASS.

- Tobacco: No monthly prices are available over a long enough time horizon to make seasonal adjustment possible; thus we use the calendar year, annual price reported in Strauss and Bean (1940), p. 69, table 27. Production data for 1932 by state are from United States Department of Agriculture (1934b), table 155, p. 486.

- Hay: Raw and seasonally adjusted monthly price data are the same as listed in section C.1. No monthly weights are available, so the annual price is a simple average of the monthly prices. Production data for 1932 by state are from United States Department of Agriculture (1934b), table 287, p. 564, for tame hay and from United States Department of Agriculture (1934b), table 288, p. 565, for wild hay. For the states Illinois, Minnesota, Missouri, North Dakota, and South Dakota we use 1932 production data from NASS.

- Potatoes: Raw and seasonally adjusted monthly price data are the same as listed in section C.1. To compute annual 1932 and 1933 prices, we weight the monthly prices using monthly potato shipments, United States Department of Agriculture (1936), table 227, p. 161. Production data for 1932 by state are from United States Department of Agriculture (1934b), table 237, p. 534-535.

- Cattle: Monthly and weighted-average calendar year producer prices are taken from United States Department of Agriculture (1936) table 307, p. 213. Seasonal adjustment is as described in section C.1. Production data for 1932 by state are from United States Department of Agriculture (1934b), table 324, pp. 590-591.

- Hogs: Monthly and weighted-average calendar year producer prices are taken from United States Department of Agriculture (1936), table 321, p. 224. Seasonal adjustment is as described in section C.1. Production data for 1932 by state are from United States Department of Agriculture (1934b), table 340, p. 601.

- Milk: Monthly and weighted-average calendar year producer prices are taken from United States Department of Agriculture (1936), table 376, p. 267. Seasonal adjustment is as described in section C.1. Production data for 1932 by state are from United States Department of Agriculture (1934b), table 383, p. 628.

- Chickens: Monthly and weighted-average calendar year producer prices are taken from United States Department of Agriculture (1936), table 410, p. 286. Seasonal adjustment is as described in section C.1. Production data for 1932 by state are from Pirtle and Slocum (1937), table 18, p. 16, for chickens sold and table 19, p. 17, for chickens 
consumed on farms. To match production data on number of chickens to price data on the value of a pound of chicken, we assume that each chicken weighs 3.7 pounds. We obtain this number by taking the ratio of the figures on price per chicken and price per pound of chicken reported in United States Department of Agriculture (1935).

- Eggs: Monthly and weighted-average calendar year producer prices are taken from United States Department of Agriculture (1936), table 419, p. 291. Seasonal adjustment is as described in section C.1. Production data for 1932 by state are from United States Department of Agriculture (1934b), table 432, p. 655.

- Apples: Monthly producer prices are from United States Department of Agriculture (1936), table 155, p. 116. Seasonal adjustment follows the procedure used for auto sales (footnote 14). The seasonal adjustment is done on data from June 1926 through December 1935, excluding 1933. Weights for annual prices are based on monthly car lot shipments, United States Department of Agriculture (1936), table 158, p. 118. Production data for 1932 by state are from United States Department of Agriculture (1934b), table 168, p. 499.

- Oranges: Annual producer price data and production data for 1932 by state are from United States Department of Agriculture (1936), table 180, p. 131. No monthly producer prices are available, so we use the annual price for each month of the corresponding year. We follow the convention in Olmstead and Rhode (2006b) of making the price in calendar year $t$ equal to the price for the crop year beginning in year $t-1$.

- Grapefruit: Annual producer price data and production data for 1932 by state are from United States Department of Agriculture (1936), table 180, p. 131. No monthly producer prices are available, so we use the annual price for each month of the corresponding year. We follow the convention in Olmstead and Rhode (2006b) of making the price in calendar year $t$ equal to the price for the crop year beginning in year $t-1$.

- Wool: Monthly and weighted-average producer prices are from United States Department of Agriculture (1936), table 347, p. 244. Seasonal adjustment follows the procedure used for auto sales (footnote 14). The seasonal adjustment is done on data from January 1926 through December 1935, excluding 1933. Production data for 1932 by state are from United States Department of Agriculture (1934b), table 362, p. 616.

C.3 Farm product value for U.S. counties Since we use national prices, all prices are identical to those described above for the state data. County-level production data are constructed as follows:

- Wheat: we calculate the county's share in 1929 state wheat production from the 1930 agricultural census (Haines et al., 2015). We then multiply 1932 state production by that share to impute 1932 county production. For the states Colorado, Illinois, Indiana, Kansas, Maryland, Missouri, Montana, North Dakota, Ohio, Oklahoma, South Dakota, Virginia, and Wyoming we use county-level 1932 production data from NASS. For Illinois, we take data on winter wheat only from NASS and add to it the data on spring wheat production reported in Illinois Cooperative Crop Reporting Service (1951). 
- Corn: we calculate the county's share in 1929 state corn production from the 1930 agricultural census (Haines et al., 2015). We then multiply 1932 state production by that share to impute 1932 county production. For the states Delaware, Illinois, Indiana, Iowa, Kentucky, Maryland, Missouri, Nebraska, North Carolina, Ohio, and Wisconsin we use county-level 1932 production data from NASS.

- Oats: we calculate the county's share in 1929 state oats production from the 1930 agricultural census (Haines et al., 2015). We then multiply 1932 state production by that share to impute 1932 county production. For the states Illinois, Minnesota, Montana, North Dakota, Ohio, South Dakota, and Wisconsin we use county-level 1932 production data from NASS.

- Cotton: we calculate the county's share in 1929 state cotton production from the 1930 agricultural census (Haines et al., 2015). We then multiply 1932 state production by that share to impute 1932 county production. For the states California, Georgia, Mississippi, and North Carolina we use county-level 1932 production data from NASS.

- Tobacco: we calculate the county's share in 1929 state tobacco production from the 1930 agricultural census (Haines et al., 2015). We then multiply 1932 state production by that share to impute 1932 county production.

- Hay: we calculate the county's share in 1929 state hay production from the 1930 agricultural census (Haines et al., 2015). We then multiply 1932 state production by that share to impute 1932 county production. For the states Illinois, Minnesota, Missouri, North Dakota, and South Dakota we use county-level 1932 production data from NASS.

- Potatoes: we calculate the county's share in 1929 state potato production from the 1930 agricultural census (Haines et al., 2015). We then multiply 1932 state production by that share to impute 1932 county production.

- Cattle: we calculate the county's share in 1929 state cattle numbers from the 1930 agricultural census (Haines et al., 2015). We then multiply 1932 state production by that share to impute 1932 county production.

- Hogs: we calculate the county's share in 1929 state hog numbers from the 1930 agricultural census (Haines et al., 2015). We then multiply 1932 state production by that share to impute 1932 county production.

- Milk: we calculate the county's share in 1929 state milk production from the 1930 agricultural census (Haines et al., 2015). We then multiply 1932 state production by that share to impute 1932 county production.

- Chickens: we calculate the county's share in 1929 state chicken numbers from the 1930 agricultural census (Haines et al., 2015). We then multiply 1932 state production by that share to impute 1932 county production. 
- Eggs: we calculate the county's share in 1929 state egg production from the 1930 agricultural census (Haines et al., 2015). We then multiply 1932 state production by that share to impute 1932 county production.

- Apples: we calculate the county's share in 1929 state apple production from the 1930 agricultural census (Haines et al., 2015). We then multiply 1932 state production by that share to impute 1932 county production.

- Oranges: we calculate the county's share in 1929 state oranges production from the 1930 agricultural census (Haines et al., 2015). We then multiply 1932 state production by that share to impute 1932 county production.

- Grapefruit: we calculate the county's share in 1929 state grapefruit production from the 1930 agricultural census (Haines et al., 2015). We then multiply 1932 state production by that share to impute 1932 county production.

- Wool: we calculate the county's share in 1929 state wool production from the 1930 agricultural census (Haines et al., 2015). We then multiply 1932 state production by that share to impute 1932 county production.

\section{Monthly state auto sales data}

Our monthly state auto sales data come from the Automotive Daily News Review and Reference Book 1935, pp. 22-23. The source is given as "R. L. Polk \& Co., New Jersey Motor List Co. and Sherlock \& Arnold."

To check the accuracy of these data, we computed annual totals by state for 1932 and 1933 and compared these to the numbers reported in Automotive Industries, 2/25/33, p. 224 (for 1932) and $2 / 24 / 34$, p. 220 (for 1933).

In 52 of 98 cases, these sources exactly agree, and in all but two cases, the two sources are within 0.2 percent of each other. The two larger discrepancies are in Indiana in 1932, where Automotive Industries records 29,202 cars sold while Automotive Daily News Review and Reference Book records 28,505 cars sold, and in Iowa in 1932 where Automotive Industries records 18,971 cars sold and Automotive Daily News Review and Reference Book records 19,525 cars sold.

When these sources differ, it may be due to misreporting / typos in the monthly data. In a few cases, these typos were obvious, and we fixed them by using reported totals to compute a residual. Automotive Daily News Review and Reference Book always reported the total by month and state for the years 1929-1934, e.g. they reported the sum of sales in Alabama for January 1929 + January 1930 . . . + January 1934. This allows us to fill in months in which there is an obvious typo. Specifically:

- January 1932, Indiana: Automotive Daily News Review and Reference Book reports car sales equal to 5180. As reported, this means car sales for the six Januarys from 1929 to 1934 total to 25,260 , much more than the reported total of 22,563. Furthermore, the 5180 figure for January 1932 is suspect because it is larger than Indiana sales in January 1930, 1931, 1933, or 1934, and it is larger than Illinois sales in January 1932. 
Thus we replace it with the difference between the reported six-January total $(22,563)$ and the sum of the reported figures for all Januarys except January 1932. The resulting number is 2,483 cars sold.

- July 1932, Iowa, Kansas, Kentucky, Louisiana, Maine, Maryland, Massachusetts, Michigan, Minnesota, Mississippi, and Missouri: In these states, the reported figure for July 1932 sales is identical to that for July 1933 sales. Since on average summer 1932 sales were below summer 1933 sales, we replace the July 1932 figure with the reported six-July sum and sales in all Julys except July 1932. In all cases, this results-as expected-in a number that is less than the July 1933 number.

- February 1929, Nebraska: Automotive Daily News Review and Reference Book reports 470 cars sold in Nebraska in February 1929. This is implausibly low (e.g. 3986 cars were sold in Nebraska in the more depressed conditions of February 1930). So we replace it with the difference between the 6-February sum and the sum of all February sales except February 1929. The resulting number is a more plausible 4705 cars sold.

\section{E Banking data: Net demand deposits by reserve district}

We seasonally adjust the series using the procedure defined in footnote 14, excluding the year 1933. Data begin in April 1923 and end in July 1935, when there is a discontinuity in the series (Federal Reserve, 1935, p. 644).

Sources:

- 1923-27: Federal Reserve Board (1928), table 87, pp. 210-213.

- 1928: Federal Reserve Board (1929), table 93, p. 187.

- 1929: Federal Reserve Board (1930), table 89, p. 175.

- 1930: Federal Reserve Board (1931), table 95, p. 183.

- 1931: Federal Reserve Board (1932), table 93, p. 187.

- 1932: Federal Reserve Board (1933), table 70, p. 125.

- 1933: Federal Reserve Board (1934), table 74, p. 167.

- 1934: Federal Reserve Board (1935), table 68, p. 153.

- 1935: Federal Reserve Board (1936), table 55, p. 151.

\section{F Model appendix}

Time is discrete and indexed by $t$. 


\section{F.1 Technology and Incomes}

The final consumption good $C_{t}$ is a CES aggregate of a farm good $F_{t}$ and labor $L_{t}$,

$$
C_{t}=\left[\psi^{\frac{1}{\varepsilon}} F_{t}^{\frac{\varepsilon-1}{\varepsilon}}+(1-\psi)^{\frac{1}{\varepsilon}} L_{t}^{\frac{\varepsilon-1}{\varepsilon}}\right]^{\frac{\varepsilon}{\varepsilon-1}}
$$

where $\varepsilon$ is the elasticity of substitution across goods. We will consider the case where labor and farm goods are complements in production, $\varepsilon<1$.

The demand functions for farm goods and labor are,

$$
\begin{aligned}
F_{t} & =\psi\left(\frac{P_{t}^{f}}{M C_{t}}\right)^{-\varepsilon} C_{t} \\
L_{t} & =(1-\psi)\left(\frac{W_{t}}{M C_{t}}\right)^{-\varepsilon} C_{t}
\end{aligned}
$$

where $P_{t}^{f}$ is the price of the farm good, and $W_{t}$ is the nominal wage. The marginal cost to produce the final good, $M C_{t}$, is a CES composite of the nominal farm price and the nominal wage,

$$
M C_{t}=\left[\psi\left(P_{t}^{f}\right)^{1-\varepsilon}+(1-\psi) W_{t}^{1-\varepsilon}\right]^{\frac{1}{1-\varepsilon}}
$$

Capitalists sell the final good at a mark-up $m_{t} \geq 1$ over marginal costs, so the final retail price is

$$
P_{t}=m_{t} M C_{t}
$$

Farm goods $F_{t}$ and labor $L_{t}$ are in perfectly elastic supply at zero marginal cost up to a full-employment limit $\bar{F}$ and $\bar{L}$. We will consider the case where $F_{t}<\bar{F}$ and $L_{t}<\bar{L}$ to capture underutilization of the factors of production during the Great Depression.

The income share of farmers is then,

$$
s_{t}^{f}=\frac{p_{t}^{f} F_{t}}{Y_{t}}=\psi m_{t}^{-\varepsilon}\left(p_{t}^{f}\right)^{1-\varepsilon}
$$

where we use the fact that $C_{t}=Y_{t}$ in equilibrium, and $p_{t}^{f}$ is the real farm product price, $\frac{P_{t}^{f}}{P_{t}}$. Since farm goods and labor are complements, the farm income share is increasing in the real farm price. Thus, a higher real farm price redistributes income towards farmers.

The income share of capitalists comes from charging a mark-up over marginal cost,

$$
s_{t}^{c a p}=\frac{\left(P_{t}-M C_{t}\right) C_{t}}{P_{t} Y_{t}}=1-\frac{1}{m_{t}}
$$


and the income share of workers is the complement,

$$
s_{t}^{w}=1-s_{t}^{f}-s_{t}^{c a p}=\frac{1}{m_{t}}-s_{t}^{f}
$$

Thus, when the farm share increases, the losses are split between workers and capitalists depending on the response of the mark-up. When the mark-up remains constant (i.e., firms raise their price sufficiently), then all losses are borne by workers. By contrast, when real wages are unchanged (e.g., final goods prices and wages are sticky), then the mark-up falls and all losses are borne by capitalists.

\section{F.2 Aggregate demand}

Any farmer, worker, or capitalist may be either unconstrained $(u)$ or constrained $(c)$ in their consumption choices. We directly parameterize consumption functions for these types,

$$
\begin{aligned}
C_{t}^{u} & =\left[\beta\left(1+r_{t}\right)\right]^{-\sigma} \bar{C}^{u} \\
C_{t}^{c} & =Y_{t}^{c} .
\end{aligned}
$$

$C_{t}^{x}$ is consumption and $Y_{t}^{x}$ is income of type $x, \beta$ is the discount factor, $r_{t}$ is the real interest rate, and $\sigma$ is the intertemporal elasticity of substitution. Unconstrained consumers follow the permanent income hypothesis, where the quantity $\bar{C}^{u}$ is their permanent income. They may consume more than their permanent income when the real interest rate is low and viceversa. In writing the Euler equation in this way, we assume perfect foresight as in Werning (2011) and Wieland (2017) and let the horizon over which the real interest rate applies be relatively long. ${ }^{59}$

By contrast, constrained consumers are at their borrowing constraint and consume all their income. We think of farmers as being primarily in the constrained group, although we allow for some of them to be unconstrained as well.

Specifically, we assume that a fraction $\theta^{f}$ of farmers and fraction $\theta^{w}$ of workers are constrained. In line with our evidence that debt problems were less severe for firms than for workers or households, we assume that no capitalist is constrained. Then the constrained income share is

$$
\begin{aligned}
s_{t}^{c} & =\theta^{w} s_{t}^{w}+\theta^{f} s_{t}^{f} \\
& =\theta^{w} \frac{1}{m_{t}}+\left(\theta^{f}-\theta^{w}\right) s_{t}^{f},
\end{aligned}
$$

and the unconstrained income share is

$$
s_{t}^{u}=1-\theta^{w} \frac{1}{m_{t}}-\left(\theta^{f}-\theta^{w}\right) s_{t}^{f} .
$$

\footnotetext{
${ }^{59}$ More precisely, we can write the perfect-foresight Euler equation as $C_{t}=\left[\tilde{\beta}^{s} \prod_{k=1}^{s}\left(1+r_{t+k}\right)\right]^{-\sigma} C_{t+s}$. We then let $s$ be sufficiently large such that $C_{t+s} \approx \bar{C}^{u}$, assuming (as in most monetary models) that the economy converges to a single deterministic steady-state. Then define $\left.r_{t}=\prod_{k=1}^{s}\left(1+r_{t+k}\right)\right]^{-1}$ as the real interest rate from $t$ to $t+s$ and $\beta=\tilde{\beta}^{s}$ as the corresponding discount factor.
} 


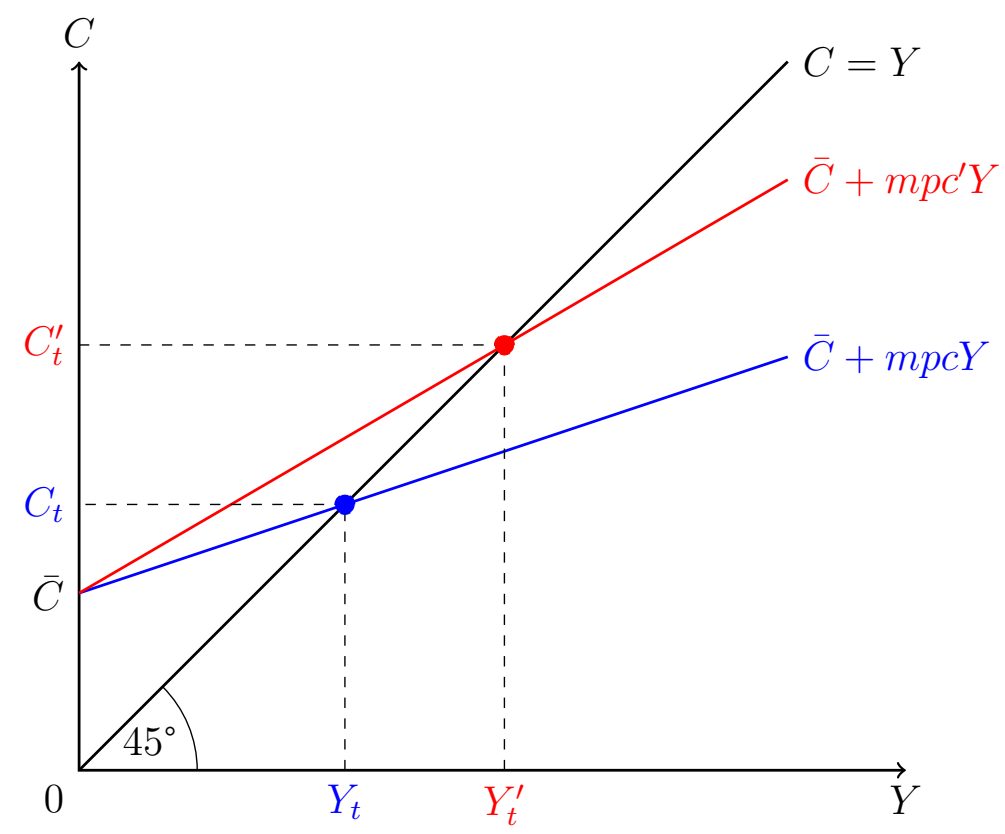

Figure F.1 - Keynesian cross diagram. Redistribution towards constrained consumers increases the average MPC in the economy from $m p c$ to $m p c^{\prime}$, and increases output from $Y_{t}$ to $Y_{t}^{\prime}$.

Market clearing implies that output equals expenditure, $Y_{t}=C_{t}=C_{t}^{u}+C_{t}^{c}$. Substituting our consumption functions yields a solution for output akin to a Keynesian cross,

$$
Y_{t}=\left[\beta\left(1+r_{t}\right)\right]^{-\sigma} \bar{C}^{u}+s_{t}^{c} Y_{t}
$$

where $\left[\beta\left(1+r_{t}\right)\right]^{-\sigma} \bar{C}^{u}$ is autonomous consumption and $s_{t}^{c}$ is the MPC. The aggregate MPC out of income is the share of constrained consumers, since they have an MPC of 1 , whereas unconstrained consumers have an MPC of zero. Thus $m p c_{t}=s_{t}^{c} \times 1+s_{t}^{u} \times 0=s_{t}^{c}$. is

Define the aggregate multiplier as $\mu_{t}=\frac{1}{1-m p c_{t}}$. Then the solution for aggregate output

$$
Y_{t}=\mu_{t}\left[\beta\left(1+r_{t}\right)\right]^{-\sigma} \bar{C}^{u}
$$

Thus, any change in aggregate output must come from a change in the multiplier $\mu_{t}$ or in the real interest rate. Redistribution of income directly affects aggregate output through the aggregate multiplier. For example, increasing the share of income going to constrained consumers will raise $s_{t}^{c}$ and thus the multiplier $\mu_{t}$, which in turn raises output. Graphically, the expenditure curve in the Keynesian cross rotates up as shown in figure F.1. Our analysis of the farm channel will focus on this mechanism.

\section{F.3 Aggregate effect}

Our experiment is an unanticipated change in the nominal farm price $P_{t}^{f}$. This requires some control by the policy maker over $P_{t}^{f}$. In an international framework we could appeal to the law of one price, so that the local farm price is the product of the foreign farm price and 
the exchange rate, $P_{t}^{f}=P_{t}^{f *} \mathcal{E}_{t}$. Then a devaluation would raise the local farm price holding the foreign farm price fixed. In our model the farm price is instead exogenous since any price $P_{t}^{f}$ clears the farm product market when there is underemployment, $F_{t}<<\bar{F}$. ${ }^{60}$ This helps us simplify the model and more transparently focus on the effects of redistribution.

For now, it will be more convenient to work with the implied change in the farm income share $d \ln s_{t}^{f}$. We can then later express that change in terms of the percent change in farm prices $d \ln P_{t}^{f}$.

The percent change in output from a percent change in the farm income share combines the effect on the aggregate multiplier (through redistribution) and the real interest rate,

$$
d \ln Y_{t}=[\underbrace{\mu_{t}}_{\text {Multiplier }} \times \underbrace{\frac{-d s_{t}^{u}}{d \ln s_{t}^{f}}}_{\text {Redistribution }}+\underbrace{\sigma \frac{-d \ln \left(1+r_{t}\right)}{d \ln s_{t}^{f}}}_{\text {Intertemporal Substitution }}] \times \underbrace{d \ln s_{t}^{f}}_{\% \text { Change farm income share }}
$$

In this model, a higher farm income share raises output to the extent that it redistributes income towards constrained consumers (lowering the unconstrained share $s_{t}^{u}$ ) and / or lowers the real interest rate.

The extent to which a higher farm income share redistributes towards high-MPC consumers depends on (1) the importance of constrained farmers and (2) the response of the mark-up $m_{t}$ to higher farm product prices, since higher prices hurt constrained workers,

$$
d s_{t}^{u}=\underbrace{-\theta^{f} s_{t}^{f} d \ln s_{t}^{f}}_{\text {Redistribution towards high-MPC farmers }}+\underbrace{\theta^{w}\left[\frac{1}{m_{t}} d \ln m_{t}+s_{t}^{f} d \ln s_{t}^{f}\right]}_{\text {Redistribution from high-MPC workers }}
$$

For what follows we parameterize the change in mark-ups by,

$$
d \ln m_{t}=-(1-\xi) m_{t} s_{t}^{f} d \ln s_{t}^{f}
$$

where $\xi=0$ implies that the mark-up fully absorbs the increase in the farm share, whereas $\xi=1$ implies that the mark-up is unchanged.

Then the aggregate effect is

$$
d \ln Y_{t}=[\underbrace{\mu_{t}}_{\text {Multiplier }} \times \underbrace{\left(\theta^{f}-\theta^{w} \xi\right)}_{\text {Redistribution to high-MPC consumers }}+\underbrace{\sigma \frac{-d \ln \left(1+r_{t}\right)}{s_{t}^{f} d \ln s_{t}^{f}}}_{\text {Intertemporal Substitution }}] \times \underbrace{s_{t}^{f} d \ln s_{t}^{f}}_{\text {Farm channel }}
$$

where the redistribution term consists of the gains to constrained farmers $\left(\theta^{f}\right)$ net of the losses to constrained workers $\left(-\theta^{w} \xi\right)$. For redistribution to be expansionary for the economy as a whole, the former must exceed the latter, $\theta^{f}>\theta^{w} \xi$.

\footnotetext{
${ }^{60}$ We assume that $P_{t}^{f}$ never rises so high that marginal cost exceeds price for final goods producers; this guarantees that output remains demand-determined as farm product prices increase.
} 


\section{F.4 Cross-section}

We are interested in recovering information about the aggregate output effect from our cross-sectional estimates. To construct a mapping between the aggregate and the cross section we split the economy into two areas, agriculture $a$ and manufacturing $m$. Local income $Y_{a, t}$ accruing to the agricultural area is,

$$
Y_{a, t} \equiv s_{a, t} Y_{t}
$$

where $s_{a, t}$ is the share of national income accruing to the local area.

We assume that the agricultural area is populated by the farmers, a fraction $\zeta$ of capitalists, and a fraction $\eta$ of workers. The share of income accruing to the agricultural area is then,

$$
\begin{aligned}
s_{a, t} & =s_{t}^{f}+\zeta s_{t}^{c a p}+\eta s_{t}^{w} \\
& =s_{t}^{f}+\zeta\left(1-\frac{1}{m_{t}}\right)+\eta\left(\frac{1}{m_{t}}-s_{t}^{f}\right) \\
& =\frac{\zeta\left(m_{t}-1\right)+\eta}{m_{t}}+(1-\eta) s_{t}^{f}
\end{aligned}
$$

and the share of income accruing to the manufacturing area is

$$
s_{m, t}=1-\frac{\zeta\left(m_{t}-1\right)+\eta}{m_{t}}-(1-\eta) s_{t}^{f} .
$$

Note that the agricultural area will in general benefit from a higher farm income share relative to the manufacturing area. This is because some part of the higher farm income share is paid for by a lower income share of individuals living in the manufacturing area (either workers or capitalists).

We next need to characterize the local unconstrained and constrained income shares. We assume that for workers the probability of being constrained is the same in both areas, $\theta^{w}=\theta_{a}^{w}=\theta_{m}^{w}$. Adding the restrictions that income shares have to sum to 1 yields the income shares of locally unconstrained and constrained consumers,

$$
\begin{aligned}
& s_{a, t}^{u}=1-\left(\theta^{f}-\eta \theta^{w}\right) \frac{s_{t}^{f}}{s_{a, t}}-\frac{\eta \theta^{w}}{m_{t} s_{a, t}} \\
& s_{a, t}^{c}=\left(\theta^{f}-\eta \theta^{w}\right) \frac{s_{t}^{f}}{s_{a, t}}+\frac{\eta \theta^{w}}{m_{t} s_{a, t}} \\
& s_{m, t}^{u}=1-(1-\eta) \frac{\theta^{w}}{m_{t}} \frac{1-m_{t} s_{t}^{f}}{s_{m, t}} \\
& s_{m, t}^{c}=(1-\eta) \frac{\theta^{w}}{m_{t}} \frac{1-m_{t} s_{t}^{f}}{s_{m, t}}
\end{aligned}
$$

Local consumption is simply the sum of consumption by local constrained consumers and 
local unconstrained consumers,

$$
\begin{aligned}
C_{a, t} & =C_{a, t}^{u}+C_{a, t}^{c} \\
& =\left[\beta\left(1+r_{t}\right)\right]^{-1} \bar{C}_{a}^{u}+m p c_{a, t} s_{a, t} Y_{t}
\end{aligned}
$$

Analogous to aggregate consumption, the first term is a permanent income component coming from unconstrained consumers, $\left[\beta\left(1+r_{t}\right)\right]^{-1} \bar{C}^{u}$. The second term again captures variable expenditure, which is a function of local income $s_{a, t} Y_{t}$ and the local MPC, $m p c_{a, t}=$ $s_{a, t}^{u} \times 0+s_{a, t}^{c} \times 1=s_{a, t}^{c}=1-s_{a, t}^{u}$. As is the case nationally, the local MPC is solely determined by the importance of constrained consumers.

In our regressions we compare the growth rate of consumption across areas conditional on a change in farm product prices. Thus, we need to characterize how local consumption in each area responds to a change in farm prices. In the model any change in consumption can be decomposed into the following terms,

$$
\begin{aligned}
& d \ln C_{a, t}=\underbrace{\frac{m p c_{a, t} s_{a, t} Y_{t}}{C_{a, t}}}_{\text {Constrained consumption share }} \times[\underbrace{d \ln m p c_{a, t}}_{\text {Redistribution within area }}+\underbrace{d \ln s_{a, t}}_{\text {Redistribution across areas }}+\underbrace{d \ln Y_{t}}_{\text {Aggregate }}]+ \\
& +\underbrace{\left(1-\frac{m p c_{a, t} s_{a, t} Y_{t}}{C_{a, t}}\right)}_{\text {Unconstrained consumption share }} \times \underbrace{d \ln \left(1+r_{t}\right)}_{\text {Intertemporal Substitution }}
\end{aligned}
$$

where the first line is the consumption response by constrained consumers, and the second line is the consumption response by unconstrained consumers. Thus, these effects are weighted by their respective consumption share.

Starting with the constrained consumers, the first term in brackets captures the withinarea redistribution effect on local consumption. When income is redistributed towards highMPC consumers, then the MPC increases, and local consumption will be higher for any level of income. The second term in brackets captures redistribution of income across areas. Since spending either accrues in region $a$ or $m$, we have $s_{a, t}+s_{m, t}=1$. Thus, an increase in the income share of the agricultural area must come at the expense of the manufacturing area. The third term in brackets captures the aggregate increase in income, which is common to both the agricultural and the manufacturing area. All these terms are multiplied by the share of consumption by constrained consumers in local consumption. When few consumers are constrained then this term is small, so that any of these three terms will only have small effects on local consumption. By contrast, the second part of this equation, the intertemporal substitution effect, will be more important when fewer consumers are constrained.

We assume that initially the importance of high-MPC consumers is the same in the agricultural and the manufacturing area. That is, $s_{a, t}^{u}=s_{m, t}^{u}=s_{t}^{u}$, which implies $m p c_{a, t}=$ $m p c_{m, t}=m p c_{t}$. In addition, we assume that the share of consumption by unconstrained consumers is the same in both areas, $\frac{\bar{C}_{a}^{u}}{C_{a, t}}=\frac{\bar{C}_{m}^{u}}{C_{u, t}}$. This implies,

$$
\frac{s_{a, t} Y_{t}}{C_{a, t}}=\frac{s_{m, t} Y_{t}}{C_{m, t}}=1
$$


These assumptions imply that, initially, both areas are equally exposed to aggregate fluctuations. Thus, any aggregate effects are differenced out in the cross-section. Importantly, we only make these assumptions on initial conditions. After redistributing towards high-MPC farmers, the MPCs and income shares may (and will) differ across regions.

We can now compute the difference in consumption growth across regions, which is one important component of our cross-sectional regression,

$$
d \ln C_{a, t}-d \ln C_{a, t}=m p c_{t}[\underbrace{d \ln m p c_{a, t}-d \ln m p c_{m, t}}_{\text {Relative redistribution within areas }}+\underbrace{d \ln s_{a, t}-d \ln s_{m, t}}_{\text {Redistribution across areas }}]
$$

The aggregate effects on output and the real interest rate are differenced out, so the relative consumption growth across regions does not directly tell us about what we are ultimately interested in. Differences in consumption growth across areas are instead due to the relative effectiveness in redistributing income towards high-MPC consumers (the first term in brackets) and redistribution across areas (the second term).

The term capturing redistribution across areas is easiest to characterize. The agricultural areas' income share change is,

$$
d \ln s_{a, t}=\underbrace{[1-\zeta(1-\xi)-\eta \xi]}_{\text {Redistribution from } m \text { to } a} \times \underbrace{\frac{s_{t}^{f}}{s_{a, t}} d \ln s_{t}^{f}}_{\text {Local exposure to farm channel }}
$$

The term in square brackets subtracts the local losses from the gains to the farmers. These are losses by the fraction $\zeta$ of local entrepreneurs, $\zeta(1-\xi)$, when mark-ups fall $\xi<1$, and losses by the fraction $\eta$ of local workers, $\eta \xi$, when real wages fall $\xi>0$. The second term captures the local exposure to the farm channel, whereby the aggregate change in the farm income share is scaled by the local income share.

We obtain an analogous expression for the manufacturing area. The key differences are that local exposure is negative (since income is redistributed away) and calculated based on the manufacturing area's income share,

$$
d \ln s_{m, t}=\underbrace{-[1-\zeta(1-\xi)-\eta \xi]}_{\text {Redistribution from } a \text { to } m} \times \underbrace{\frac{s_{t}^{f}}{s_{m, t}} d \ln s_{t}^{f}}_{\text {Local exposure to farm channel }}
$$

Next we determine how effectively income is redistributed towards high-MPC consumers in the agricultural area,

$$
\begin{aligned}
d \ln m p c_{a, t} & =-\frac{s_{a, t}^{u}}{m p c_{a, t}} d \ln s_{a, t}^{u} \\
& =\underbrace{\frac{1}{m p c_{a, t}}}_{\text {Sensitivity of mpc }} \times \underbrace{\left[\left(\theta^{f}-\theta^{w} \eta \xi\right)-\left(1-s_{a, t}^{u}\right)(1-\zeta(1-\xi)-\eta \xi)\right]}_{\text {Local redistribution to constrained consumers }} \times \underbrace{\frac{s_{t}^{f}}{s_{a, t}} d \ln s_{t}^{f}}_{\text {Local exposure to farm channel }}
\end{aligned}
$$


The first term determines how sensitive the local MPC is to changes in the income share of constrained consumers. The second term captures how the income share of unconstrained consumers varies with the farm income share. This consists of how much income we move towards the constrained farmers and away from constrained workers, $\theta^{f}-\theta^{w} \eta \xi$, modulated by the increase in local income to constrained agents $\left(1-s_{a, t}^{u}\right)(1-\zeta(1-\xi)-\eta \xi) .{ }^{61}$ The third term is the local exposure to the change in the farm income share.

Analogously, we obtain an expression for the change in the MPC in the manufacturing area,

$$
\begin{aligned}
d \ln m p c_{m, t} & =-\frac{s_{m, t}^{u}}{m p c_{m, t}} d \ln s_{m, t}^{u} \\
& =\underbrace{\frac{1}{m p c_{m, t}}}_{\text {Sensitivity of mpc }} \times \underbrace{\left[-(1-\eta) \theta^{w} \xi+\left(1-s_{m, t}^{u}\right)(1-\zeta(1-\xi)-\eta \xi)\right]}_{\text {Local redistribution to constrained consumers }} \times \underbrace{\frac{s_{t}^{f}}{s_{m, t}} d \ln s_{t}^{f}}_{\text {Local exposure to farm channel }}
\end{aligned}
$$

The manufacturing MPC decreases with the income losses to constrained workers, - 1 $\eta) \theta^{w} \xi$, but the fall in the local constrained income share is mitigated to the extent that local income (the denominator) falls.

Combining these expressions we can determine the difference in consumption growth across areas,

$$
d \ln C_{a, t}-d \ln C_{m, t}=\underbrace{\left[\theta^{f}-\theta^{w} \xi \frac{\eta-s_{a, t}}{1-s_{a, t}}\right]}_{\text {Relative redistribution towards high-MPC consumers }} \times \underbrace{\frac{s_{t}^{f}}{s_{a, t}} d \ln s_{t}^{f}}_{\text {Local exposure to farm channel }}
$$

The first term in brackets, $\theta^{f}$, captures that redistribution to constrained farmers will raise consumption in the agricultural area relative to the manufacturing area. The second term captures how redistribution from unconstrained workers affects the cross-sectional consumption growth rates. Its sign is ambiguous. If $\eta=1$, so all workers reside in the agricultural area, then this reduction in consumption accrues in the agricultural area and thus reduces the cross-sectional difference. However, when $\eta$ is sufficiently small, $\eta<s_{a, t}$, then workers' losses disproportionally accrue in the manufacturing area. In that case the term becomes positive and amplifies the cross-sectional consumption differences.

Our model-based cross-sectional coefficient is this difference in consumption growth divided by the difference in farm population shares. Let the aggregate farm population share be $\phi^{f}$ and the local population shares by $\phi_{a}$ and $\phi_{m}$. Then the difference in farm population

\footnotetext{
${ }^{61}$ To see the necessity of this last term suppose that only farmers live in the agricultural area, $\eta=\zeta=$ 1. Then redistributing to farmers cannot change the local constrained share $s_{a, t}^{c}=\theta^{f}$. In this case the redistribution towards farmers and the local increase in (constrained) income are the same, leaving the ratio unchanged.
} 
shares is $\phi_{a}^{f}-\phi_{m}^{f}=\phi_{a}^{f}-0=\frac{\phi^{f}}{\phi_{a}}$, which yields a cross-sectional coefficient,

$$
\begin{aligned}
\beta & =\frac{d \ln C_{a, t}-d \ln C_{a, t}}{\frac{\phi^{f}}{\phi_{a}}}=\left[\theta^{f}-\theta^{w} \xi \frac{\eta-s_{a, t}}{1-s_{a, t}}\right] \frac{\phi_{a}}{\phi^{f}} \frac{s_{t}^{f}}{s_{a, t}} d \ln s_{t}^{f} \\
\Rightarrow \quad \beta \times \phi^{f} & =\underbrace{\left[\theta^{f}-\theta^{w} \xi \frac{\eta-s_{a, t}}{1-s_{a, t}}\right]}_{\text {Relative redistribution towards high-MPC consumers }} \times \underbrace{\frac{\phi_{a}}{s_{a, t}}}_{\text {Relative income p.c. }} \times \underbrace{s_{t}^{f} d \ln s_{t}^{f}}_{\% \Delta \text { National farm channel }}
\end{aligned}
$$

The left-hand-side is what we call the "naive" extrapolation from the cross-section to the aggregate. We simply multiply the cross-sectional coefficient with the national farm population share. The right-hand-side tells us what this quantity measures. It shares some similarities with the the aggregate effect (9) we want to uncover, but also some important differences.

First, term $\theta^{f}+\theta^{w} \xi_{\frac{s_{a, t}-\eta}{1-s_{a, t}}}$ will, in general, differ from the analogous term in the aggregate effect (9), $\theta^{f}-\theta^{w} \xi$. As an instructive case, these two terms coincide when $\eta=1$. Then both the losses and the gains to high-MPC consumers accrue only in the agricultural area. So the manufacturing area provides an appropriate counterfactual for measuring the redistribution to high-MPC consumers. However, when $\eta<1$, then the cross-sectional term will be larger. This is because redistributing away from high-MPC consumers in the manufacturing area reduces manufacturing consumption, which amplifies the cross-sectional coefficient but also reduces the aggregate effect of redistribution.

Second, the term $\frac{\phi_{a}}{s_{a, t}}=\frac{\text { U.S. income p.c. }}{\text { Farm area income p.c. }}$ was not present in the aggregate effect. In our model, the importance of the farm channel for an area is a function of the farm income share, the ratio of local farm income to total local income. The higher the farm income share, the greater the fraction of local income "treated" by higher farm prices and the greater the expected consumption growth. The farm population measure (and all our other available measures) only captures this exposure imperfectly. Farm income and population share are linked through the identity Farm income share $\equiv \frac{\text { Farm income per farmer }}{\text { Income per capita }} \times$ Farm population share. Holding relative incomes fixed, if the farm population share rises one percentage point in the cross-section, the local farm income share rises by $\frac{\text { Local farm income per farmer }}{\text { Farm area income per capita }} \times$ $1 \%$. The national farm income share increases by $\frac{\text { National farm income per farmer }}{\text { National income per capita }} \times 1 \%$. To correct for the relative difference in treatment we multiply by $\frac{\text { U.S. income p.c. }}{\text { Farm area income p.c. }}$.

Third, there is no multiplier in the cross-sectional expression whereas there is an aggregate multiplier for the economy as a whole. Even though local MPCs can be quite sizable, a local multiplier requires that some fraction of spending remains in the local area. Otherwise both areas benefit equally from higher local spending, which is differenced out in our specification.

Substituting the cross-sectional coefficient into equation (9) yields the following mapping 
to the aggregate output effect:

$$
\begin{aligned}
& d \ln Y=\underbrace{\beta \times \phi^{f}}_{\begin{array}{c}
\text { "naive" } \\
\text { extrapolation }
\end{array}} \times \underbrace{\frac{\text { Farm area income per capita }}{\text { National income per capita }}}_{\text {Relative income p.c. }} \times \underbrace{\left(\frac{1-\xi \frac{\theta^{w}}{\theta^{f}}}{1-\xi \frac{\theta^{w}}{\theta^{f}} \frac{\eta-s_{a, t}}{1-s_{a, t}}}\right)}_{\begin{array}{c}
\text { Redistribution from } \\
\text { high-MPC consumers }
\end{array}} \times \underbrace{\mu_{t}}_{\text {Multiplier }} \\
& +\underbrace{-\sigma d \ln \left(1+r_{t}\right)}_{\text {Intertemporal Substitution }} .
\end{aligned}
$$

In the text we further simplify the redistribution correction to $1-\xi \frac{\theta^{w}}{\theta^{f}}$. This is exact when the share of worker income accruing to the agricultural region is commensurate to the income share of the agricultural region, $\eta=s_{a, t}$. For reasonable parameterizations of $\eta$ this is a good approximation. 